\title{
Halide-selective, proton-coupled anion transport by phenylthiosemicarbazones ${ }^{\dagger}$
}

Ethan N.W. Howe, ${ }^{\text {aq }}$ Vai-Vai Tiffany Chang, ${ }^{a, b}$ Xin Wu, ${ }^{a}$ William Lewis, ${ }^{a}$ Lauren K. Macreadie, ${ }^{a}$ and Philip A. Gale*a,c

${ }^{a}$ School of Chemistry (F11), The University of Sydney, NSW 2006, Australia.

${ }^{b}$ Chemistry, University of Southampton, Southampton SO17 1BJ, UK.

'The University of Sydney Nano Institute (Sydney Nano), The University of Sydney, NSW 2006,

Australia.

"Present address: GlaxoSmithKline, GSK Jurong, 1 Pioneer Sector 1, Singapore 628413

*philip.gale@sydney.edu.au

${ }^{\dagger}$ Dedicated to Professor Lechosław Latos-Grażyński on the occasion of his 70th birthday.

Keywords: Anion transport; Hydrogen bonding; Thiosemicarbazones; Switchable receptors

\section{Highlights}

- A new class of phenylthiosemicarbazone-based anion receptors have been synthesized and shown to function as $\mathrm{pH}$-switchable transmembrane anion transporters.

- An intramolecular hydrogen bond locks the thiourea binding site and inhibits chloride/nitrate exchange at $\mathrm{pH}$ 7.2. Protonation of phenylthiosemicarbazones at $\mathrm{pH} 4.5$ switches on chloride/nitrate exchange activity.

- Anion transport selectivity analysis reveals strong halide over oxyanion preference exhibited by protonated phenylthiosemicarbazones.

- The $\mathrm{pH}$-switchable chloride/nitrate exchange is shown to originate from inhibition of rate-limiting nitrate transport at $\mathrm{pH}$ 7.2.

Abstract: Phenylthiosemicarbazones (PTSCs) are proton-coupled anion transporters with $\mathrm{pH}-$ switchable behaviour known to be regulated by an imine protonation equilibrium. Previously, chloride/nitrate exchange by PTSCs was found to be inactive at $\mathrm{pH} 7.2$ due to locking of the thiourea anion binding site by an intramolecular hydrogen bond, and switched $\mathrm{ON}$ upon imine protonation at $\mathrm{pH}$ 4.5. The rate-determining process of the $\mathrm{pH}$ switch, however, was not examined. We here develop a new series of PTSCS and demonstrate their conformational behaviour by X-ray crystallographic analysis and $\mathrm{pH}$-switchable anion transport properties by liposomal assays. We report the surprising finding that these compounds are extremely selective for halides over oxyanions in membrane transport. Owing to the high chloride over nitrate selectivity, the $\mathrm{pH}$-dependent chloride/nitrate exchange of PTSCs originates from the rate-limiting nitrate transport process being inhibited at neutral $\mathrm{pH}$, whereas chloride transport remains efficient under both neutral and acidic conditions.

\section{Introduction}

Small-molecule transmembrane anion transporters are promising anti-cancer drug candidates due to their ability to disrupt $\mathrm{pH} / \mathrm{anion}$ gradients and membrane potential across cell membranes and in organelles.[1, 2] The research of synthetic anion transporters was initially inspired by the natural product prodigiosin which facilitates efficient $\mathrm{H}^{+} / \mathrm{Cl}^{-}$symport and as a result neutralizes acidic $\mathrm{pH}$ 
inside vacuolar organelles including lysosomes, endosomes and Golgi apparatus.[3-5] While prodigiosin exhibits potent anion transport activity under both neutral and acidic conditions, synthetic anion transporters with $\mathrm{pH}$-dependent transport activities have been design with a potential to target the acidic intracellular environment of tumours and reduce the toxicity towards normal cells.[6-10]

Phenylthiosemicarbazones (PTSCs) are a class of pH-switchable anion transporters previously reported to exhibit up to 640 -fold increase in chloride/nitrate exchange activity on going from $\mathrm{pH} 7.2$ to 4.0.[11] This $\mathrm{pH}$ dependence was regulated by protonation of the imine nitrogen at acidic $\mathrm{pH}$, which led to a conformational switch of the thiourea motif from an inactive anti-conformation to an active anion binding syn-conformation (Fig. 1a). For a better understanding of anion transport and $\mathrm{pH}$ switching mechanism of this class of transporters, we decided to study an expanded library of PTSCs and here report our serendipitous discovery of their extremely high halide over oxyanion transport selectivity leading to the $\mathrm{pH}$-switchable chloride/nitrate exchange being regulated by the rate-limiting nitrate transport process.

(a)<smiles>[R]/C=C\N([2H])NC[R]</smiles><smiles>C1=C[CH+]C=C1</smiles><smiles>[R]C=[N+]1[CH][CH][NH2+]C([R])=[SH]1</smiles>

Neutral PTSC<smiles></smiles>
anti-conformation<smiles>c1ccccc1</smiles>

PTSCH $^{+}$ syn-conformation

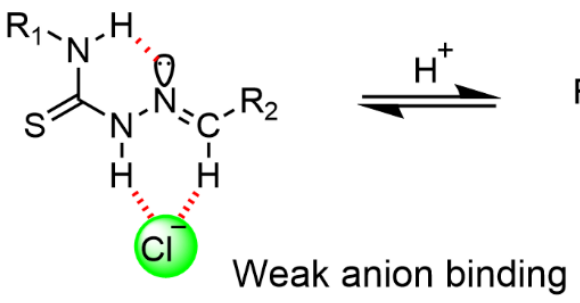

(b)<smiles>[R]c1ccc(NC(=S)N/N=C/c2ccc(CCCC)cc2)cc1</smiles>

$1 \mathrm{R}=\mathrm{H}$

$2 \mathrm{R}=\mathrm{Me}$

$4 \mathrm{R}=\mathrm{CF}_{3}$

$3 \mathrm{R}=\mathrm{OMe}$

$5 \mathrm{R}=\mathrm{OCF}_{3}$

$7 \mathrm{R}=\mathrm{F}$

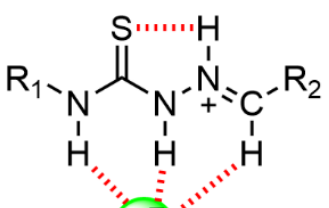

(CI) Doubly ionic hydrogen bonds Strong anion binding<smiles>CCCCc1ccc(/C=N/NC(=S)Nc2cc(F)c(F)c(F)c2)cc1</smiles>

8<smiles>CCCCc1ccc(/C=N/NC(=S)Nc2cc(C(F)(F)F)cc(C(F)(F)F)c2)cc1</smiles>

6<smiles>CCCCc1ccc(/C=N/NC(=S)Nc2c(F)c(F)c(F)c(F)c2F)cc1</smiles>

9

Fig. 1. (a) Mechanism for pH-switchable anion binding by phenylthiosemicarbazones (PTSCs). (b) Structures of new PTSC transporters 1-9.

\section{Experimental section}




\subsection{Materials}

All chemicals and solvents were purchased from commercial sources (Alfa Aesar, Fisher Scientific and Sigma Aldrich). 1-Palmitoyl-2-oleoyl-sn-glycero-3-phosphocholine (POPC) was purchased from Corden Pharma GmbH. All deuterated solvents for NMR were purchased from Cambridge Isotope Laboratories. Commercially available reagent grade chemicals were used without further purification unless otherwise specified.

\subsection{Instruments}

${ }^{1} \mathrm{H}$ and ${ }^{13} \mathrm{C}$ NMR spectra were recorded on Bruker Avance AVII400 and AVIIIHD400 FT-NMR spectrometers with $5 \mathrm{~mm}$ BBFO z-gradient probes, operating at a frequency of $400 \mathrm{MHz}$ for ${ }^{1} \mathrm{H} \mathrm{NMR}$ and $101 \mathrm{MHz}$ for ${ }^{13} \mathrm{C}$ NMR respectively.

LR-MS samples were analysed using a Bruker amaZon SL mass spectrometer equipped with a quadrupole analyser. Samples were introduced to the mass spectrometer via direct injection. Low resolution mass spectra were recorded using positive/negative ion electrospray ionization.

Fluorescence measurements were performed using an Agilent Cary Eclipse Fluorescence Spectrophotometer equipped with a stirrer plate and a temperature controller.

X-ray diffraction data were collected at $100 \mathrm{~K}$ on a SuperNova Dual, $\mathrm{Cu}$ at home/near Atlas diffractometer.

\subsection{Syntheses}

The respective substituted $N$-phenyl thiosemicarbazide $(\sim 300 \mathrm{mg}$ ) was suspended in absolute ethanol $(10 \mathrm{~mL})$ and the mixture was treated with 4-butylbenzaldehyde ( 1.1 equivalent) and stirred at room temperature under nitrogen atmosphere for $>8 \mathrm{~h}$. The products were re-precipitated with a suitable solvent and were collected by filtration. Characterization data for transporters 1-9 is provided in Supplemental Material.

\subsection{Crystallographic analysis}

The solutions of X-ray diffraction data for transporter 1 were obtained by direct methods using SHELXT[12] followed by successive refinements using full matrix least squares method against $F^{2}$ using SHELXL-2018/3.[13] The program OLEX2 [14] was used was used as a graphical SHELX interface. See Supplemental Material for crystal and data refinement parameters.

\subsection{Membrane transport assays}

Large unilamellar vesicles of POPC were prepared by hydrating a lipid film using an internal solution, followed by 9 freeze-thaw cycles and extrusion 25 times through a $200 \mathrm{~nm}$ polycarbonate membrane. Finally, the vesicles were subject to dialysis or Sephadex size-exclusion chromatography using the required external solution to remove unencapsulated chloride ions (ISE assay) or the fluorescence $\mathrm{pH}$ indicator 8-hydroxypyrene-1,3,6-trisulfonate (HPTS assay) to obtain vesicle stock suspensions for membrane transport studies.

The vesicles stock suspensions were diluted to POPC concentrations of $1 \mathrm{mM}$ (ISE assay) and $0.1 \mathrm{mM}$ using the required external solution. DMSO solutions of transporters were added to the vesicle suspensions and the membrane transport kinetics was studied by measuring the chloride concentrations in the external solutions using a chloride selective electrode (ISE assay) or by monitoring the ratiometric fluorescence response from intravesicular pH indicator HPTS (HPTS assay). See Supplemental Material for detailed assay conditions. 


\section{Results and Discussion}

\subsection{Synthesis of anion transporters 1-9 and crystallographic analysis of 1}

Transporters 1-9 bearing aryl substituents on both sides of the PTSC core were synthesized by imine condensation of 4-pentylbenzaldehyde with the corresponding phenylthiosemicarbazide. Single crystals of transporter 1 (CCDC 2103182) of suitable quality for X-ray diffraction were obtained via slow evaporation of a DMSO solution. Tranporter 1 crystallizes in the monoclinic space group $P 2_{1} / c$ with two formula units in the asymmetric unit. The crystal structure highlights the thione form to be predominant due to the CS bond lengths (1.6869(18) $\AA$ and 1.6788(19) $\AA$ ) and the $\mathrm{C}=\mathrm{N}-\mathrm{N}$ angles $\left(116.15(16)^{\circ}\right.$ and $\left.114.90(16)^{\circ}\right)$ being similar to other thione tautomeric structures. The presence of two $\mathrm{NH}$ and one carbazone $\mathrm{CH}$ hydrogen-bond donor group, permits the formation of multiple hydrogen bonds between pairs of $\mathbf{1}$.

Each pair is held together through phenyl ring edge-to-face $\mathrm{C}-\mathrm{H} \cdots \pi$ stacking interactions between aromatic rings (3.2106(10) $\AA$ and 3.295(10) $\AA$ ). Close $\mathrm{C}(13)-\mathrm{H} \cdots \mathrm{N}(6)(3.570(3) \AA$ ) and $\mathrm{C}(5)-\mathrm{H} \cdots \mathrm{S}(2)$ $(3.677(2) \AA)$ interactions further stabilise the pairs of receptors. Pairs run parallel along the a-axis, $180^{\circ}$ to one another, held together through close hydrogen bonding interactions between the thiosemicarbazone groups. The $R_{2}^{2}(6)$ and $R_{2}^{2}$ (8) motifs present between the carbazone groups of adjacent pairs necessitates their parallel position. Overall, this arrangement forms $2 \mathrm{D}$ sheets running along the ab axis.

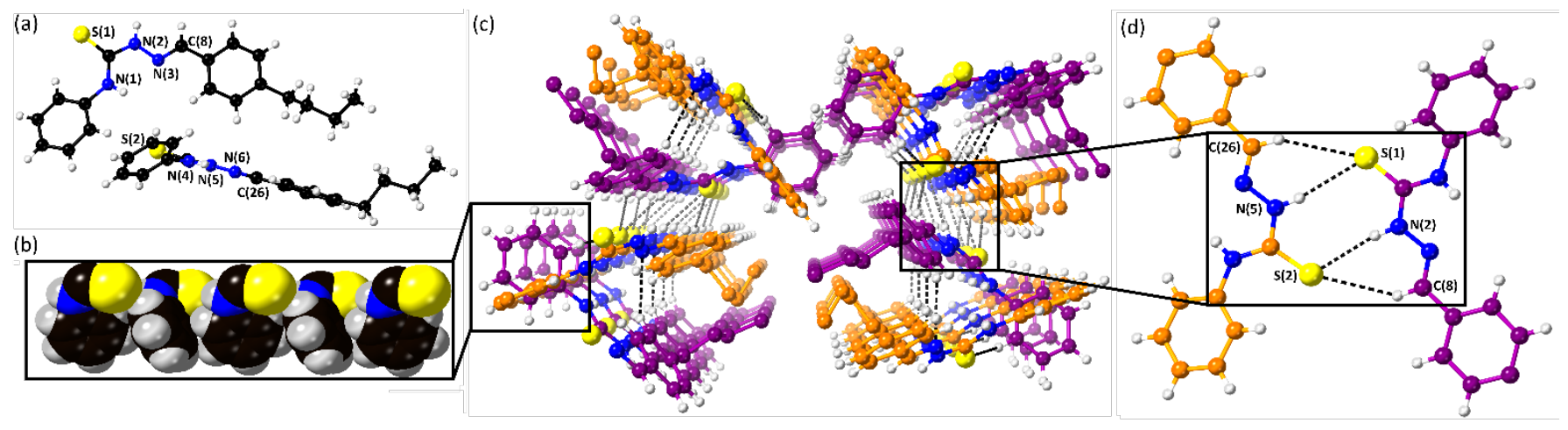

Fig. 2. (a) Two crystallographically unique receptors 1 found in the asymmetric unit. (b) phenyl ring edge-to-face stacking observed between both crystallographically unique receptors. (c) Packing diagram of 1 shown along the $a$ axis with carbon atoms from each receptor coloured either purple or orange for clarity. Black dashed bonds represent close $\mathrm{H}$ bonds holding together a pair of receptors while grey dashed bonds represent close $\mathrm{H}$ bonds between the pairs. Hydrogen atoms on butyl chains omitted for clarity. (d) Hydrogen bonding $R_{2}^{2}(6)$ and $R \frac{2}{2}(8)$ motifs between receptor pairs.

\section{$3.2 \mathrm{pH}$-dependent $\mathrm{Cl}^{-} / \mathrm{NO}_{3}{ }^{-}$exchange studies}

The transporters were initially evaluated for their $\mathrm{pH}$ switchability by comparing their $\mathrm{Cl}^{-} / \mathrm{NO}_{3}{ }^{-}$ exchange activities under neutral and acidic conditions. POPC vesicles with internal $\mathrm{NaCl}(489 \mathrm{mM})$ buffered at $\mathrm{pH} 4.5$ or 7.2 were suspended in a $\mathrm{NaNO}_{3}(489 \mathrm{mM})$ external solution buffered at $\mathrm{pH} 4.5$ or 7.2. Anion transporters were added to the vesicles as DMSO solutions and $\mathrm{Cl}^{-}$efflux facilitated by an anion transporter was monitored using a chloride ion selective electrode (ISE). Similarly to previously reported PTSCs, transporters 1-9 were inactive $\mathrm{Cl}^{-} / \mathrm{NO}_{3}{ }^{-}$exchangers at $\mathrm{pH} 7.2$ but became "switched ON" to facilitate rapid anion exchange at pH 4.5 (Figs. 3, S20-S37). To quantify the pH switchability, concentration-dependent Hill plot analysis were conducted to give an effective transporter concentration that facilitates $50 \%$ of $\mathrm{Cl}^{-}$efflux at $270 \mathrm{~s}\left(\mathrm{EC}_{50}\right.$ values) at $\mathrm{pH} 4.5$ and pH 7.2. 
As shown by Table 1, compound 1 was identified as the most active anion transporter, showing a low $\mathrm{EC}_{50}$ of 0.0175 mol\% (with respect to lipids) at $\mathrm{pH} 4.5$ and $\sim 550$-fold reduced activity at pH 7.0. For transporters 5 and 7-9, the $\mathrm{Cl}^{-} / \mathrm{NO}_{3}{ }^{-}$exchange was almost completely suppressed at $\mathrm{pH} 7.2$, with modest-to-high activities observed at pH 4.5. The much weaker anion transport activities of 5 and 79 at pH 7.2 compared with 1-3 are attributed to the presence of electron-withdrawing substituents lowing the $\mathrm{p} K_{\mathrm{a}}$ of the iminium group and thereby inhibiting imine protonation at $\mathrm{pH} 7.2$ as required for anion transport. Transporter 6 precipitated upon addition to the vesicle suspensions as DMSO solutions which prohibited a detailed analysis of its $\mathrm{pH}$ switchability.

(a)

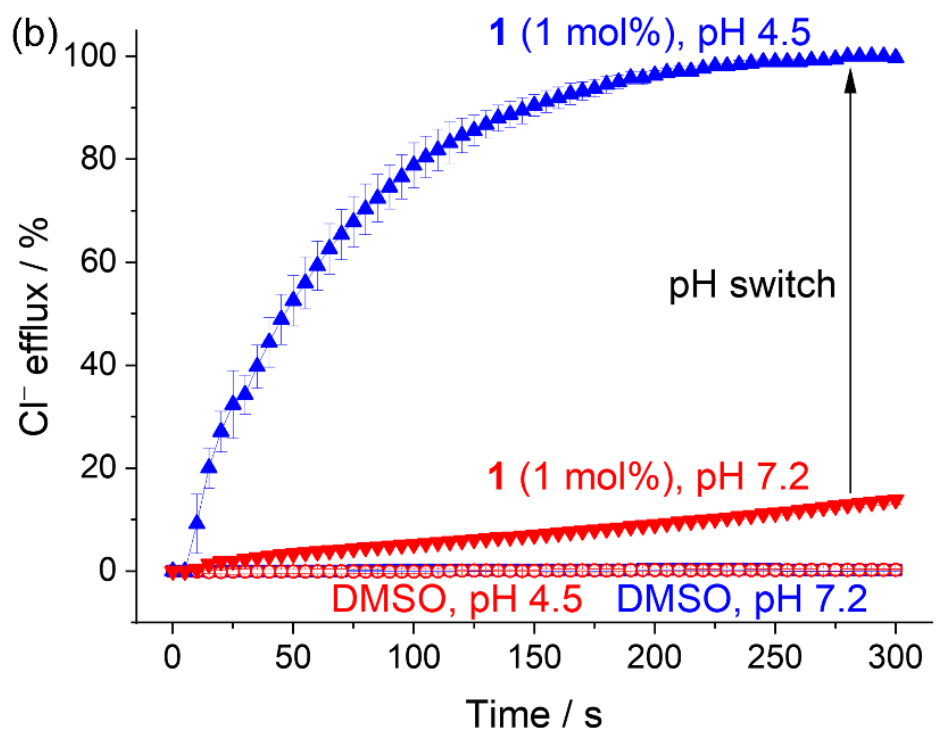

Fig. 3. (a) Schematic representation of the $\mathrm{Cl}^{-} / \mathrm{NO}_{3}{ }^{-}$exchange assay. (b) $\mathrm{Cl}^{-} / \mathrm{NO}_{3}{ }^{-}$exchange assay for transporter 1 and DMSO control using vesicles with internal and external solutions buffered at $\mathrm{pH} 4.5$ (blue) and pH 7.2 (red). Error bars represent standard deviations from three runs.

Table 1 Hill analysis for $\mathrm{Cl}^{-} / \mathrm{NO}_{3}{ }^{-}$exchange by PTSCs 1 - 9 .

\begin{tabular}{|c|c|c|c|c|c|}
\hline \multirow[t]{2}{*}{ PTSC } & \multicolumn{2}{|c|}{$\mathrm{Cl}^{-} / \mathrm{NO}_{3}{ }^{-}$at $\mathrm{pH} 7.2$} & \multicolumn{2}{|c|}{$\mathrm{Cl}^{-} / \mathrm{NO}_{3}{ }^{-}$at $\mathrm{pH} 4.5$} & \multirow{2}{*}{$\begin{array}{l}\mathrm{EC}_{50}(\mathrm{pH} 7.2) \\
/ \mathrm{EC}_{50}(\mathrm{pH} 4.5)\end{array}$} \\
\hline & $\mathrm{EC}_{50} / \mathrm{mol} \%$ & $n$ & $\mathrm{EC}_{50} / \mathrm{mol} \%$ & $n$ & \\
\hline 1 & 9.6 & 1.2 & 0.018 & 1.7 & 550 \\
\hline 2 & 3.9 & 0.92 & 0.020 & 1.8 & 190 \\
\hline 3 & 2.8 & 1.6 & 0.044 & 0.82 & 64 \\
\hline 4 & $--^{a}$ & $--^{a}$ & 8.5 & 0.35 & $--^{a}$ \\
\hline 5 & $-^{a}$ & $-^{a}$ & 0.17 & 0.44 & $--^{a}$ \\
\hline 6 & $-^{a}$ & $-^{a}$ & $-^{a}$ & $--^{a}$ & $--^{a}$ \\
\hline 7 & $--^{a}$ & $-^{a}$ & 0.035 & 1.0 & $--^{a}$ \\
\hline 8 & $-^{a}$ & $-^{a}$ & 3.7 & 0.36 & $--^{a}$ \\
\hline 9 & $-^{a}$ & $-^{a}$ & 1.1 & 0.66 & $--^{a}$ \\
\hline
\end{tabular}


${ }^{\text {a }}$ Too inactive for Hill analysis.

\section{$3.3 \mathrm{pH}$-dependent studies of $\mathrm{Cl}^{-}$uniport and $\mathrm{H}^{+} / \mathrm{Cl}^{-}$symport}

With the $\mathrm{pH}$-dependent $\mathrm{Cl}^{-} / \mathrm{NO}_{3}{ }^{-}$exchange confirmed for the new PTSCs, we next investigated the $\mathrm{Cl}^{-}$ uniport and $\mathrm{H}^{+} / \mathrm{Cl}^{-}$symport activities of transporters 1-9 at pH 4.5 and $\mathrm{pH} 7.2$ using our previously developed cationophore-coupled ISE assays.[15] These assays complement the $\mathrm{Cl}^{-} / \mathrm{NO}_{3}{ }^{-}$exchange assay by providing additional insights into electrogenic/electroneutral transport phenomena and revealing the potentially slow $\mathrm{NO}_{3}{ }^{-}$transport that could rate-limit the $\mathrm{Cl}^{-} / \mathrm{NO}_{3}{ }^{-}$exchange process.[16] POPC vesicles were loaded with $\mathrm{KCl}(300 \mathrm{mM})$ at $\mathrm{pH} 4.5$ or 7.2 , and suspended in an external solution containing inert $\mathrm{K}_{2} \mathrm{SO}_{4}(150 \mathrm{mM})$ at $\mathrm{pH} 4.5$ or 7.2 . Anion transporters were added along with a cationophore (valinomycin or monensin) to facilitate $\mathrm{KCl}$ efflux. In the presence of $\mathrm{K}^{+}$uniporter valinomycin, the anion transporter needs to facilitate $\mathrm{Cl}^{-}$uniport to give $\mathrm{KCl}$ efflux (Fig. 4a bottom). By contrast, in the presence of $\mathrm{K}^{+} / \mathrm{H}^{+}$exchanger monensin, $\mathrm{H}^{+} / \mathrm{Cl}^{-}$symport facilitated by the anion transporter is required to generate net $\mathrm{KCl}$ efflux (Fig. 4a top). Similar to prodigiosin, the previously reported PTSCs were shown to facilitate $\mathrm{H}^{+} / \mathrm{Cl}^{-}$symport (coupling to monensin) but no $\mathrm{Cl}^{-}$uniport (coupling to valinomycin) at $\mathrm{pH}$ 4.5.[11] This was attributed to the inability of the cationic protonated $\mathrm{PTSCH}^{+}$(decomplexed transporter) to diffuse through the membrane without a bound anion. Back diffusion of the decomplexed transporter is a necessary step for $\mathrm{Cl}^{-}$uniport but not for anion exchange or $\mathrm{H}^{+} / \mathrm{Cl}^{-}$symport.[17] Previously, the cationophore-coupled assays were not conducted at pH 7.2.

Consistent with previous findings, the new PTSCs 1-9 induced efficient $\mathrm{Cl}^{-}$efflux with monensin and low-to-negligible $\mathrm{Cl}^{-}$efflux with valinomycin at $\mathrm{pH} 4.5$ (Fig. 4 blue, Table 2), indicating the strong preference for $\mathrm{H}^{+} / \mathrm{Cl}^{-}$symport over $\mathrm{Cl}^{-}$uniport for these transporters. Significant $\mathrm{Cl}^{-}$uniport activities (relative to $\mathrm{H}^{+} / \mathrm{Cl}^{-}$symport activities), however, could be observed for polyfluorinated transporters 6 , 8 and 9 at pH 7.2. This can be attributed to the neutral form of PTSCs facilitating $\mathrm{Cl}^{-}$uniport via $\mathrm{Cl}^{-}$ binding in the syn-conformation (Fig. 1a left) followed by transmembrane diffusion of the anionic complex, release of $\mathrm{Cl}^{-}$and the back diffusion of the neutral uncomplexed PTSC. This alternative mechanism required a significant anion binding affinity of the neutral form (in which only one thiourea $\mathrm{NH}$ and a weak imine $\mathrm{CH}$ donor are available for anion binding) and therefore was only observed for the more acidic transporters in the series. 
(a)

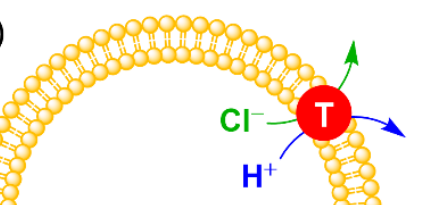

$\mathrm{KCl}(300 \mathrm{mM})$

$\mathrm{K}^{+}$

\section{Mon}

$\mathrm{H}^{+}$

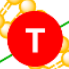

$\mathrm{Cl}$

$\mathrm{KCl}(300 \mathrm{mM})$

$\mathrm{K}^{+}$

VIn (b)

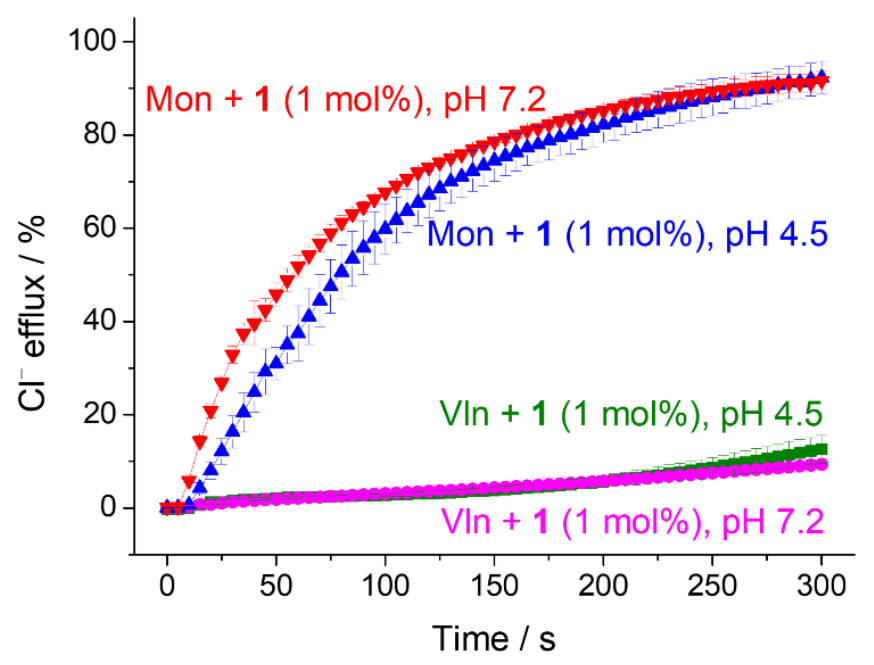

Fig. 4. (a) Schematic representation of $\mathrm{H}^{+} / \mathrm{Cl}^{-}$symport (top, anion transporter $\mathrm{T}$ coupling to monensin, Mon) and $\mathrm{Cl}^{-}$uniport (bottom, anion transporter T coupling to valinomycin, VIn) assays. (b) $\mathrm{H}^{+} / \mathrm{Cl}^{-}$ symport (red and blue) and $\mathrm{Cl}^{-}$uniport (green and pink) assays for transporter $\mathbf{1}$ at $\mathrm{pH} 4.5$ (blue and green) and $\mathrm{pH} 7.2$ (red and pink). The $\mathrm{Cl}^{-}$efflux induced by the anion transporter or cationophore alone is negligible (Fig. S38). Error bars represent standard deviations from three runs.

Table 2 Cationophore-coupled assays for PTSCs 1-9.

\begin{tabular}{|c|c|c|c|c|c|}
\hline \multirow{3}{*}{ PTSC } & \multirow{3}{*}{ Concentration } & \multicolumn{2}{|c|}{$\mathrm{pH} 7.2$} & \multicolumn{2}{|c|}{$\mathrm{pH} 4.5$} \\
\hline & & \multicolumn{2}{|c|}{$\mathrm{Cl}^{-}$efflux at $300 \mathrm{~s} / \%$} & \multicolumn{2}{|c|}{$\mathrm{Cl}^{-}$efflux at $300 \mathrm{~s} / \%$} \\
\hline & & Mon $^{a}$ & $\mathrm{Vln}^{\mathrm{b}}$ & Mon $^{a}$ & $\mathrm{~V} l \mathrm{n}^{\mathrm{b}}$ \\
\hline 1 & $1 \mathrm{~mol} \%$ & 92 & 9.4 & 92 & 13 \\
\hline 2 & $1 \mathrm{~mol} \%$ & 100 & 15 & 81 & 8.3 \\
\hline 3 & $1 \mathrm{~mol} \%$ & 99 & 6.2 & 83 & 6.2 \\
\hline 4 & $10 \mathrm{~mol} \%$ & 49 & 13 & 33 & 7.5 \\
\hline 5 & $10 \mathrm{~mol} \%$ & 50 & 8.3 & 38 & 3.4 \\
\hline 6 & 10 mol\% & 9.4 & 8.4 & 3.9 & 0.60 \\
\hline 7 & $1 \mathrm{~mol} \%$ & 95 & 19 & 98 & 11 \\
\hline 8 & $10 \mathrm{~mol} \%$ & 35 & 15 & 12 & 3.3 \\
\hline 9 & $10 \mathrm{~mol} \%$ & 49 & 28 & 20 & 5.5 \\
\hline
\end{tabular}

${ }^{a} \mathrm{Cl}^{-}$efflux by PTSC in the presence of monensin (Mon, $0.1 \mathrm{~mol} \%$ ), which indicates the $\mathrm{H}^{+} / \mathrm{Cl}^{-}$symport activity of PTSC. 
${ }^{b} \mathrm{Cl}^{-}$efflux by PTSC in the presence of valinomycin (VIn, 0.1 mol\%), which indicates the $\mathrm{Cl}^{-}$uniport activity of PTSC.

Surprisingly, while these PTSCs are inactive $\mathrm{Cl}^{-} / \mathrm{NO}_{3}{ }^{-}$exchangers at $\mathrm{pH} 7.2$, we observed highly efficient $\mathrm{H}^{+} / \mathrm{Cl}^{-}$symport (coupling to monensin) for all compounds at $\mathrm{pH} 7.2$ (Fig. $4 \mathrm{~b}$ red, Table 2). No enhancement of $\mathrm{H}^{+} / \mathrm{Cl}^{-}$symport activity was observed on acidifying the vesicle suspensions from 7.2 to 4.5. These results appear to indicate the lack of $\mathrm{pH}$ switchability for the $\mathrm{H}^{+} / \mathrm{Cl}^{-}$symport facilitated by PTSCs in the tested $\mathrm{pH}$ range, contrasting the strong $\mathrm{pH}$ switchability in the $\mathrm{Cl}^{-} / \mathrm{NO}_{3}{ }^{-}$exchange assay (Fig. 3, Table 1).

We hypothesised that the seemingly contradictory $\mathrm{pH}$-dependent results in the two assays could be related to different rate-limiting steps for $\mathrm{H}^{+} / \mathrm{Cl}^{-}$symport and $\mathrm{Cl}^{-} / \mathrm{NO}_{3}{ }^{-}$exchange. As shown by our previous studies, most hydrogen bond-based anion transporters facilitate the transport of the more lipophilic anion $\mathrm{NO}_{3}{ }^{-}$faster than $\mathrm{Cl}^{-}$as governed by the ease of anion dehydration. However, exceptions have been found for a few transporters, most notably the tripodal tris-(thio)ureas [16, 18]. These transporters are $\mathrm{Cl}^{-}>\mathrm{NO}_{3}{ }^{-}$selective due to their structural mismatch for binding planar $\mathrm{NO}_{3}{ }^{-}$ ions, leading to underestimated $\mathrm{Cl}^{-}$transport activity when tested under the $\mathrm{Cl}^{-} / \mathrm{NO}_{3}{ }^{-}$exchange assay.

\subsection{Anion transport selectivity studies}

To understand the $\mathrm{pH}$-dependent $\mathrm{Cl}^{-} / \mathrm{NO}_{3}{ }^{-}$exchange property of the PTSCs, we determined the anion transport selectivity of 1 as a representative example under an HPTS assay utilising a transmembrane anion gradient to induce a $\mathrm{pH}$ gradient (Fig. 5a).[19] In this assay, vesicles containing $\mathrm{NaCl}(100 \mathrm{mM})$ and the $\mathrm{pH}$ indicator HPTS (1 mM) buffered at pH 7.0 were suspended in $\mathrm{NaX}\left(100 \mathrm{mM}, \mathrm{X}=\mathrm{Cl}^{-}, \mathrm{Br}^{-}\right.$, $\mathrm{NO}_{3}{ }^{-}, \mathrm{I}^{-}$, or $\mathrm{ClO}_{4}{ }^{-}$) at $\mathrm{pH}$ 7.0. Transporter 1 was added to induce a $\mathrm{pH}$ gradient where an acidification of the vesicular interiors indicates faster $\mathrm{HX}$ influx than $\mathrm{HCl}$ efflux (i.e., $\mathrm{X}^{-}>\mathrm{Cl}^{-}$selectivity) and vice versa. The assay revealed a selectivity pattern of $\mathrm{I}^{-}>\mathrm{Br}^{-}>\mathrm{Cl}^{-}>\mathrm{ClO}_{4}{ }^{-}>\mathrm{NO}_{3}{ }^{-}$(Fig. 5b). Compared with a neutral mono-thiourea transporter showing a Hofmeister-type selectivity pattern (i.e., $\mathrm{ClO}_{4}^{-}>\mathrm{I}^{-}>$ $\mathrm{NO}_{3}{ }^{-}>\mathrm{Br}^{-}>\mathrm{Cl}^{-}$),[19] the selectivity profile of 1 features a strong halide-over-oxyanion preference with the selectivity sequence within each category (halides or oxyanions) governed by the ease of anion dehydration. This halide selectivity presumably originated from the covalent character of the strong doubly ionic hydrogen bonds[20] in anion binding by protonated PTSCs. As the lone pair orbitals ( $\mathrm{HOMOs)} \mathrm{of} \mathrm{the} \mathrm{halide} \mathrm{ions} \mathrm{are} \mathrm{of} \mathrm{higher} \mathrm{energies} \mathrm{than} \mathrm{those} \mathrm{of} \mathrm{the} \mathrm{tested} \mathrm{oxyanions}\left(\mathrm{ClO}_{4}{ }^{-}\right.$and $\left.\mathrm{NO}_{3}{ }^{-}\right)$, charge transfer between the anion HOMO and the antibonding orbital (LUMO) of the hydrogen bond donor is more favourable for halides than for the oxyanions, which accounts for the halide over oxyanion selectivity here observed for doubly ionic hydrogen bonds. Corroborating the abovementioned hypothesis, a similar halide over oxyanion selectivity has been observed with a Pd(II)based anion transporter in which anion binding (via metal coordination) features a strong covalent character.[21] Unfortunately, we were unable to determine the anion binding constants for the protonated PTSCs to evaluate the anion binding selectivity because of their instability.[11] To quantify the $\mathrm{Cl}^{-} \mathrm{vs} \mathrm{NO}_{3}{ }^{-}$transport selectivity of 1 , a pH gradient dissipation assay[22] was conducted by applying a transmembrane $\mathrm{pH}$ gradient $(\mathrm{pH} 7.0$ inside and $\mathrm{pH}$ 8.0) and measuring the rate of $\mathrm{pH}$ gradient dissipation under $\mathrm{NaCl}^{\text {in }} / \mathrm{NaCl}^{\text {out }}$ and $\mathrm{NaNO}_{3}{ }^{\text {in }} / \mathrm{NaNO}_{3}{ }^{\text {out }}$ conditions. These assays have been designed to evaluate $\mathrm{H}^{+} / \mathrm{X}^{-}$symport activities of anion transporters (Fig. 5b). The results demonstrate rapid $\mathrm{H}^{+} / \mathrm{Cl}^{-}$symport and no discernible $\mathrm{H}^{+} / \mathrm{NO}_{3}{ }^{-}$symport from DMSO control baseline for transporter 1 used at the same concentration (Fig. $5 \mathrm{~d}$ ), confirming its extremely high $\mathrm{Cl}^{-}>\mathrm{NO}_{3}{ }^{-}$selectivity at neutral to slightly basic $\mathrm{pH}$. 
(a) Anion gradient ( $\mathrm{pH}$ gradient induction) assay

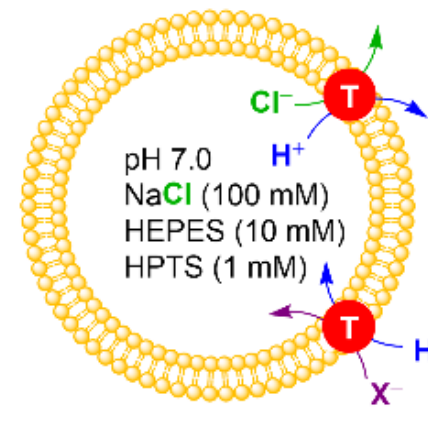

(c)

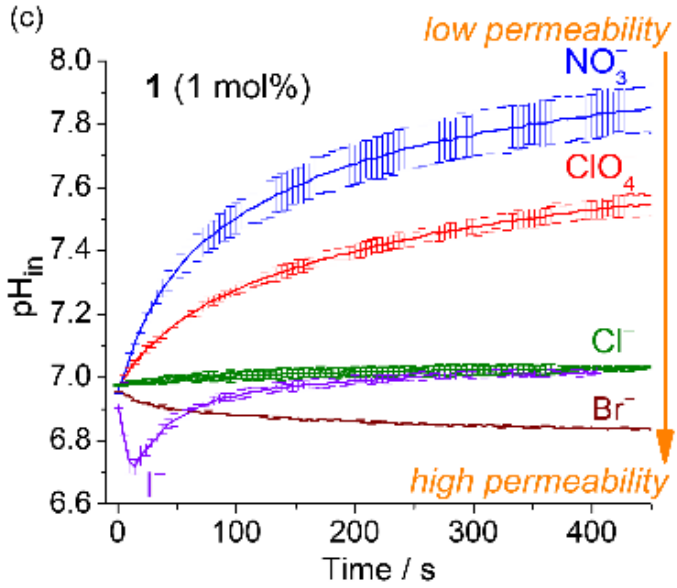

(b) $\mathrm{pH}$ gradient dissipation assay

If $\mathrm{HCl}>\mathrm{HX}$, dominant $\mathrm{HCl}$ efflux

leads to $\mathrm{pH}_{\text {in }}$ increase

$\mathrm{pH} 7.0$

$\mathrm{NaX}(100 \mathrm{mM})$

HEPES (10 mM)

If $\mathrm{HX}>\mathrm{HX}$,

dominant $\mathrm{HX}$ influx

leads to $\mathrm{pH}_{\text {in }}$ decrease

(d)

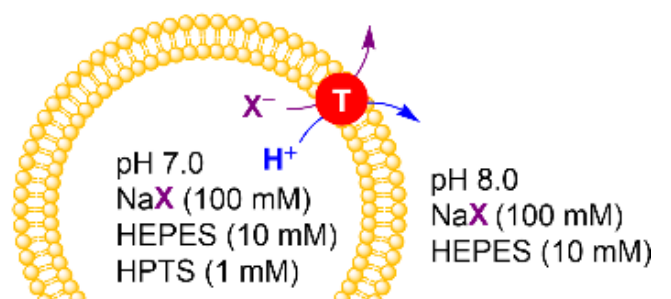

Fig. 3. Determination of anion transport selectivity of $\mathbf{1}$ using an anion gradient (pH gradient induction) assay (a, c) and a pH gradient dissipation assay (b, d). In (c) purple line, efficient $\mathrm{Cl}^{-} / \mathrm{I}^{-}$exchange led to rapid dissipation of the initially induced $\mathrm{pH}$ gradient. Note that in (d) $\mathbf{1}$ was tested at a higher concentration because of the lowered transporter activity under the assay conditions (pH 8.0 outside). Error bars represent standard deviations from two runs.

The abovementioned selectivity results indicate the rate-limiting $\mathrm{NO}_{3}{ }^{-}$transport process as the determinant for the $\mathrm{pH}$ switchable $\mathrm{Cl}^{-} / \mathrm{NO}_{3}{ }^{-}$exchange by PTSCs. In lipid-water biphasic systems, $\mathrm{NO}_{3}{ }^{-}$ binding to the protonated PTSCs is expected to be drastically weaker than $\mathrm{Cl}^{-}$binding. As a result, a lower solution $\mathrm{pH}$ is required to shift the equilibrium from the free neutral PTSC to the PTSCH+... $\mathrm{X}^{-}$ion pair complex for $\mathrm{NO}_{3}{ }^{-}$binding than for $\mathrm{Cl}^{-}$binding. This leads to inhibition of the $\mathrm{Cl}^{-} / \mathrm{NO}_{3}{ }^{-}$exchange by slow $\mathrm{NO}_{3}{ }^{-}$transport at $\mathrm{pH} 7.2$ and the "switch-ON" of the $\mathrm{Cl}^{-} / \mathrm{NO}_{3}{ }^{-}$exchange by enhanced $\mathrm{NO}_{3}{ }^{-}$binding equilibrium at $\mathrm{pH}$ 4.5. In addition, at neutral $\mathrm{pH}$ under the $\mathrm{NaCl} / \mathrm{NaNO}_{3}{ }^{\text {out }}$ ISE assay conditions, the vesicle interiors were basified due to selective $\mathrm{HCl}$ efflux by PTSCs (Fig. $5 \mathrm{c}$ blue), which could further reduce the ability of the PTSCs to form protonated anion complexes.

\section{Conclusions}

In summary, we have developed an expanded class of phenylthiosemicarbazones as $\mathrm{pH}$-switchable $\mathrm{Cl}^{-} / \mathrm{NO}_{3}{ }^{-}$exchangers with supressed activity at $\mathrm{pH} 7.2$ and enhanced activity at $\mathrm{pH} 4.5$. We showed that these transporters are active $\mathrm{H}^{+} / \mathrm{Cl}^{-}$symporters and inactive $\mathrm{Cl}^{-}$uniporters at $\mathrm{pH} 4.5$ similar to the behaviour of prodigiosin. Most importantly, we demonstrate the strong halide over oxyanion transport selectivity of the phenylthiosemicarbazones presumably due to the covalency of the doubly ionic hydrogen bond interactions leading to the preference for halide ions over oxyanions with low $\mathrm{HOMO}$ energies. As a result, while $\mathrm{Cl}^{-}$transport was efficient at both $\mathrm{pH} 4.5$ and pH 7.2, the slow $\mathrm{NO}_{3}{ }^{-}$transport turned out to be the rate-limiting factor for the suppressed $\mathrm{Cl}^{-} / \mathrm{NO}_{3}{ }^{-}$exchange at $\mathrm{pH} 7.2$ and the activation at $\mathrm{pH}$ 4.5. Our results provide important insights for understanding the 
behaviour and improving the robustness of $\mathrm{pH}$-dependent anion transporters aimed at therapeutic applications. In particular, the study demonstrates the limitation of the anion exchange assay and the benefit of measuring $\mathrm{pH}$-dependent $\mathrm{H}^{+} / \mathrm{Cl}^{-}$symport and $\mathrm{Cl}^{-}$uniport activities when studying $\mathrm{pH}-$ switchable transporters.

\section{Acknowledgements}

We acknowledge and pay respect to the Gadigal people of the Eora Nation, the traditional owners of the land on which we research, teach and collaborate at the University of Sydney. P.A.G. thanks the University of Sydney and the Australian Research Council (DP200100453) for funding.

\section{References}

[1] J.T. Davis, P.A. Gale, R. Quesada, Advances in anion transport and supramolecular medicinal chemistry, Chem. Soc. Rev., 49 (2020) 6056-6086.

[2] X. Wu, A.M. Gilchrist, P.A. Gale, Prospects and Challenges in Anion Recognition and Transport, Chem, 6 (2020) 1296-1309.

[3] T. Sato, H. Konno, Y. Tanaka, T. Kataoka, K. Nagai, H.H. Wasserman, S. Ohkuma, Prodigiosins as a new group of $\mathrm{H}^{+} / \mathrm{Cl}^{-}$symporters that uncouple proton translocators, J. Biol. Chem., 273 (1998) $21455-21462$.

[4] S. Ohkuma, T. Sato, M. Okamoto, H. Matsuya, K. Arai, T. Kataoka, K. Nagai, H.H. Wasserman, Prodigiosins uncouple lysosomal vacuolar-type ATPase through promotion of $\mathrm{H}^{+} / \mathrm{Cl}^{-}$symport, Biochem. J., 334 (1998) 731-741.

[5] T. Kataoka, M. Muroi, S. Ohkuma, T. Waritani, J. Magae, A. Takatsuki, S. Kondo, M. Yamasaki, K. Nagai, Prodigiosin 25-C uncouples vacuolar type $\mathrm{H}^{+}$-ATPase, inhibits vacuolar acidification and affects glycoprotein processing, FEBS Lett., 359 (1995) 53-59.

[6] Z.-K. Wang, X.-Q. Hong, J. Hu, Y.-Y. Xing, W.-H. Chen, Synthesis and biological activity of squaramido-tethered bisbenzimidazoles as synthetic anion transporters, RSC Adv., 11 (2021) 39723980.

[7] L. Tapia, Y. Pérez, M. Bolte, J. Casas, J. Solà, R. Quesada, I. Alfonso, pH-Dependent Chloride Transport by Pseudopeptidic Cages for the Selective Killing of Cancer Cells in Acidic Microenvironments, Angew. Chem. Int. Ed., 58 (2019) 12465-12468.

[8] A. Saha, N. Akhtar, V. Kumar, S. Kumar, H.K. Srivastava, S. Kumar, D. Manna, pH-Regulated anion transport activities of bis(iminourea) derivatives across the cell and vesicle membrane, Org. Biomol. Chem., 17 (2019) 5779-5788.

[9] A. Roy, D. Saha, P.S. Mandal, A. Mukherjee, P. Talukdar, pH-Gated Chloride Transport by a Triazine-Based Tripodal Semicage, Chem. Eur. J., 23 (2017) 1241-1247.

[10] N. Busschaert, R.B.P. Elmes, D.D. Czech, X. Wu, I.L. Kirby, E.M. Peck, K.D. Hendzel, S.K. Shaw, B. Chan, B.D. Smith, K.A. Jolliffe, P.A. Gale, Thiosquaramides: pH switchable anion transporters, Chem. Sci., 5 (2014) 3617-3626.

[11] E.N.W. Howe, N. Busschaert, X. Wu, S.N. Berry, J. Ho, M.E. Light, D.D. Czech, H.A. Klein, J.A. Kitchen, P.A. Gale, pH-Regulated Nonelectrogenic Anion Transport by Phenylthiosemicarbazones, J. Am. Chem. Soc., 138 (2016) 8301-8308.

[12] G. Sheldrick, A short history of SHELX, Acta Crystallogr. A, 64 (2008) 112-122.

[13] G. Sheldrick, Crystal structure refinement with SHELXL, Acta Crystallogr. C, 71 (2015) 3-8.

[14] O.V. Dolomanov, L.J. Bourhis, R.J. Gildea, J.A.K. Howard, H. Puschmann, OLEX2: a complete structure solution, refinement and analysis program, J. Appl. Crystallogr., 42 (2009) 339-341.

[15] X. Wu, E.N.W. Howe, P.A. Gale, Supramolecular Transmembrane Anion Transport: New Assays and Insights, Acc. Chem. Res., 51 (2018) 1870-1879.

[16] Y. Yang, X. Wu, N. Busschaert, H. Furuta, P.A. Gale, Dissecting the chloride-nitrate anion transport assay, Chem. Commun., 53 (2017) 9230-9233. 
[17] X. Wu, J.R. Small, A. Cataldo, A.M. Withecombe, P. Turner, P.A. Gale, Voltage-Switchable HCl Transport Enabled by Lipid Headgroup-Transporter Interactions, Angew. Chem. Int. Ed., 58 (2019) $15142-15147$.

[18] L.A. Jowett, E.N.W. Howe, X. Wu, N. Busschaert, P.A. Gale, New Insights into the Anion Transport Selectivity and Mechanism of Tren-based Tris-(thio)ureas, Chem. Eur. J., 24 (2018) 1047510487.

[19] X. Wu, P.A. Gale, Measuring anion transport selectivity: a cautionary tale, Chem. Commun., 57 (2021) 3979-3982.

[20] P.A. Hunt, C.R. Ashworth, R.P. Matthews, Hydrogen bonding in ionic liquids, Chem. Soc. Rev., 44 (2015) 1257-1288.

[21] D. Milano, B. Benedetti, M. Boccalon, A. Brugnara, E. lengo, P. Tecilla, Anion transport across phospholipid membranes mediated by a diphosphine-Pd(II) complex, Chem. Commun., 50 (2014) 9157-9160.

[22] S. Matile, N. Sakai, The characterization of synthetic ion channels and pores, in: C.A. Schalley (Ed.) Analytical Methods in Supramolecular Chemistry, Wiley-VCH, Place Published, 2012, pp. 711742. 


\section{Supplementary Material}

\section{Halide-selective, proton-coupled anion transport by phenylthiosemicarbazones}

Ethan N.W. Howe, ${ }^{\mathrm{a}}$ Vai-Vai Tiffany Chang, ${ }^{\mathrm{a}}$ Xin Wu, ${ }^{\mathrm{a}}$ William Lewis, ${ }^{\mathrm{a}}$ Lauren K. Macreadie, ${ }^{\mathrm{a}}$ and Philip A. Gale *a,b

${ }^{a}$ School of Chemistry, The University of Sydney, NSW 2006, Australia

${ }^{b}$ The University of Sydney Nano Institute (SydneyNano), The University of Sydney, NSW 2006, Australia

*Corresponding author. Email: philip.gale@sydney.edu.au

\section{Contents}

S1 Compound characterisations

S2 ISE assay

S2.1 General Procedure for $\mathrm{Cl}^{-} / \mathrm{NO}_{3}{ }^{-}$Exchange

S2.2 General Procedure for cationophore-coupled assay..... S16

$\mathrm{S} 2.4 \mathrm{Cl}^{-} / \mathrm{NO}_{3}{ }^{-}$exchange assay data and Hill analysis. S18

S2.5 Cationophore-coupled assay data. S27

S2.6 Comparison of $\mathrm{Cl}^{-} / \mathrm{NO}_{3}{ }^{-}$exchange and cationophore-coupled assay .536

S3 HPTS assay S40

S3.1 Vesicle preparation S40

S3.2 Anion gradient assay S40

S3.3 pH gradient dissipation assay S41

S4 X-ray crystallography S42

S5 References S43 


\section{S1 Compound characterisations}

Characterisation of (E)-2-(4-butylbenzylidene)-N-phenylhydrazine-1carbothioamide 1

Afforded white crystalline solid (94\% yield), $\mathrm{mp} 162-163{ }^{\circ} \mathrm{C}$.

${ }^{1} \mathrm{H}$ NMR (400 MHz, $\left.\left(\mathrm{CD}_{3}\right)_{2} \mathrm{SO}, 298 \mathrm{~K}, \mathrm{ppm}\right) \delta: 11.77$ (s, 1H, $\left.\mathrm{N} H^{\beta}\right), 10.06\left(\mathrm{~s}, 1 \mathrm{H}, \mathrm{N} H^{\alpha}\right)$, $8.13(\mathrm{~s}, 1 \mathrm{H}, \mathrm{NCH}), 7.80$ (d, J = 8.3 Hz, 2H, $\mathrm{ArH} \times 2$ ), 7.57 (d, J = 8.0 Hz, 2H, ArH × 2), $7.37(\mathrm{t}, J=7.6 \mathrm{~Hz}, 2 \mathrm{H}, \mathrm{ArH} \times 2), 7.25(\mathrm{~d}, J=8.0 \mathrm{~Hz}, 2 \mathrm{H}, \mathrm{ArH} \times 2), 7.20(\mathrm{t}, J=7.3 \mathrm{~Hz}$, $1 \mathrm{H}, \mathrm{ArH}$ ), 2.61 (t, $J=7.7 \mathrm{~Hz}, 2 \mathrm{H}, \mathrm{CH}_{2}$ ), 1.56 (quint, $J=7.9 \mathrm{~Hz}, 2 \mathrm{H}, \mathrm{CH}_{2}$ ), 1.31 (sext, $J$ $\left.=7.5 \mathrm{~Hz}, 2 \mathrm{H}, \mathrm{CH}_{2}\right), 0.90\left(\mathrm{t}, J=7.2 \mathrm{~Hz}, 3 \mathrm{H}, \mathrm{CH}_{3}\right)$.

${ }^{13} \mathrm{C}$ NMR (101 MHz, $\left.\left(\mathrm{CD}_{3}\right)_{2} \mathrm{SO}, 298 \mathrm{~K}, \mathrm{ppm}\right) \delta: 144.7,143.0,139.1,131.5,128.6$, 128.0, 127.6, 125.8, 125.2, 34.7, 32.9, 21.7, 13.7.

MS (APCl$\left.{ }^{+}\right) \mathrm{m} / \mathrm{z}$ : calcd for $\mathrm{C}_{18} \mathrm{H}_{22} \mathrm{~N}_{3} \mathrm{~S}: 312.15$, found: 312.09 .
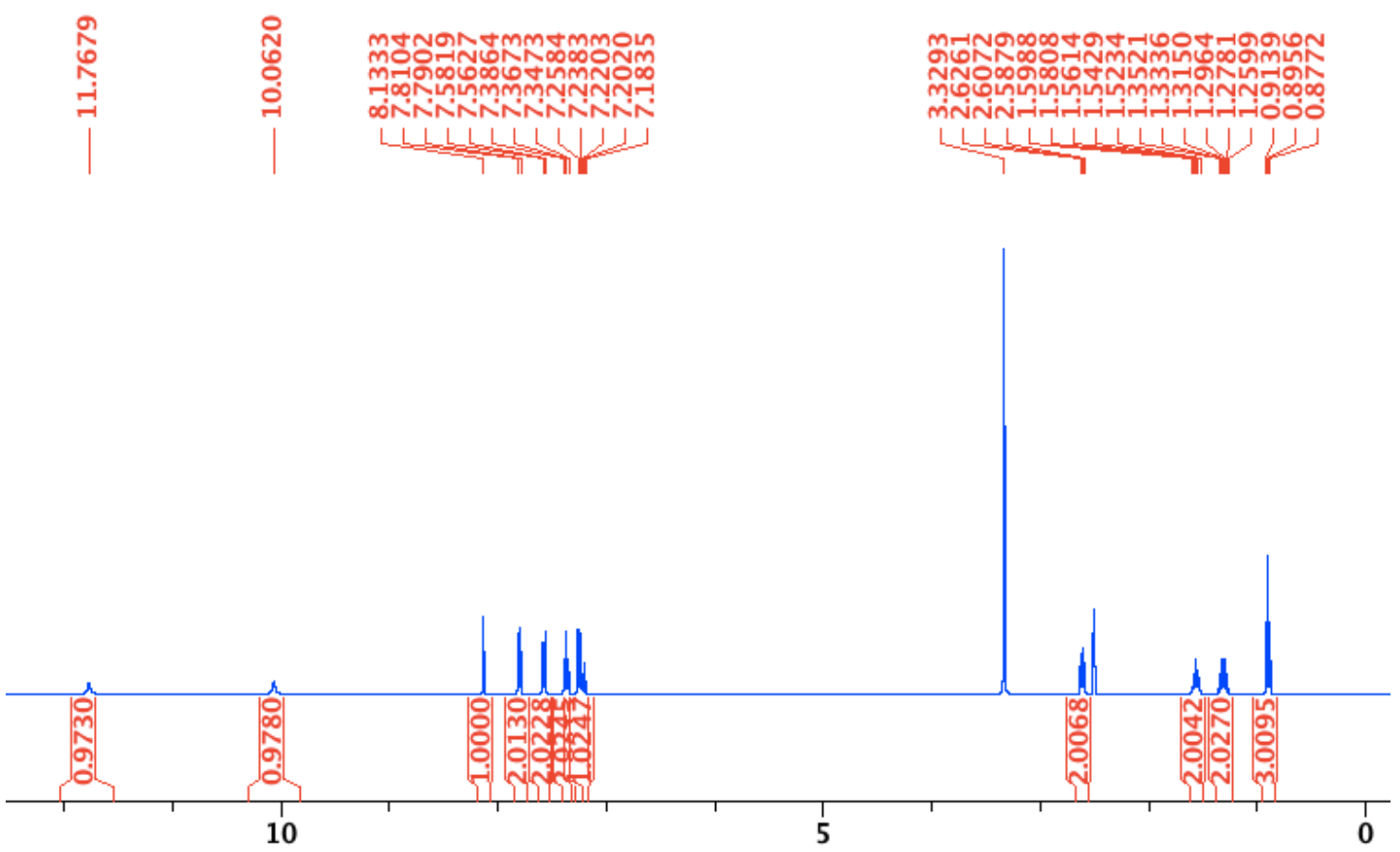

Fig. $\mathbf{S 1}{ }^{1} \mathrm{H}$ NMR (400 MHz) spectrum of compound 1 in DMSO-d6. 


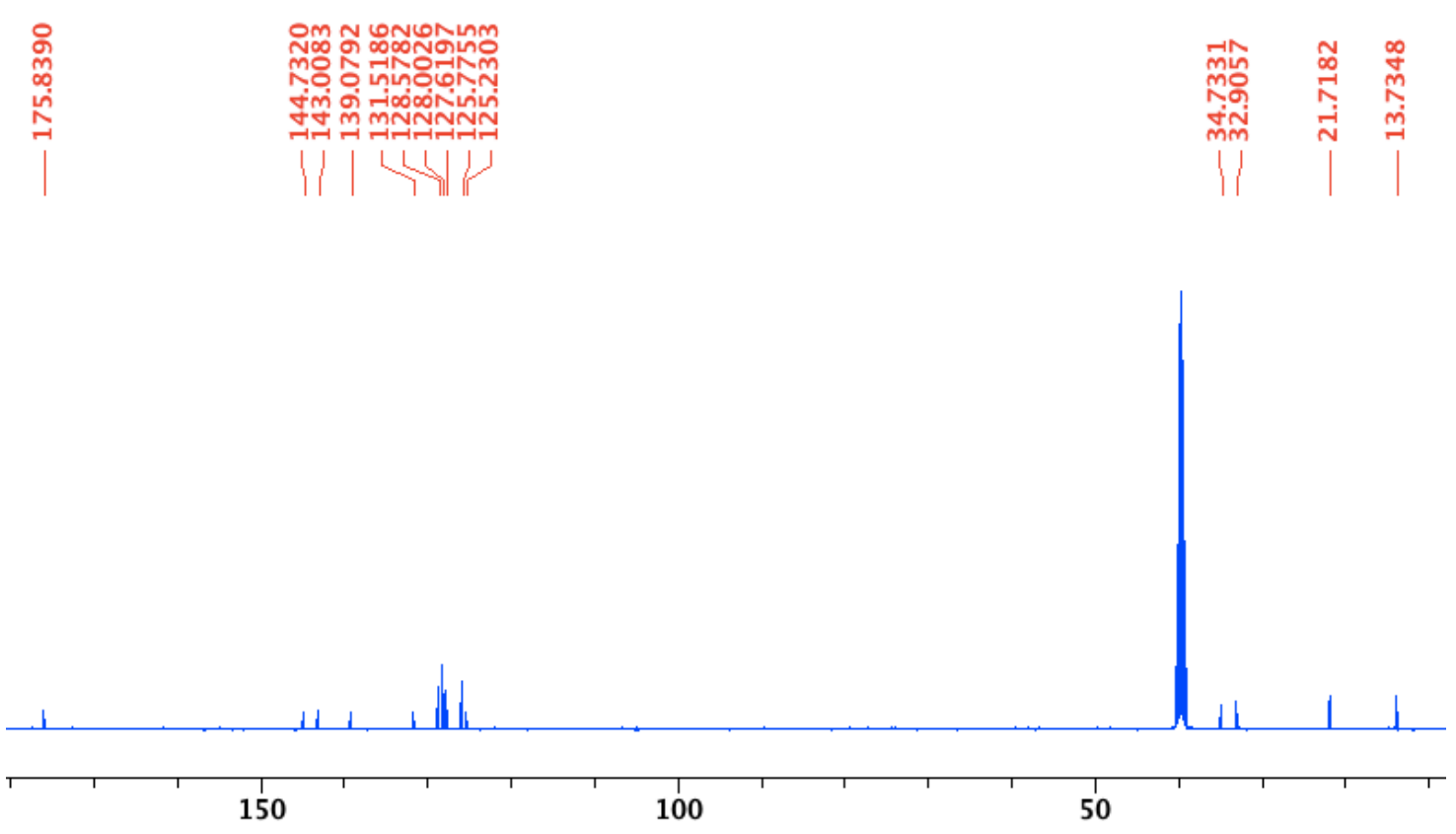

Fig. S2 ${ }^{13} \mathrm{C}$ NMR $(101 \mathrm{MHz})$ spectrum of compound 1 in DMSO-d 6 .

\section{Characterisation of (E)-2-(4-butylbenzylidene)-N-(p-tolyl)hydrazine-1-}

\section{carbothioamide 2}

Afforded white crystalline solid (96\% yield), $\mathrm{mp} 152-153^{\circ} \mathrm{C}$

${ }^{1} \mathrm{H}$ NMR $\left(400 \mathrm{MHz},\left(\mathrm{CD}_{3}\right)_{2} \mathrm{SO}, 298 \mathrm{~K}, \mathrm{ppm}\right) \delta: 11.72\left(\mathrm{~s}, 1 \mathrm{H}, \mathrm{N} H^{\beta}\right), 9.99\left(\mathrm{~s}, 1 \mathrm{H}, \mathrm{N} H^{\alpha}\right)$, $8.12(\mathrm{~s}, 1 \mathrm{H}, \mathrm{NCH}), 7.79$ (d, J = 8.5 Hz, $2 \mathrm{H}, \mathrm{ArH} \times 2), 7.43(\mathrm{~d}, J=8.5 \mathrm{~Hz}, 2 \mathrm{H}, \mathrm{ArH} \times 2$ ), $7.24(\mathrm{~d}, J=8.1 \mathrm{~Hz}, 2 \mathrm{H}, \mathrm{ArH} \times 2), 7.17(\mathrm{~d}, J=8.5 \mathrm{~Hz}, 2 \mathrm{H}, \operatorname{Ar} H \times 2), 2.60(\mathrm{t}, J=7.6 \mathrm{~Hz}$, $2 \mathrm{H}, \mathrm{CH}_{2}$ ), 2.31 (s, 3H, $\mathrm{CH}_{3}$ ), 1.56 (quint, $J=7.8 \mathrm{~Hz}, 2 \mathrm{H}, \mathrm{CH}_{2}$ ), 1.31 (sext, $J=7.4 \mathrm{~Hz}$, $\left.2 \mathrm{H}, \mathrm{CH}_{2}\right), 0.89$ (t, $\mathrm{J}=7.4 \mathrm{~Hz}, 3 \mathrm{H}, \mathrm{CH}_{3}$ ).

${ }^{13} \mathrm{C}$ NMR $\left(101 \mathrm{MHz},\left(\mathrm{CD}_{3}\right)_{2} \mathrm{SO}, 298 \mathrm{~K}, \mathrm{ppm}\right) \delta: 175.9,144.7,142.8,136.5,134.4$, 131.6, 128.6, 128.5, 127.6, 125.7, 34.7, 32.9, 21.7, 20.6, 13.7.

MS (APCl $\left.{ }^{+}\right) \mathrm{m} / \mathrm{z}$ : calcd for $\mathrm{C}_{19} \mathrm{H}_{24} \mathrm{~N}_{3} \mathrm{~S}: 326.17$, found: 326.13 . 


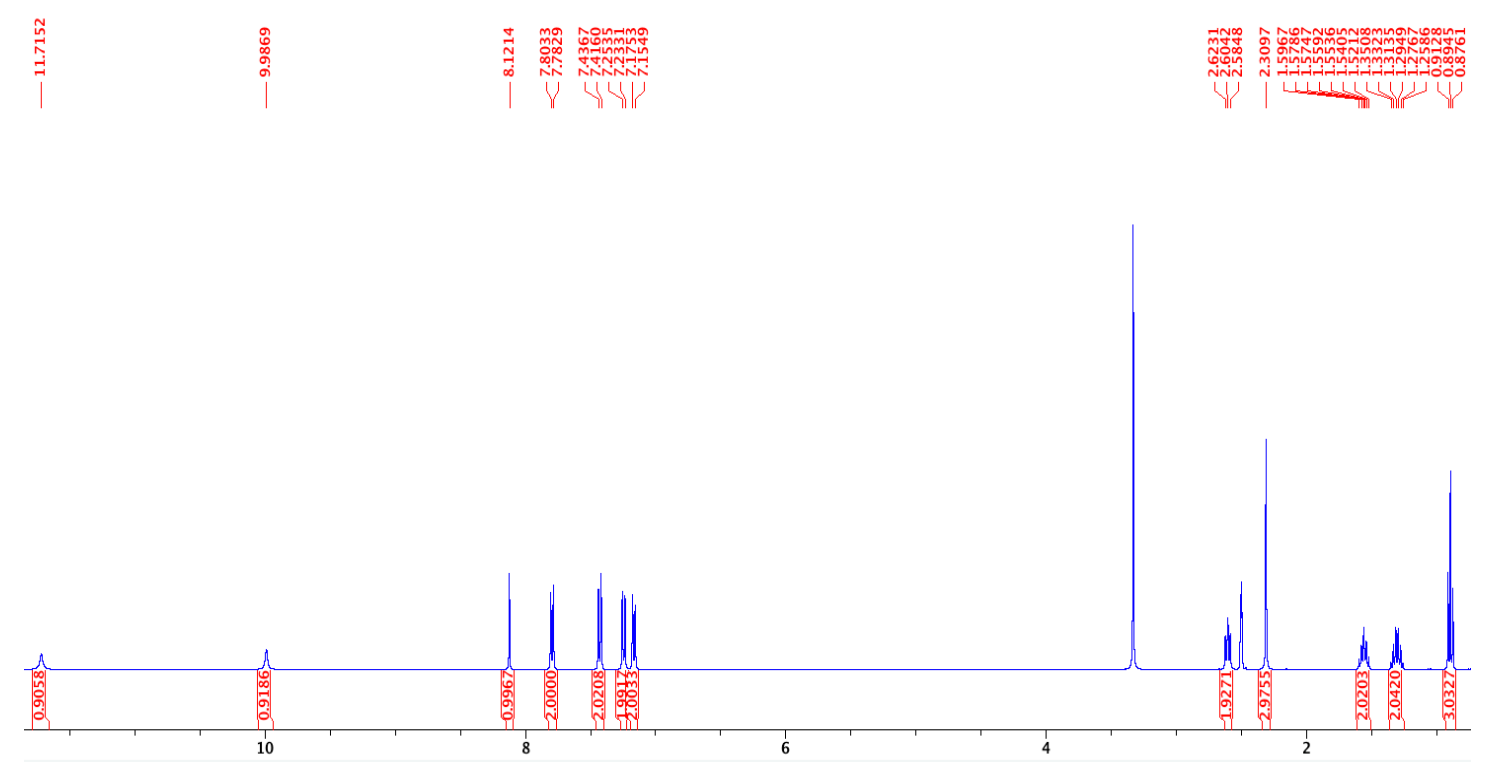

Fig. S3 ${ }^{1} \mathrm{H}$ NMR $(400 \mathrm{MHz})$ spectrum of compound 2 in DMSO-d6.
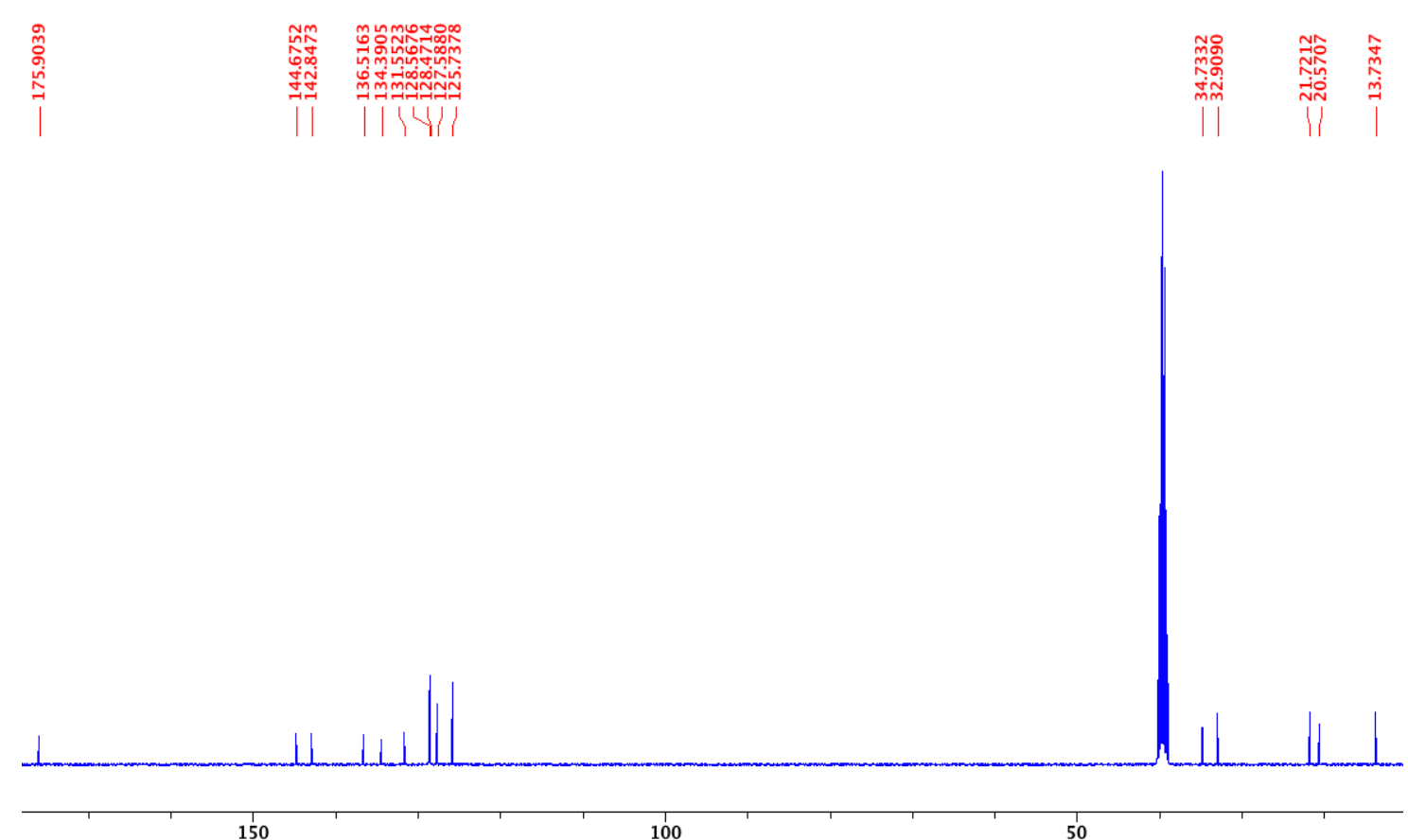

Fig. S4 ${ }^{13} \mathrm{C}$ NMR $(101 \mathrm{MHz})$ spectrum of compound 2 in DMSO-d6.

Characterisation of (E)-2-(4-butylbenzylidene)-N-(4-methoxyphenyl)hydrazine1-carbothioamide 3

Afforded white solid (90\% yield), mp $126-128{ }^{\circ} \mathrm{C}$

${ }^{1} \mathrm{H}$ NMR (400 MHz, $\left.\left(\mathrm{CD}_{3}\right)_{2} \mathrm{SO}, 298 \mathrm{~K}, \mathrm{ppm}\right)$ d: 11.68 (s, $\left.1 \mathrm{H}, \mathrm{N} H^{\beta}\right), 9.96\left(\mathrm{~s}, 1 \mathrm{H}, \mathrm{N} H^{\alpha}\right)$, $8.11(\mathrm{~s}, 1 \mathrm{H}, \mathrm{NCH}), 7.79$ (d, J=7.9 Hz, 2H, $\mathrm{ArH} \times 2$ ), 7.40 (d, J=8.7 Hz, 2H, $\operatorname{ArH} \times 2$ ), $7.24(\mathrm{~d}, J=8.3 \mathrm{~Hz}, 2 \mathrm{H}, \mathrm{ArH} \times 2), 6.93(\mathrm{~d}, \mathrm{~J}=9.1 \mathrm{~Hz}, 2 \mathrm{H}, \mathrm{ArH} \times 2), 3.77\left(\mathrm{~s}, 3 \mathrm{H}, \mathrm{OCH}_{3}\right)$, 2.60 (t, $J=7.5 \mathrm{~Hz}, 2 \mathrm{H}, \mathrm{CH}_{2}$ ), 1.56 (quint, $J=7.6 \mathrm{~Hz}, 2 \mathrm{H}, \mathrm{CH}_{2}$ ), 1.31 (sext, $J=7.5 \mathrm{~Hz}$, $\left.2 \mathrm{H}, \mathrm{CH}_{2}\right), 0.89\left(\mathrm{t}, \mathrm{J}=7.3 \mathrm{~Hz}, 3 \mathrm{H}, \mathrm{CH}_{3}\right)$. 
${ }^{13} \mathrm{C}$ NMR (101 MHz, $\left.\left(\mathrm{CD}_{3}\right)_{2} \mathrm{SO}, 298 \mathrm{~K}, \mathrm{ppm}\right) \delta: 176.2,156.9,144.6,142.7,132.0$, 131.6, 128.6, 127.6, 127.5, 113.2, 55.2, 34.7, 32.9, 21.7, 13.7.

MS $\left(\mathrm{APCl}^{+}\right) \mathrm{m} / \mathrm{z}$ : calcd for $\mathrm{C}_{19} \mathrm{H}_{24} \mathrm{~N}_{3} \mathrm{OS}$ : 342.16, found: 342.12 .

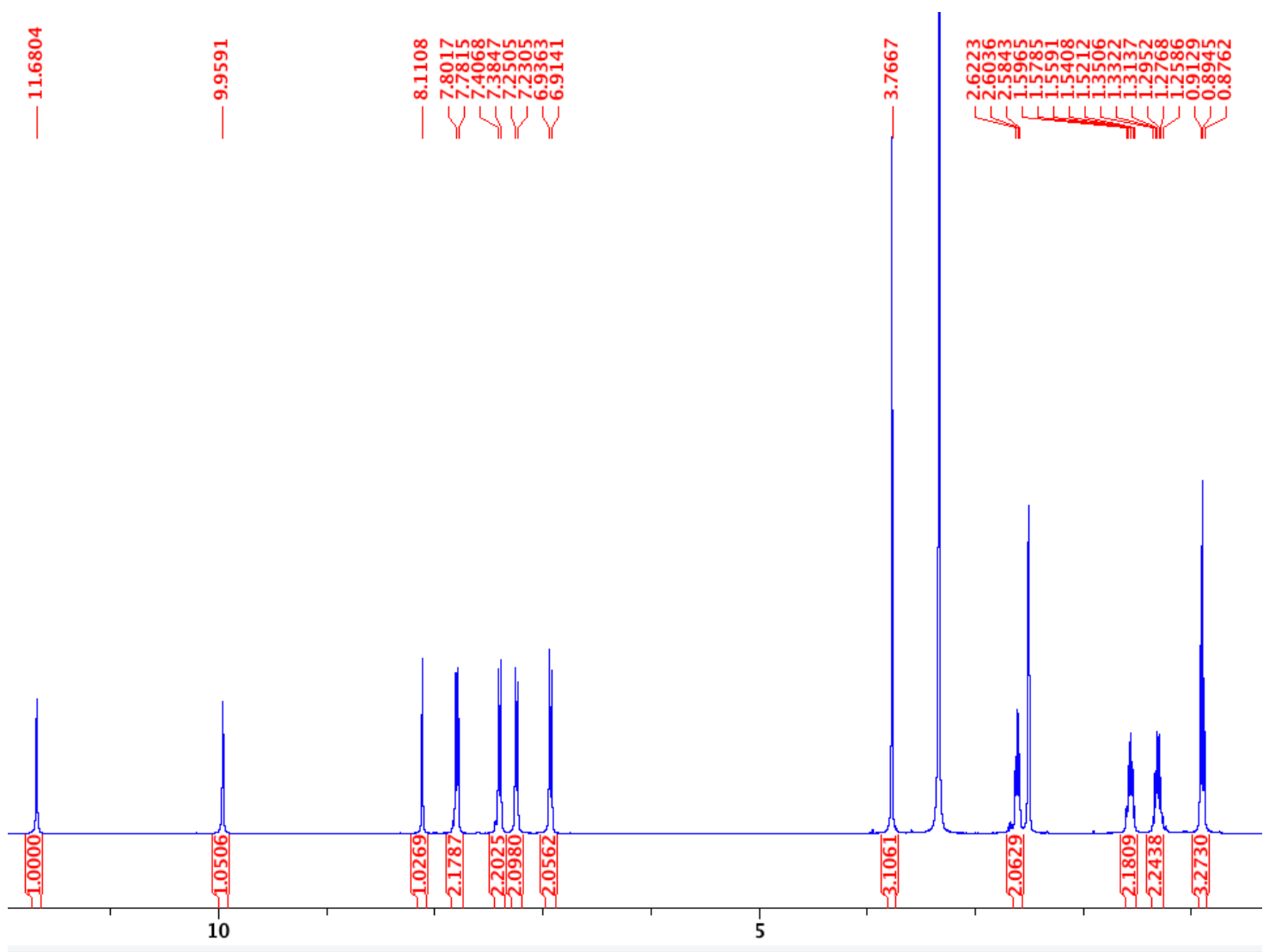

Fig. $S 5{ }^{1} \mathrm{H}$ NMR $(400 \mathrm{MHz})$ spectrum of compound 3 in DMSO- $d_{6}$.

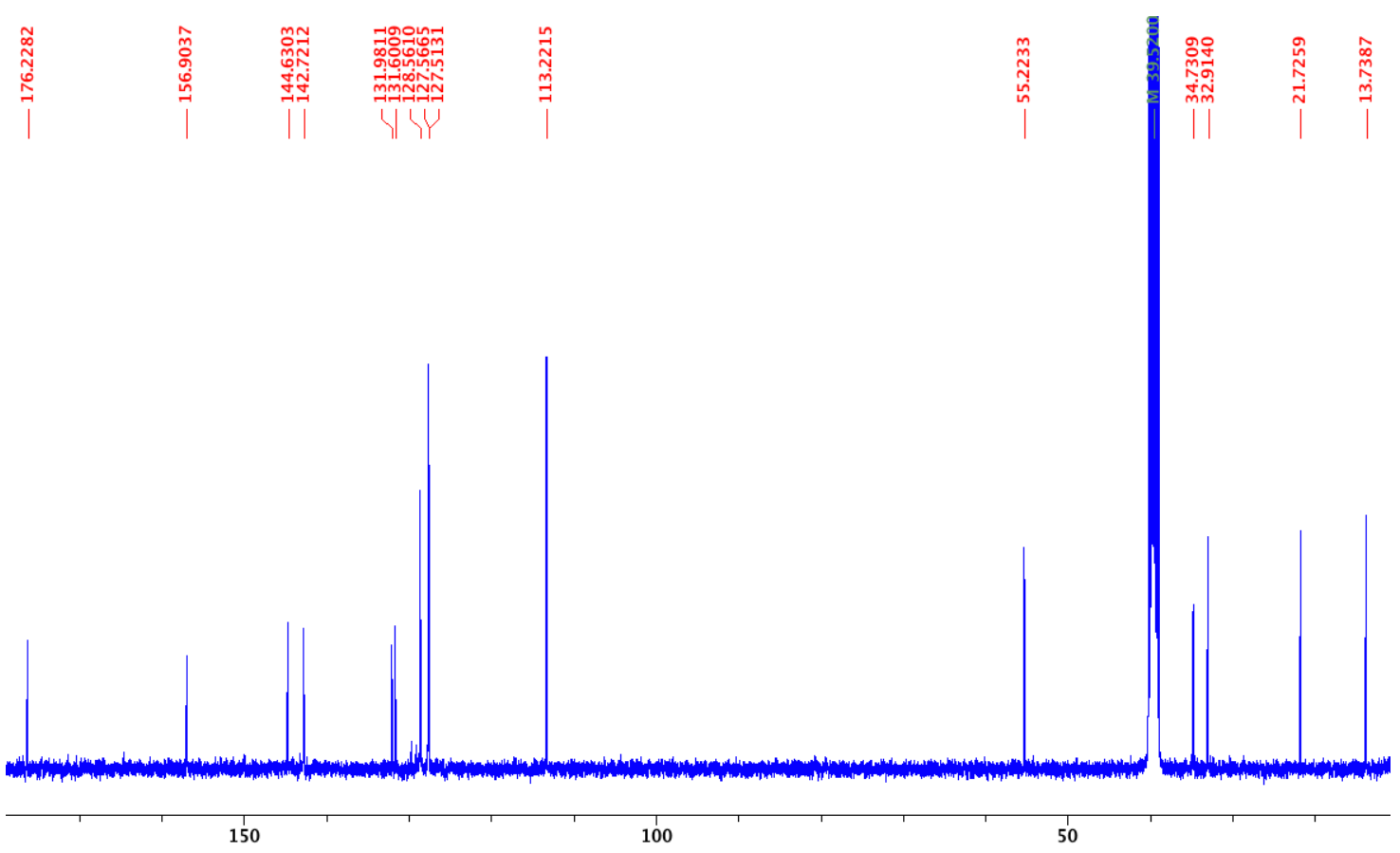

Fig. S6 ${ }^{13} \mathrm{C}$ NMR $(101 \mathrm{MHz})$ spectrum of compound 3 in DMSO-d 6 . 


\section{Characterisation of (E)-2-(4-butylbenzylidene)- $\mathrm{N}-(4-$}

\section{(trifluoromethyl)phenyl)hydrazine-1-carbothioamide 4}

Afforded white crystalline solid (95\% yield), mp $167-169{ }^{\circ} \mathrm{C}$

${ }^{1} \mathrm{H}$ NMR (400 MHz, $\left.\left(\mathrm{CD}_{3}\right)_{2} \mathrm{SO}, 298 \mathrm{~K}, \mathrm{ppm}\right) \delta: 11.98$ (s, $\left.1 \mathrm{H}, \mathrm{N} H^{\beta}\right), 10.26\left(\mathrm{~s}, 1 \mathrm{H}, \mathrm{N} H^{\alpha}\right)$, $8.17(\mathrm{~s}, 1 \mathrm{H}, \mathrm{NCH}), 7.91$ (d, J = 8.4 Hz, 2H, $\mathrm{ArH} \times 2$ ), 7.81 (d, J = 8.0 Hz, 2H, ArH × 2), $7.73(\mathrm{~d}, J=8.7 \mathrm{~Hz}, 2 \mathrm{H}, \mathrm{ArH} \times 2), 7.26(\mathrm{~d}, J=8.0 \mathrm{~Hz}, 2 \mathrm{H}, \mathrm{ArH} \times 2), 2.61$ (t, J=7.6 Hz, $2 \mathrm{H}, \mathrm{CH}_{2}$ ), 1.56 (quint, $J=7.6 \mathrm{~Hz}, 2 \mathrm{H}, \mathrm{CH}_{2}$ ), 1.31 (sext, $J=7.5 \mathrm{~Hz}, 2 \mathrm{H}, \mathrm{CH}_{2}$ ), 0.89 (t, $\left.J=7.5 \mathrm{~Hz}, 3 \mathrm{H}, \mathrm{CH}_{3}\right)$.

${ }^{13} \mathrm{C}$ NMR (101 MHz, $\left.\left(\mathrm{CD}_{3}\right)_{2} \mathrm{SO}, 298 \mathrm{~K}, \mathrm{ppm}\right) \delta: 175.6,145.0,143.8,142.8,131.3$, 128.6, 127.7, 125.4, 125.1 (q, $\left.{ }^{3} J(C, F)=4 \mathrm{~Hz}\right), 125.0\left(q,{ }^{2} J(C, F)=32 \mathrm{~Hz}\right), 124.3$ (q, $\left.{ }^{1} J(C, F)=272 \mathrm{~Hz}\right), 34.7,32.9,21.7,13.7$.

${ }^{19} \mathrm{~F}$ NMR (376 MHz, DMSO-d6, dppm) ס: -60.47 (s, 3F)

MS $\left(\mathrm{APCl}^{+}\right) \mathrm{m} / \mathrm{z}$ : calcd for $\mathrm{C}_{19} \mathrm{H}_{21} \mathrm{~F}_{3} \mathrm{~N}_{3} \mathrm{~S}: 380.14$, found: 380.10 .
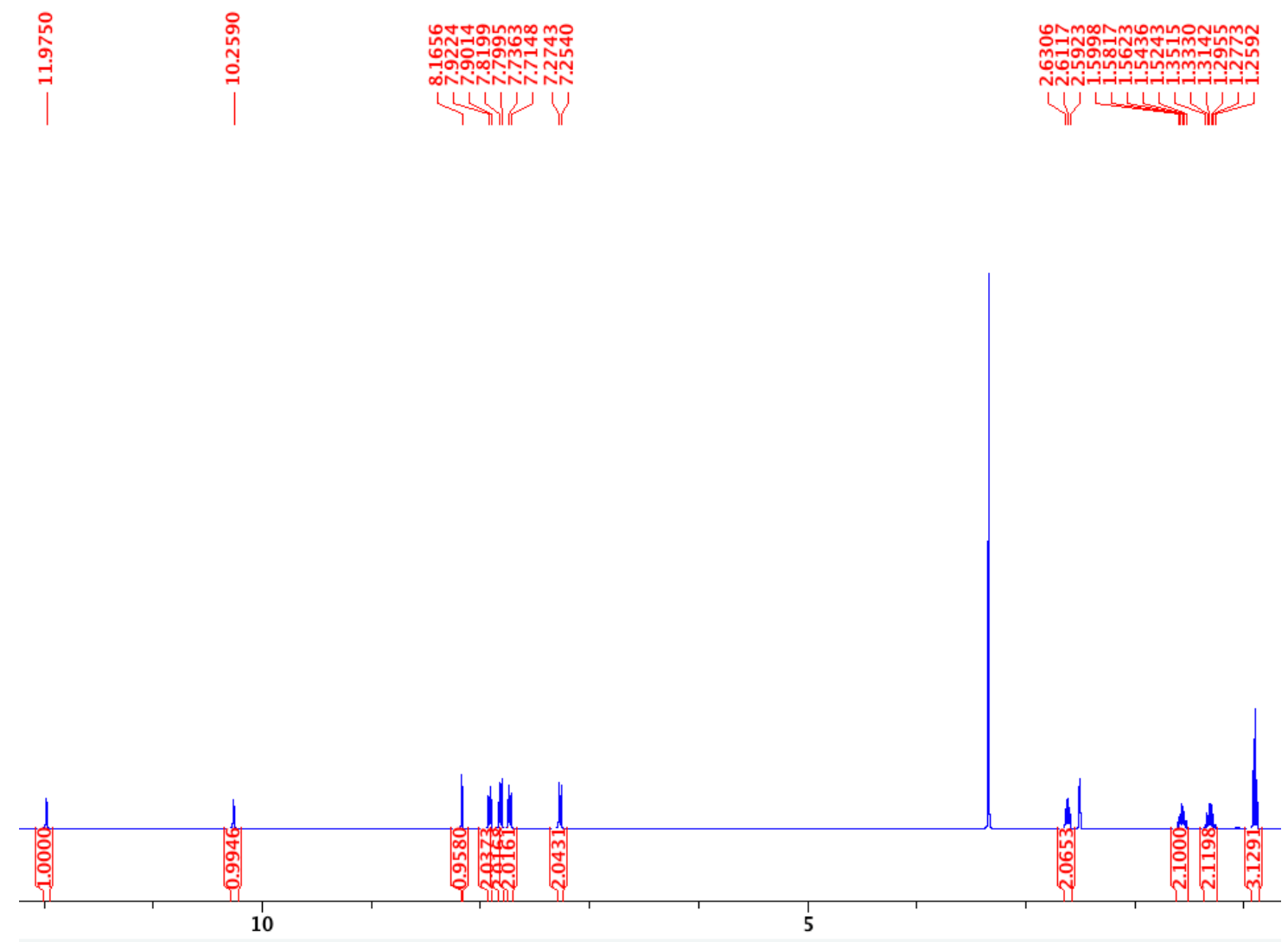

Fig. $57{ }^{1} \mathrm{H}$ NMR $(400 \mathrm{MHz})$ spectrum of compound 4 in DMSO- $d_{6}$. 


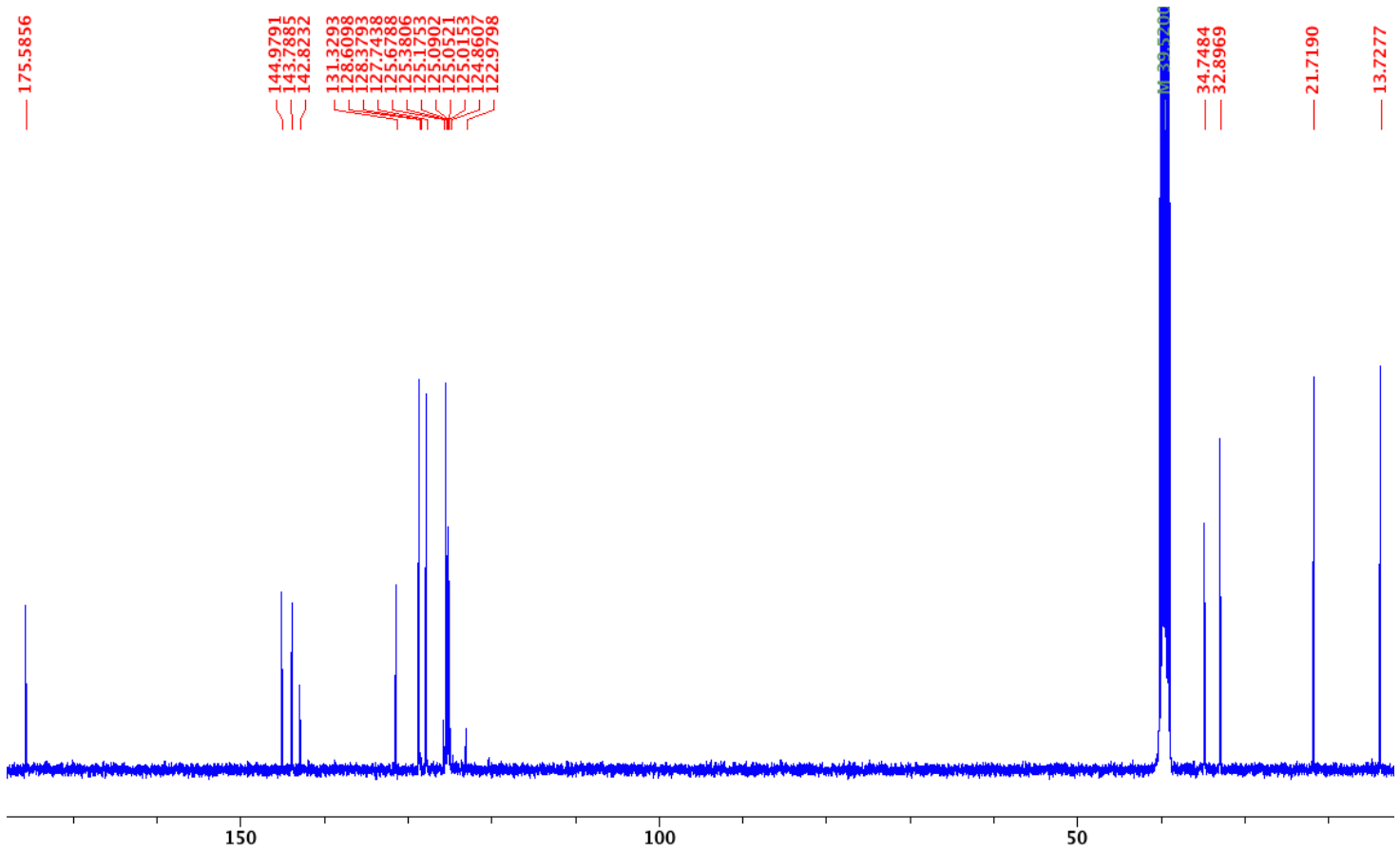

Fig. S8 ${ }^{13} \mathrm{C}$ NMR $(101 \mathrm{MHz})$ spectrum of compound 4 in DMSO- $d_{6}$.

\section{Characterisation of (E)-2-(4-butylbenzylidene)- $N$-(4-}

\section{(trifluoromethoxy)phenyl)hydrazine-1-carbothioamide 5}

Afforded white solid ( $91 \%$ yield), mp $122-125^{\circ} \mathrm{C}$

${ }^{1} \mathrm{H}$ NMR $\left(400 \mathrm{MHz},\left(\mathrm{CD}_{3}\right)_{2} \mathrm{SO}, 298 \mathrm{~K}, \mathrm{ppm}\right) \delta: 11.16\left(\mathrm{~s}, 1 \mathrm{H}, \mathrm{NH}{ }^{\beta}\right), 10.42\left(\mathrm{~s}, 1 \mathrm{H}, \mathrm{NH} H^{\alpha}\right)$, 8.69 (s, $1 \mathrm{H}, \mathrm{NCH}$ ), 8.35 (d, $J=8.9 \mathrm{~Hz}, 2 \mathrm{H}, \mathrm{ArH} \times 2$ ), 8.21 (d, $J=8.0 \mathrm{~Hz}, 2 \mathrm{H}, \mathrm{ArH} \times 2$ ), $7.77(\mathrm{~d}, J=8.9 \mathrm{~Hz}, 2 \mathrm{H}, \mathrm{ArH} \times 2), 7.73(\mathrm{~d}, J=8.0 \mathrm{~Hz}, 2 \mathrm{H}, \mathrm{ArH} \times 2), 3.11(\mathrm{t}, J=7.6 \mathrm{~Hz}$, $2 \mathrm{H}, \mathrm{CH}_{2}$ ), 2.06 (quint, $J=7.6 \mathrm{~Hz}, 2 \mathrm{H}, \mathrm{CH}_{2}$ ), 1.81 (sext, $J=7.4 \mathrm{~Hz}, 2 \mathrm{H}, \mathrm{CH}_{2}$ ), 1.37 (t, $\left.J=7.5 \mathrm{~Hz}, 3 \mathrm{H}, \mathrm{CH}_{3}\right)$.

${ }^{13} \mathrm{C}$ NMR (101 MHz, $\left.\left(\mathrm{CD}_{3}\right)_{2} \mathrm{SO}, 298 \mathrm{~K}, \mathrm{ppm}\right) \delta: 187.2,156.4\left(\mathrm{~d},{ }^{3} \mathrm{~J}(\mathrm{C}, \mathrm{F})=2 \mathrm{~Hz}\right), 156.1$, 153.9, 148.9, 142.2, 139.4, 138.2, $136.7\left(\mathrm{~d},{ }^{2} \mathrm{~J}(\mathrm{C}, \mathrm{F})=26 \mathrm{~Hz}\right), 136.7,131.4,131.2(\mathrm{~d}$, $\left.{ }^{1} J(C, F)=255 \mathrm{~Hz}\right), 45.8,43.9,32.6,23.8$.

${ }^{19} \mathrm{~F}$ NMR (376 MHz, DMSO-d6, dppm) $\delta:-58.68$ (s, 3F)

MS (ESI $\left.{ }^{+}\right) \mathrm{m} / \mathrm{z}$ : calcd for $\mathrm{C}_{19} \mathrm{H}_{21} \mathrm{~F}_{3} \mathrm{~N}_{3} \mathrm{OS}: 396.14$, found: 396.17 . 

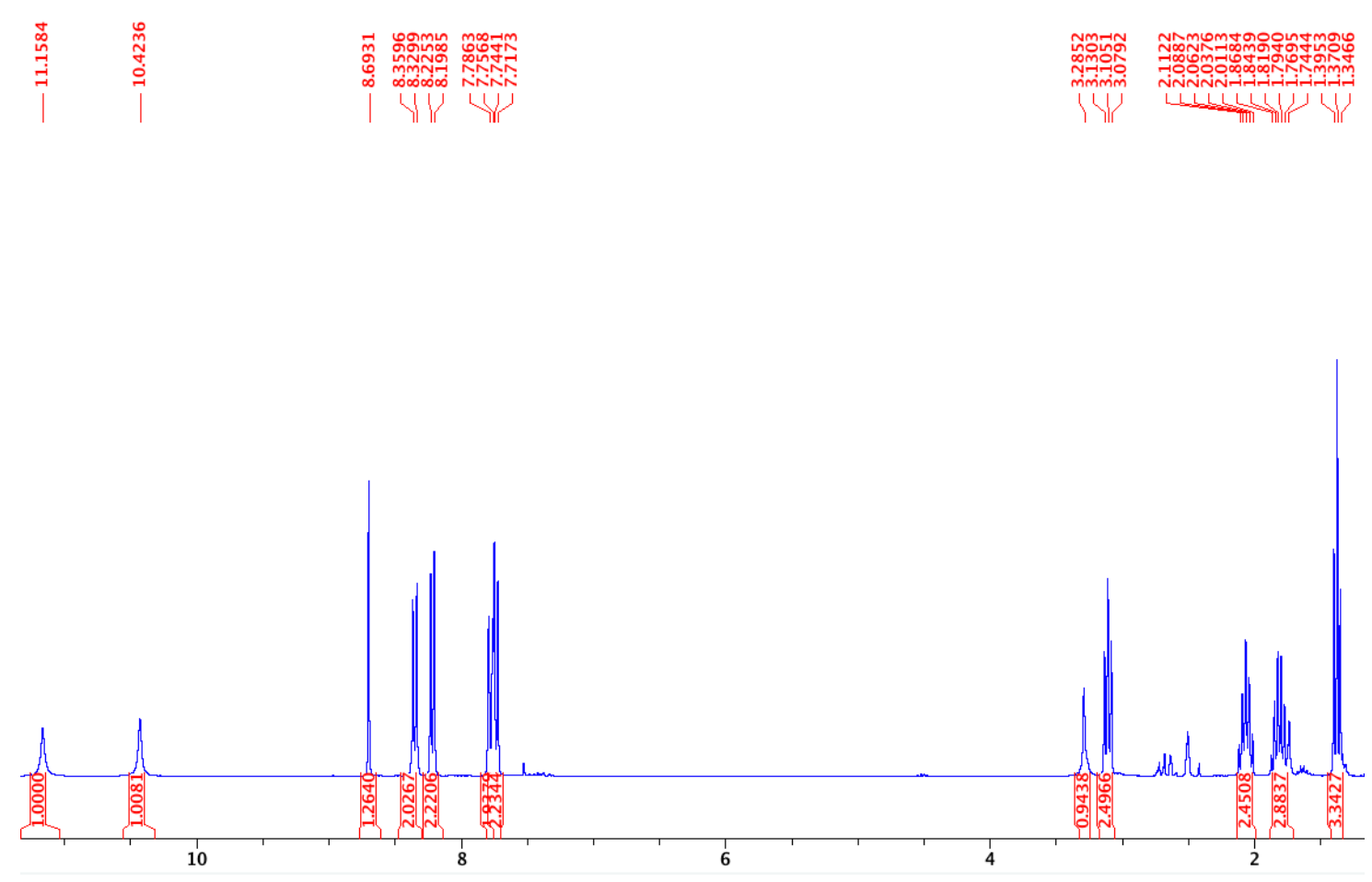

Fig. $S 9{ }^{1} \mathrm{H}$ NMR $(400 \mathrm{MHz})$ spectrum of compound 5 in DMSO-d $d_{6}$.
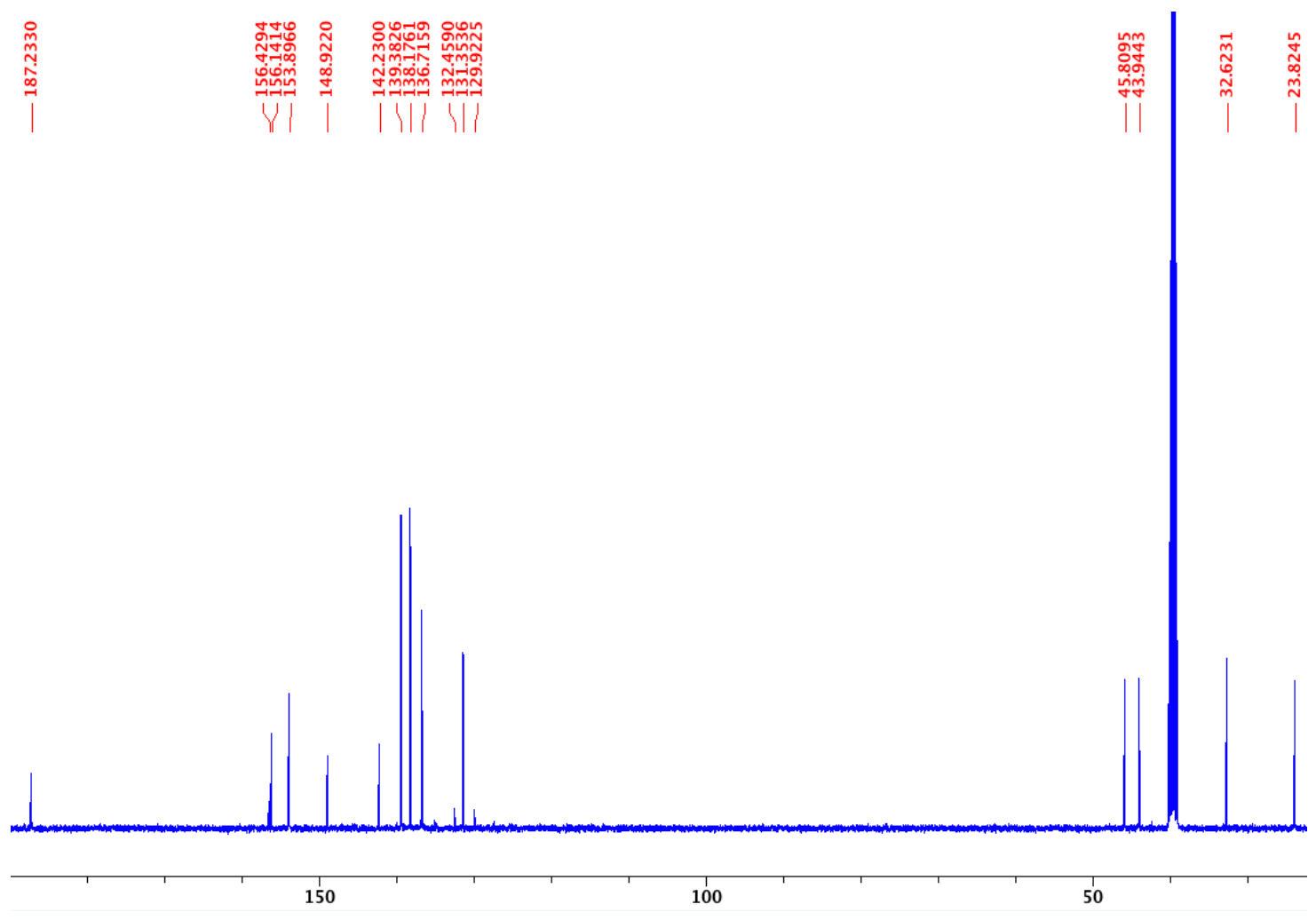

Fig. $S 10{ }^{13} \mathrm{C}$ NMR (101 MHz) spectrum of compound 5 in DMSO-d 6 . 


\section{Characterisation of $(E)-\mathrm{N}-(3,5-b i s($ trifluoromethyl)phenyl)-2-(4-}

\section{butylbenzylidene)hydrazine-1-carbothioamide 6}

Afforded white solid (77\% yield), mp $176-177^{\circ} \mathrm{C}$

${ }^{1} \mathrm{H}$ NMR (400 MHz, $\left.\left(\mathrm{CD}_{3}\right)_{2} \mathrm{SO}, 298 \mathrm{~K}, \mathrm{ppm}\right) \delta: 12.16$ (s, $\left.1 \mathrm{H}, \mathrm{N} H^{\beta}\right), 10.46\left(\mathrm{~s}, 1 \mathrm{H}, \mathrm{N} H^{\alpha}\right.$ ), 8.49 (s, 2H, $\mathrm{ArH} \times 2), 8.19(\mathrm{~s}, 1 \mathrm{H}, \mathrm{NCH}), 7.88(\mathrm{~s}, 1 \mathrm{H}, \mathrm{ArH}), 7.83(\mathrm{~d}, J=8.1 \mathrm{~Hz}, 2 \mathrm{H}$, $\mathrm{ArH} \times 2), 7.28(\mathrm{~d}, J=8.1 \mathrm{~Hz}, 2 \mathrm{H}, \mathrm{ArH} \times 2), 2.62\left(\mathrm{t}, J=7.6 \mathrm{~Hz}, 2 \mathrm{H}, \mathrm{CH}_{2}\right), 1.57$ (quint, $J=7.6 \mathrm{~Hz}, 2 \mathrm{H}, \mathrm{CH}_{2}$ ), 1.31 (sext, $J=7.5 \mathrm{~Hz}, 2 \mathrm{H}, \mathrm{CH}_{2}$ ), 0.90 (t, $J=7.5 \mathrm{~Hz}, 3 \mathrm{H}, \mathrm{CH}_{3}$ ). ${ }^{13} \mathrm{C}$ NMR (101 MHz, $\left.\left(\mathrm{CD}_{3}\right)_{2} \mathrm{SO}, 298 \mathrm{~K}, \mathrm{ppm}\right) \delta: 175.6,145.2,144.4,141.1,131.2$, $129.7\left(\mathrm{q},{ }^{2} \mathrm{~J}(\mathrm{C}, \mathrm{F})=33 \mathrm{~Hz}\right), 128.6,127.8,125.3\left(\mathrm{q},{ }^{3} \mathrm{~J}(\mathrm{C}, \mathrm{F})=4 \mathrm{~Hz}\right), 123.3\left(\mathrm{q},{ }^{1} \mathrm{~J}(\mathrm{C}, \mathrm{F})=\right.$ $272 \mathrm{~Hz}), 117.8\left(\mathrm{q},{ }^{3} \mathrm{~J}(\mathrm{C}, \mathrm{F})=4 \mathrm{~Hz}\right), 34.8,32.9,21.7,13.7$.

${ }^{19} \mathrm{~F}$ NMR (376 MHz, DMSO-d6, dppm) ס: -61.39 (s, 6F)

MS (APCl $\left.{ }^{+}\right) \mathrm{m} / \mathrm{z}$ : calcd for $\mathrm{C}_{20} \mathrm{H}_{20} \mathrm{~F}_{6} \mathrm{~N}_{3} \mathrm{~S}: 448.13$, found: 448.10 .

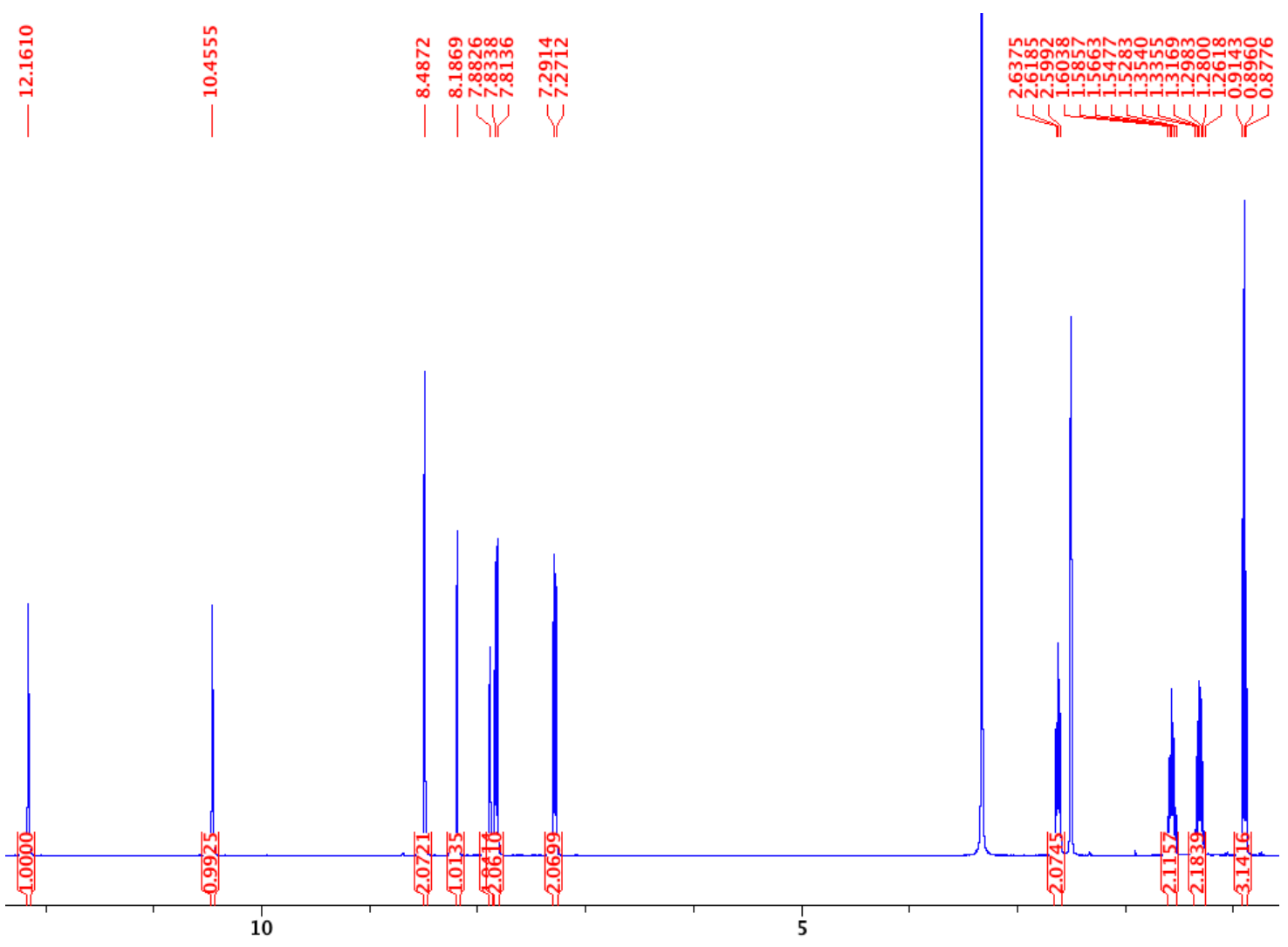

Fig. $511^{1} \mathrm{H}$ NMR $(400 \mathrm{MHz})$ spectrum of compound 6 in DMSO-d 6 . 


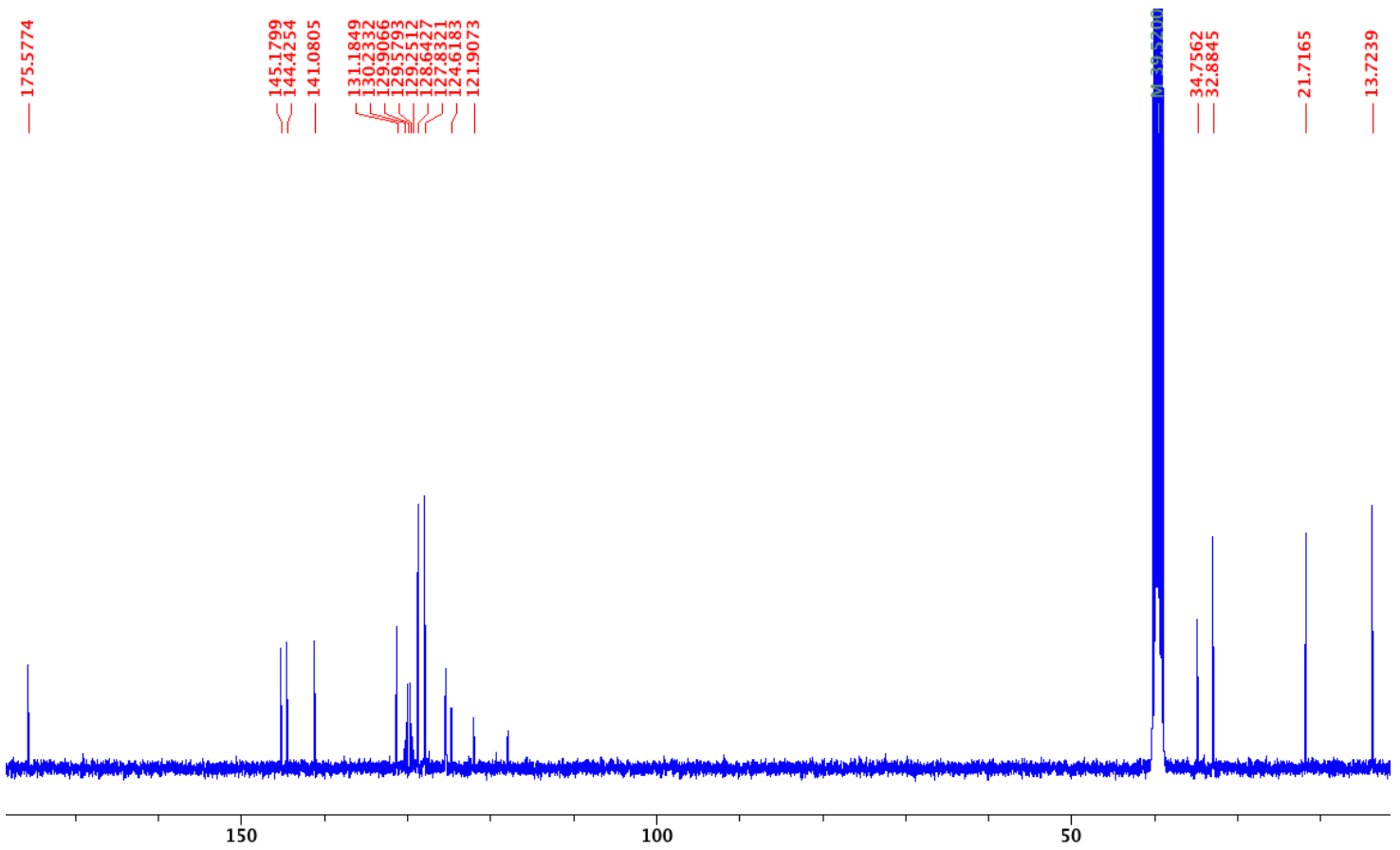

Fig. $\mathbf{S} 12{ }^{13} \mathrm{C}$ NMR $(101 \mathrm{MHz})$ spectrum of compound 6 in DMSO-d6.

Characterisation of (E)-2-(4-butylbenzylidene)- $\mathrm{N}$-(4-fluorophenyl)hydrazine-1carbothioamide 7

Afforded white crystalline solid ( $88 \%$ yield), $\mathrm{mp} 137-139{ }^{\circ} \mathrm{C}$

${ }^{1} \mathrm{H}$ NMR $\left(400 \mathrm{MHz},\left(\mathrm{CD}_{3}\right)_{2} \mathrm{SO}, 298 \mathrm{~K}, \mathrm{ppm}\right) \delta: 11.79\left(\mathrm{~s}, 1 \mathrm{H}, \mathrm{NH} H^{\beta}\right), 10.07\left(\mathrm{~s}, 1 \mathrm{H}, \mathrm{NH}{ }^{\alpha}\right)$, $8.13(\mathrm{~s}, 1 \mathrm{H}, \mathrm{NCH}), 7.80(\mathrm{~d}, J=8.3 \mathrm{~Hz}, 2 \mathrm{H}, \mathrm{ArH} \times 2), 7.55(\mathrm{dd}, J=8.8,5.1 \mathrm{~Hz}, 2 \mathrm{H}, \mathrm{ArH}$ $\times 2), 7.25(\mathrm{~d}, J=8.3 \mathrm{~Hz}, 2 \mathrm{H}, \mathrm{ArH} \times 2), 7.20(\mathrm{dd} J=9.1,8.8 \mathrm{~Hz}, 2 \mathrm{H}, \mathrm{ArH} \times 2), 2.61(\mathrm{t}$, $J=7.2 \mathrm{~Hz}, 2 \mathrm{H}, \mathrm{CH}_{2}$ ), 1.56 (quint, $J=7.2 \mathrm{~Hz}, 2 \mathrm{H}, \mathrm{CH}_{2}$ ), 1.31 (sext, $J=7.2 \mathrm{~Hz}, 2 \mathrm{H}$, $\left.\mathrm{CH}_{2}\right), 0.89\left(\mathrm{t}, J=7.2 \mathrm{~Hz}, 3 \mathrm{H}, \mathrm{CH}_{3}\right)$.

${ }^{13} \mathrm{C}$ NMR (101 MHz, $\left.\left(\mathrm{CD}_{3}\right)_{2} \mathrm{SO}, 298 \mathrm{~K}, \mathrm{ppm}\right) \delta: 176.2,159.6\left(\mathrm{~d},{ }^{1} \mathrm{~J}(\mathrm{C}, \mathrm{F})=242 \mathrm{~Hz}\right)$, 144.8, 143.1, $135.4\left(\mathrm{~d},{ }^{4} \mathrm{~J}(\mathrm{C}, \mathrm{F})=3 \mathrm{~Hz}\right), 131.5,128.6,128.1\left(\mathrm{~d},{ }^{3} \mathrm{~J}(\mathrm{C}, \mathrm{F})=8 \mathrm{~Hz}\right), 127.6$, $114.6\left(d,{ }^{2} J(C, F)=23 \mathrm{~Hz}\right), 34.76,32.93,21.75,13.76$.

${ }^{19} \mathrm{~F}$ NMR (376 MHz, DMSO-d6, dppm) $\delta:-117.22$ (s, 1F)

MS (ESI $\left.{ }^{+}\right) \mathrm{m} / \mathrm{z}$ : calcd for $\mathrm{C}_{18} \mathrm{H}_{21} \mathrm{FN}_{3} \mathrm{~S}$ : 330.14 , found: 330.15 ; calcd for $\mathrm{C}_{18} \mathrm{H}_{20} \mathrm{FN}_{3} \mathrm{SNa}$ : 352.13, found: 352.14 . 


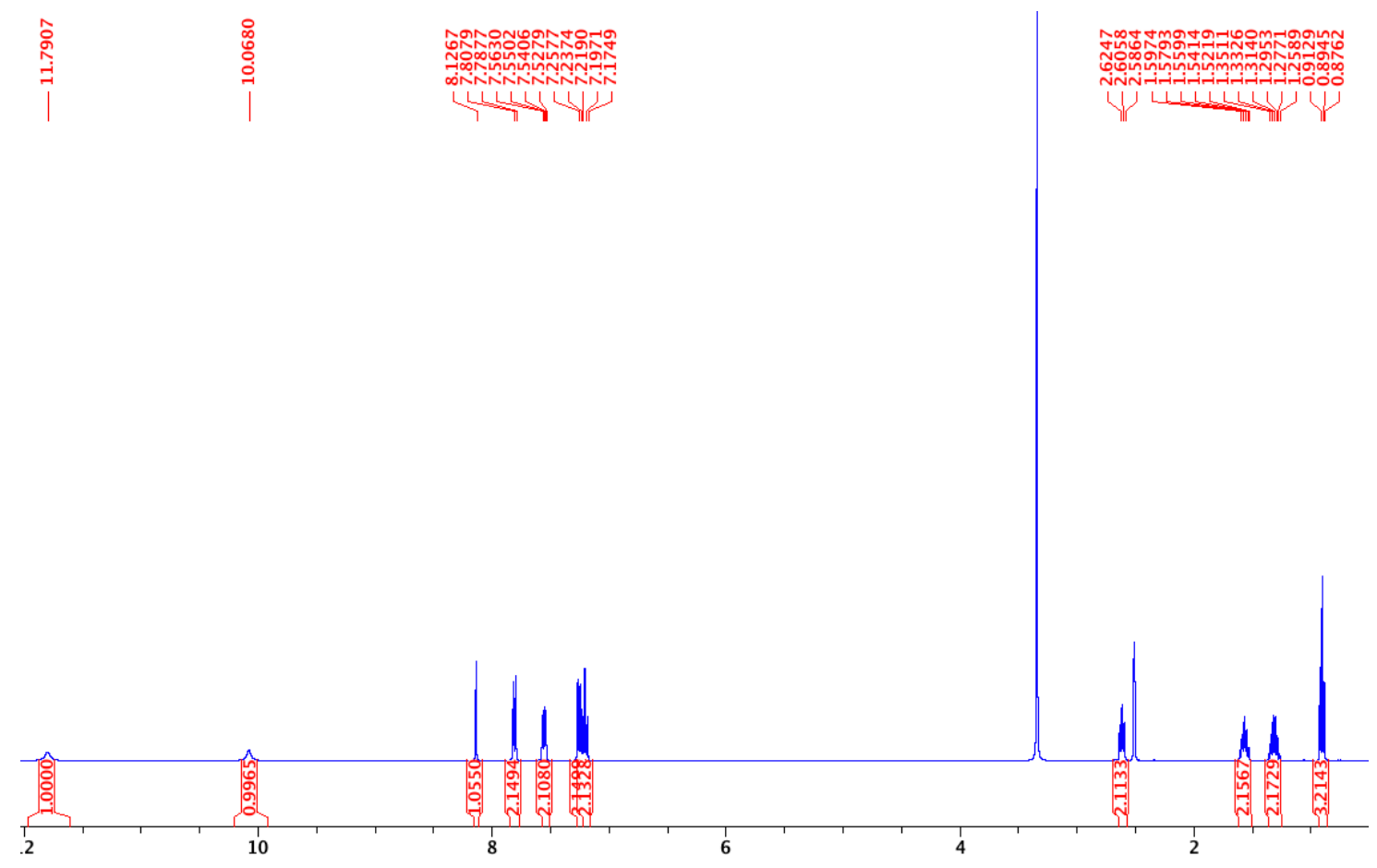

Fig. S13 ${ }^{1} \mathrm{H}$ NMR (400 MHz) spectrum of compound 7 in DMSO-d 6 .

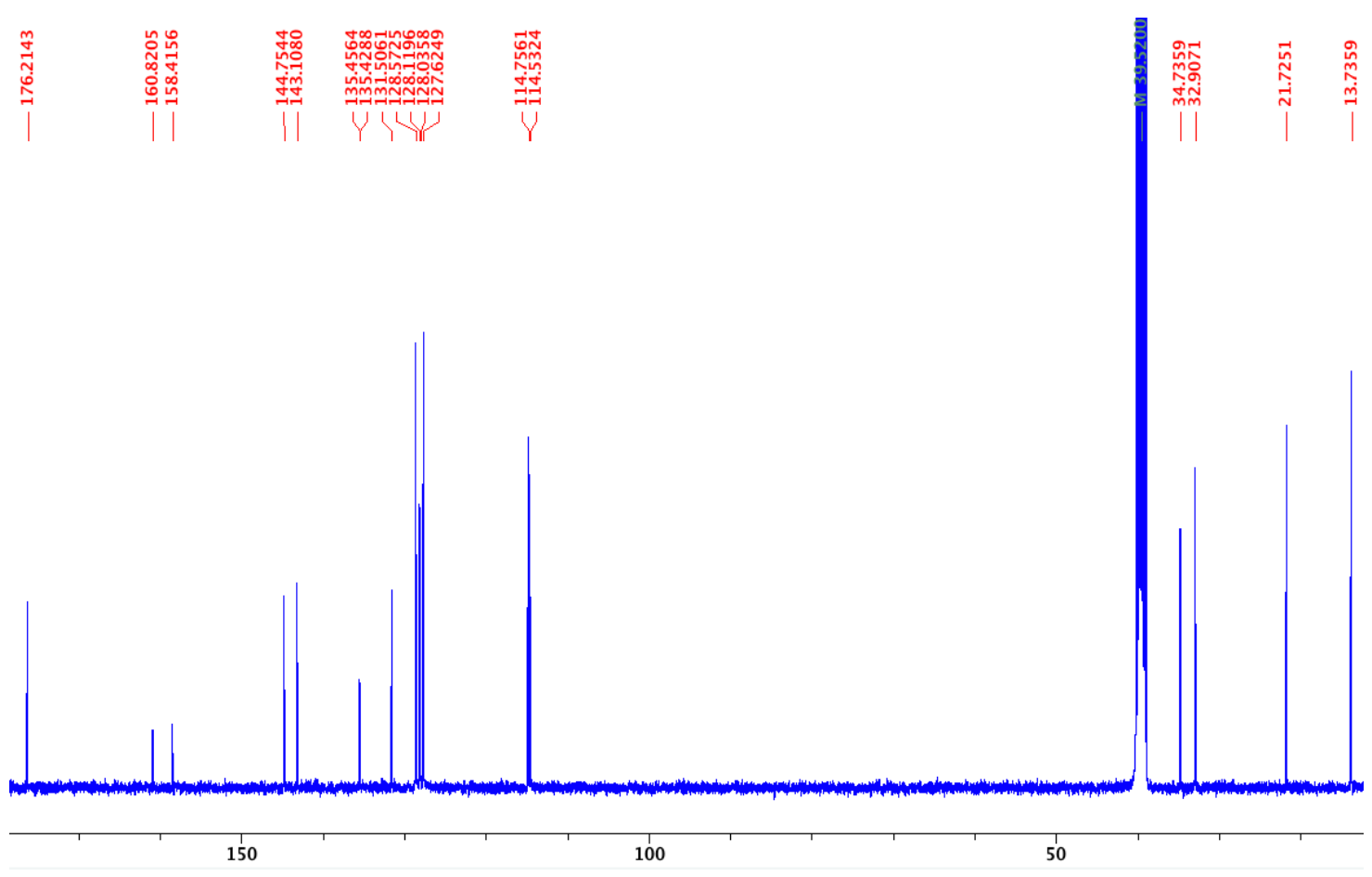

Fig. S14 ${ }^{13} \mathrm{C}$ NMR $(101 \mathrm{MHz})$ spectrum of compound 7 in DMSO-d 6. 


\section{Characterisation of (E)-2-(4-butylbenzylidene)- $\mathrm{N}-(3,4,5-$}

\section{trifluorophenyl)hydrazine-1-carbothioamide 8}

Afforded white crystalline solid (92\% yield), mp $153-154{ }^{\circ} \mathrm{C}$

${ }^{1} \mathrm{H}$ NMR (400 MHz, $\left.\left(\mathrm{CD}_{3}\right)_{2} \mathrm{SO}, 298 \mathrm{~K}, \mathrm{ppm}\right) \delta: 12.02$ (s, $\left.1 \mathrm{H}, \mathrm{N} H^{\beta}\right), 10.16\left(\mathrm{~s}, 1 \mathrm{H}, \mathrm{N} H^{\alpha}\right.$ ), 8.15 (s, 1H, NCH), 7.80 (d, J=8.0 Hz, 2H, ArH × 2), 7.74 (dd, J=10.0, 6.0 Hz, 2H, $\mathrm{ArH} \times 2), 7.27(\mathrm{~d}, J=8.0 \mathrm{~Hz}, 2 \mathrm{H}, \mathrm{ArH} \times 2), 2.61$ (t, $\left.J=7.6 \mathrm{~Hz}, 2 \mathrm{H}, \mathrm{CH}_{2}\right), 1.56$ (quint, $J=7.5 \mathrm{~Hz}, 2 \mathrm{H}, \mathrm{CH}_{2}$ ), 1.31 (sext, $J=7.5 \mathrm{~Hz}, 2 \mathrm{H}, \mathrm{CH}_{2}$ ), 0.90 (t, $J=7.4 \mathrm{~Hz}, 3 \mathrm{H}, \mathrm{CH}_{3}$ ).

${ }^{13} \mathrm{C}$ NMR (101 MHz, $\left.\left(\mathrm{CD}_{3}\right)_{2} \mathrm{SO}, 298 \mathrm{~K}, \mathrm{ppm}\right) \delta: 175.5,149.3\left(\mathrm{dm},{ }^{1} \mathrm{~J}(\mathrm{C}, \mathrm{F})=244 \mathrm{~Hz}\right)$, 145.1, 144.0, $136.0\left(\mathrm{~d},{ }^{1} \mathrm{~J}(\mathrm{C}, \mathrm{F})=247 \mathrm{~Hz}\right), 135.4\left(\mathrm{~d},{ }^{3} \mathrm{~J}(\mathrm{C}, \mathrm{F})=4 \mathrm{~Hz}\right), 131.2,128.6$, 127.8, $109.8\left(d,{ }^{2} J(C, F)=23 \mathrm{~Hz}\right), 34.7,32.9,21.7,13.7$.

${ }^{19} \mathrm{~F}$ NMR (376 MHz, DMSO-d6, dppm) $\delta:-136.18$ (d, $\left.J=23 \mathrm{~Hz}, 2 \mathrm{~F}\right),-165.98$ (t, $J=23$ $\mathrm{Hz}, 1 \mathrm{~F})$

MS $\left(\mathrm{ESI}^{+}\right) \mathrm{m} / \mathrm{z}$ : calcd for $\mathrm{C}_{18} \mathrm{H}_{19} \mathrm{~F}_{3} \mathrm{~N}_{3} \mathrm{~S}$ : 366.12, found: 366.15; calcd for $\mathrm{C}_{18} \mathrm{H}_{18} \mathrm{~F}_{3} \mathrm{~N}_{3} \mathrm{SNa}$ : 388.11, found: 388.10.

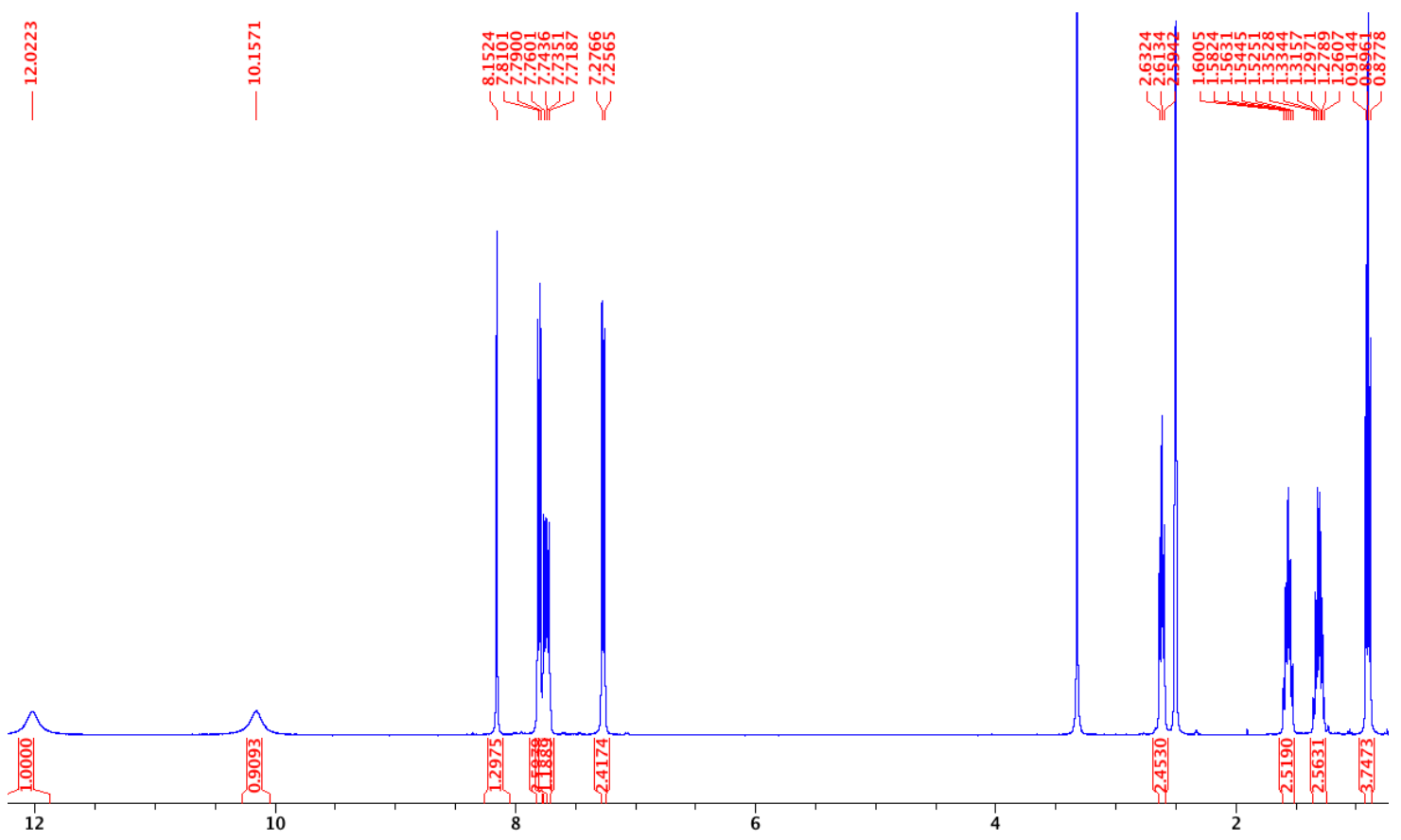

Fig. S15 ${ }^{1} \mathrm{H}$ NMR (400 MHz) spectrum of compound 8 in DMSO-d $d_{6}$. 


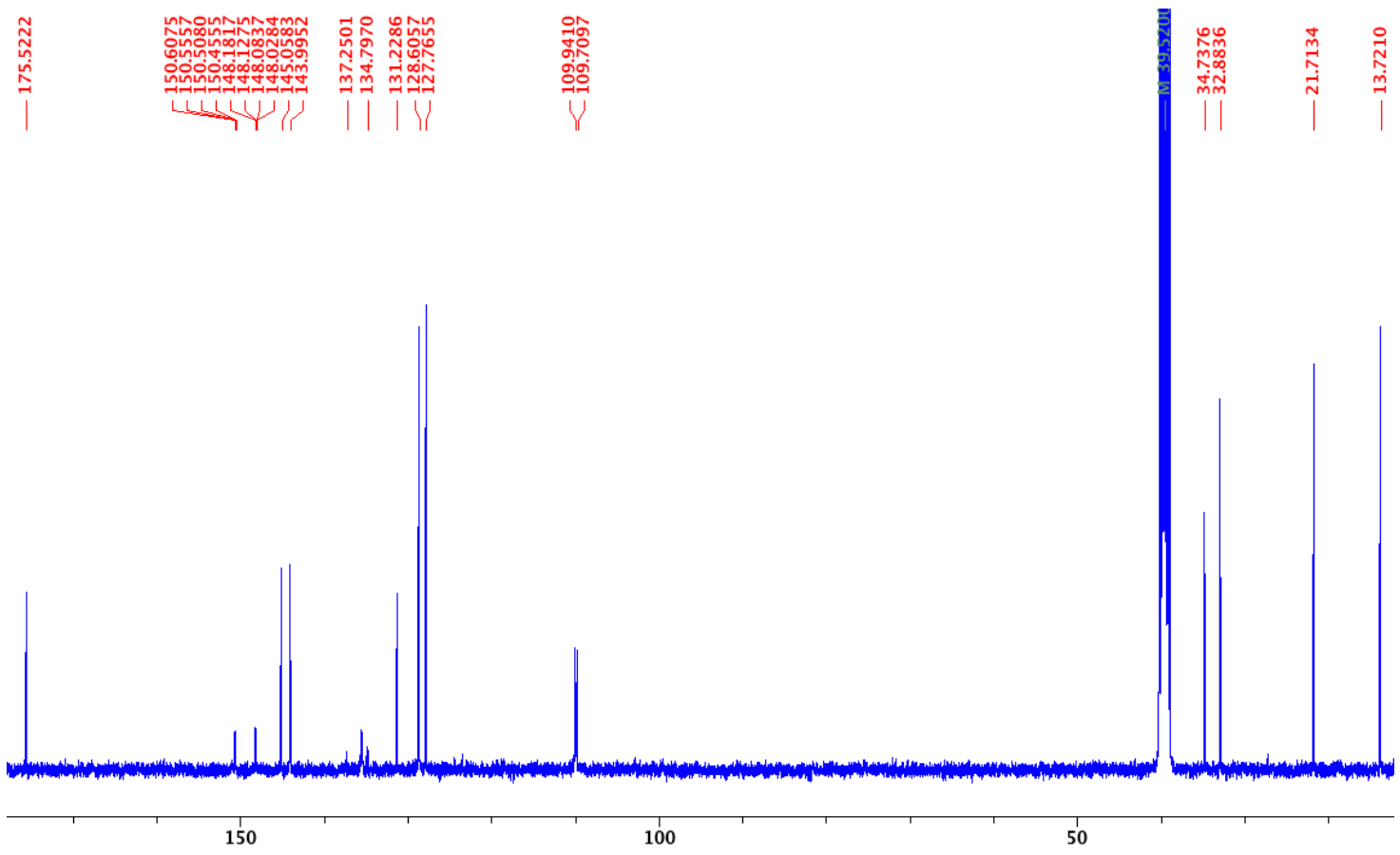

Fig. S16 ${ }^{13} \mathrm{C}$ NMR $(101 \mathrm{MHz})$ spectrum of compound 8 in DMSO-d6.

Characterisation of (E)-2-(4-butylbenzylidene)- $\mathbf{N}$-(perfluorophenyl)hydrazine-1carbothioamide 9

Afforded white solid (85\% yield), mp $187-189{ }^{\circ} \mathrm{C}$

${ }^{1} \mathrm{H}$ NMR (400 MHz, $\left.\left(\mathrm{CD}_{3}\right)_{2} \mathrm{SO}, 298 \mathrm{~K}, \mathrm{ppm}\right) \delta: 12.31$ (s, 1H, $\left.\mathrm{N} H^{\beta}\right), 9.93$ (s, 1H, $\mathrm{NH}^{\alpha}$ ), $8.16(\mathrm{~s}, 1 \mathrm{H}, \mathrm{NCH}), 7.79$ (d, J = 8.2 Hz, 2H, $\mathrm{ArH} \times 2$ ), 7.27 (d, J = 8.2 Hz, 2H, ArH × 2), 2.61 (t, $J=7.6 \mathrm{~Hz}, 2 \mathrm{H}, \mathrm{CH}_{2}$ ), 1.56 (quint, $J=7.6 \mathrm{~Hz}, 2 \mathrm{H}, \mathrm{CH}_{2}$ ), 1.31 (sext, $J=7.4 \mathrm{~Hz}$, $\left.2 \mathrm{H}, \mathrm{CH}_{2}\right), 0.89\left(\mathrm{t}, \mathrm{J}=7.4 \mathrm{~Hz}, 3 \mathrm{H}, \mathrm{CH}_{3}\right)$.

${ }^{13} \mathrm{C}$ NMR (101 MHz, $\left.\left(\mathrm{CD}_{3}\right)_{2} \mathrm{SO}, 298 \mathrm{~K}, \mathrm{ppm}\right) \delta: 177.7,145.2,144.6,144.1$ (d, ${ }^{1} \mathrm{~J}(\mathrm{C}, \mathrm{F})$ $=245 \mathrm{~Hz}), 137.2\left(\mathrm{~d},{ }^{1} \mathrm{~J}(\mathrm{C}, \mathrm{F})=254 \mathrm{~Hz}\right), 131.2,128.7,127.7,115.6\left(\mathrm{~d},{ }^{2} J(\mathrm{C}, \mathrm{F})=15\right.$ $\mathrm{Hz}), 115.5\left(\mathrm{~d},{ }^{2} \mathrm{~J}(\mathrm{C}, \mathrm{F})=16 \mathrm{~Hz}\right), 34.8,32.9,21.7,13.7$.

${ }^{19} \mathrm{~F}$ NMR (376 MHz, DMSO-d6, dppm) $\delta:-144.77$ (d, J = $\left.19 \mathrm{~Hz}, 2 \mathrm{~F}\right),-155.89$ (t, J=22 $\mathrm{Hz}, 1 \mathrm{~F}),-144.77(\mathrm{t}, \mathrm{J}=21 \mathrm{~Hz}, 2 \mathrm{~F})$.

MS $\left(\mathrm{ESI}^{+}\right) \mathrm{m} / \mathrm{z}$ : calcd for $\mathrm{C}_{18} \mathrm{H}_{17} \mathrm{~F}_{5} \mathrm{~N}_{3} \mathrm{~S}$ : 402.11, found: 402.14; calcd for $\mathrm{C}_{18} \mathrm{H}_{16} \mathrm{~F}_{5} \mathrm{~N}_{3} \mathrm{SNa}: 424.09$, found: 424.10. 


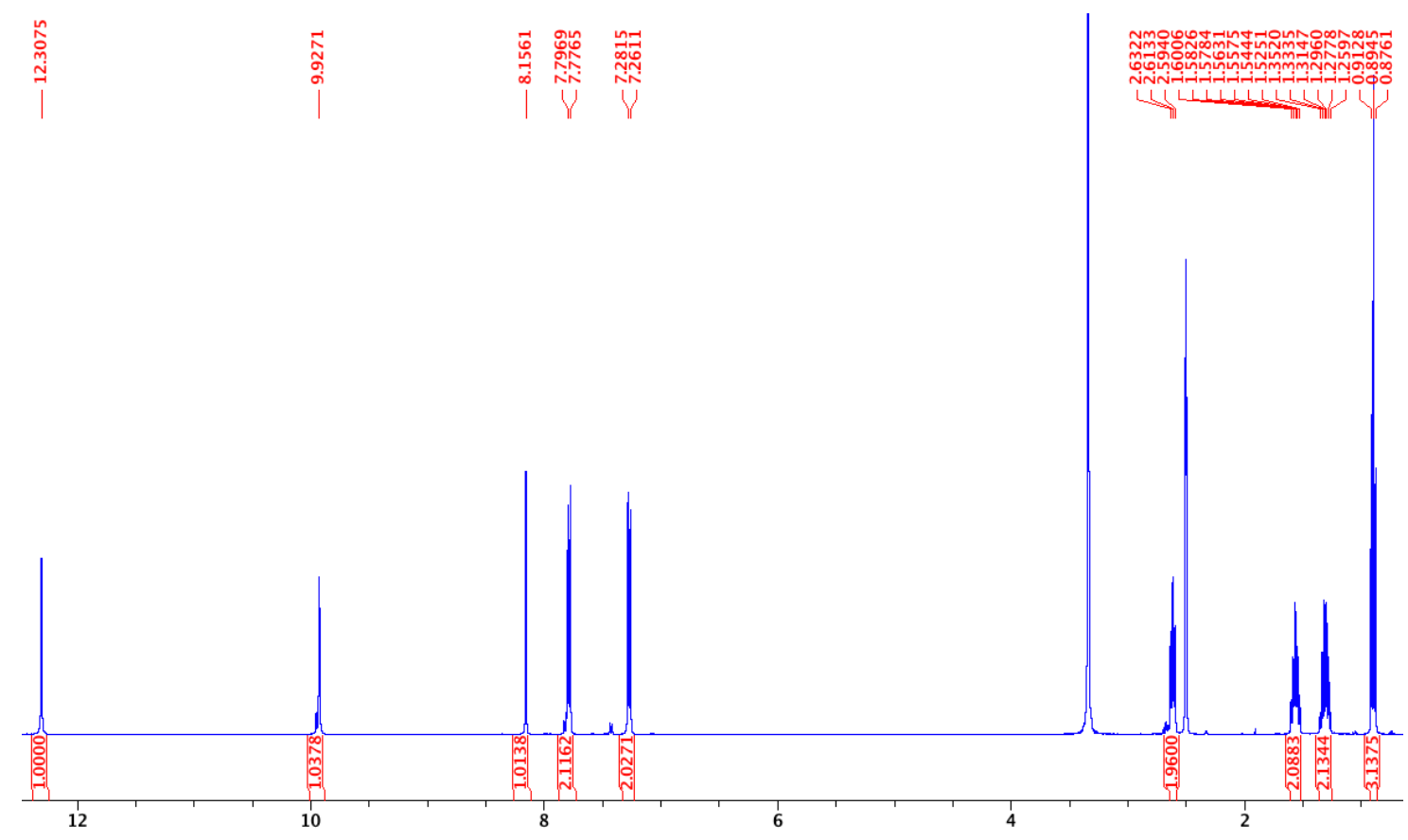

Fig. $\mathbf{S 1 7}{ }^{1} \mathrm{H}$ NMR (400 MHz) spectrum of compound 9 in DMSO-d6.
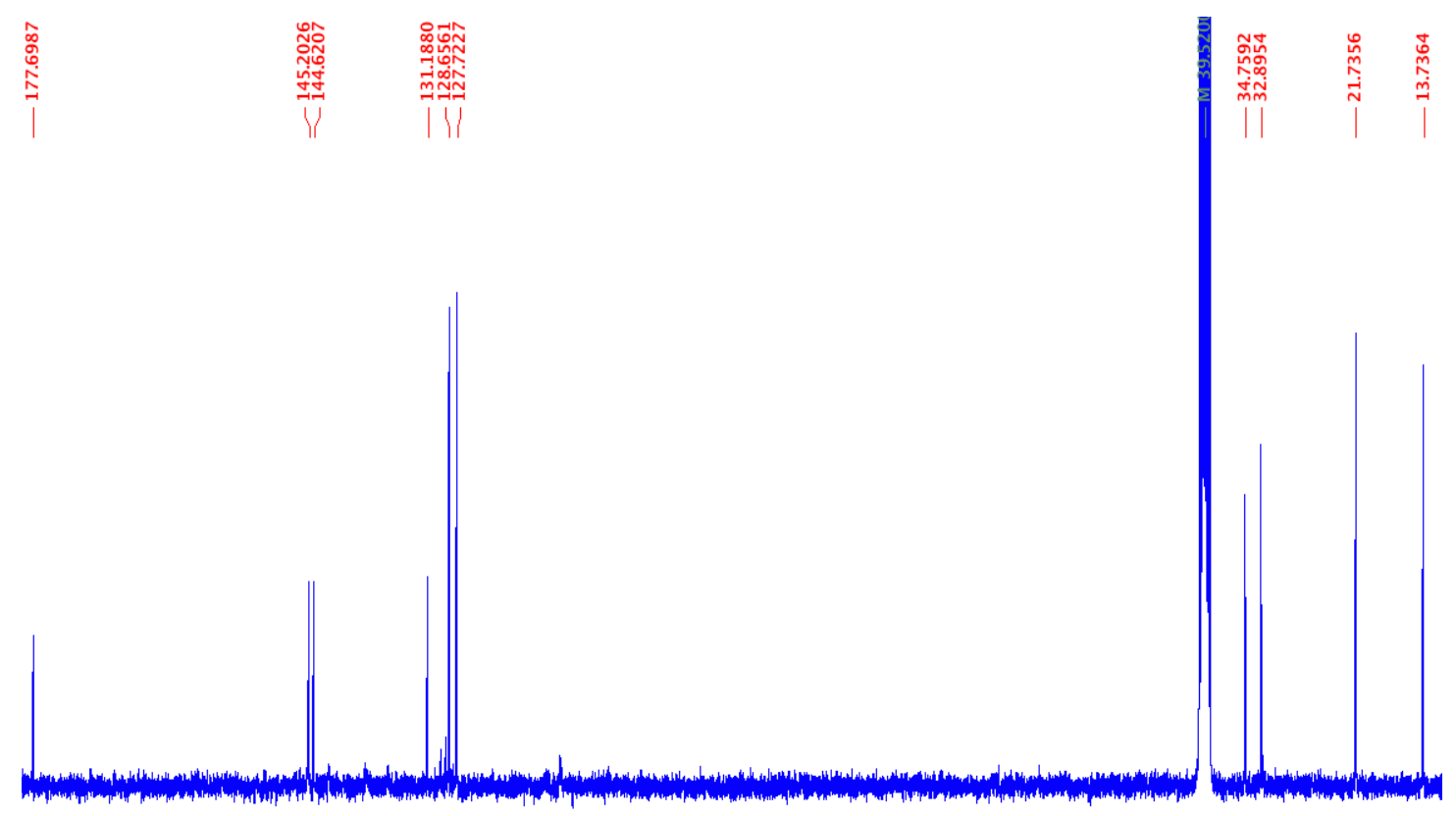

150 100 50

Fig. S18 ${ }^{13} \mathrm{C}$ NMR $(101 \mathrm{MHz})$ spectrum of compound 9 in DMSO- $d_{6}$. 


\section{S2 ISE assay}

\section{S2.1 General Procedure for $\mathrm{Cl}-/ \mathrm{NO}_{3}-$ Exchange}

External chloride concentrations during transport experiments were determined using a chloride-selective electrode. The electrode was calibrated against sodium chloride solutions of known concentrations prior to each experiment and the calibration was fitted against a logarithmic function: $y=A \cdot \log (x)+B$, where $y$ is the electrode read-out in $\mathrm{mV}$ and $\mathrm{x}$ is the chloride concentration in $\mathrm{M}$.

A lipid film of POPC was formed from a chloroform solution under reduced pressure and dried under vacuum for at least 8 hours. The lipid film was hydrated by vortexing with a metal chloride $(\mathrm{MCl})$ buffered solution (intravesicular/internal solution). The lipid suspension was then subjected to 9 freeze-thaw cycles, where the suspension was alternatingly allowed to freeze in a liquid nitrogen bath, followed by thawing in a water bath. The lipid suspension was allowed to age for 30 minutes at room temperature and was extruded 25 times through a $200 \mathrm{~nm}$ polycarbonate membrane using a extruder set. The unilamellar vesicles (LUVs) were dialyzed against the extravesicular/external buffered solution for a minimum of 2 hours to remove unencapsulated $\mathrm{MCl}$ salts. The lipid solution obtained after dialysis was diluted to a standard volume of $10 \mathrm{~mL}$ with the external buffered solution to obtain the lipid stock solution with a known lipid concentration.

The internal and external solutions vary from experiment to experiment. The buffers for various pHs were prepared with a constant buffer concentration $(5.0 \mathrm{mM}$, citrate buffer for $\mathrm{pH} 4.5$ and phosphate buffer for $\mathrm{pH} 7.2$ ) and total ionic strength (500 mM) for both intra- and extravesicular solutions. Typically, for each measurement, the lipid stock solution was diluted with the external buffered solution to a standard volume (5.0 $\mathrm{mL}$ ) with a lipid concentration of $1.0 \mathrm{mM}$. A DMSO solution $(10 \mu \mathrm{L})$ of the test compound (carrier) was added to the liposome solution to start the experiment and the chloride efflux was monitored using a chloride-selective electrode. At 5 minutes, the detergent solution $(50 \mu \mathrm{L})$ was added to lyse the vesicles, and the total chloride reading was taken at $7 \mathrm{~min}$. The initial value was set as $0 \%$ chloride efflux and the final chloride reading (at 7 minutes) was set as $100 \%$ chloride efflux, to normalize the collected data from each measurement. 


\section{S2.2 General Procedure for cationophore-coupled assay}

Chloride concentrations during transport experiments were monitored using a chloride-selective electrode. POPC LUVs (mean diameter $200 \mathrm{~nm}$ ) with internal $\mathrm{KCl}$ and external $\mathrm{K}_{2} \mathrm{SO}_{4}$ were prepared as follows. A lipid film of POPC was formed from a chloroform solution under reduced pressure and dried under vacuum for at least 8 hours. The lipid film was hydrated by vortexing with the intravesicular $\mathrm{KCl}(300 \mathrm{mM})$ solution. The lipid suspension was then subjected to 9 freezethaw cycles, where the suspension was alternatingly allowed to freeze in a liquid nitrogen bath, followed by thawing in a water bath. The lipid suspension was allowed to age for 30 minutes at room temperature and was extruded 25 times through a $200 \mathrm{~nm}$ polycarbonate membrane using an extruder set. The resulting large unilamellar vesicles (LUVs) with a mean diameter of $200 \mathrm{~nm}$ were dialyzed against the extravesicular $\mathrm{K}_{2} \mathrm{SO}_{4}(100 \mathrm{mM})$ for a minimum of 2 hours to remove unencapsulated $\mathrm{KCl}$ salts. The lipid solution obtained after dialysis was diluted to a standard volume $(10 \mathrm{~mL})$ with the extravesicular buffered solution to obtain the lipid stock solution with a known lipid concentration.

A DMSO solution $(10 \mu \mathrm{L})$ of the anionophore was added to the liposome solution to start the experiment and the chloride efflux was monitored using a chloride-sensitive electrode. When a cationophore (valinomycin or monensin) was used, a DMSO solution of the cationophore $(0.5 \mathrm{mM}, 10 \mu \mathrm{L})$ was added to the liposome solution prior to the addition of the test anionophore. At $5 \mathrm{~min}$, the detergent solution $(50 \mu \mathrm{L})$ was added to lyse the vesicles, and the total chloride reading was taken at $7 \mathrm{~min}$. The initial value was set at $0 \%$ chloride efflux and the final chloride reading (at 7 minutes) was set as $100 \%$ chloride efflux, to normalise the collected data from each measurement. The $\mathrm{KCl}$ assay involves two complementary cationophores, monensin and valinomycin, which can determine whether the transport process is electrogenic chloride transport or electroneutral $\mathrm{H}^{+} / \mathrm{Cl}^{-}$cotransport. An electrogenic processes result in a net alteration of charge across the membrane due to ion transport, whereas electroneutral process has a charge balance that can be achieved with transport of a species with the same charge or cotransport of a species with opposite charge. Monensin functions as a $\mathrm{M}^{+} / \mathrm{H}^{+}$antiporter in the lipid bilayer as the deprotonated monensin is unable to diffuse through the membrane unless it is binding a cation, thus it can facilitate electroneutral transport. Valinomycin can only facilitate electrogenic transport, the anionphore transports $\mathrm{Cl}^{-}$coupled with $\mathrm{K}^{+}$transport mediated by 
valinomycin. Chloride efflux is measured by ISE from POPC LUVs loaded with $\mathrm{KCl}$ (300 mM) and suspended in $\mathrm{K}_{2} \mathrm{SO}_{4}(100 \mathrm{mM})$, adjusted to $\mathrm{pH} 4.5$ with $\mathrm{KOH}$ in citrate $(5.0 \mathrm{mM})$ or $\mathrm{pH} 7.2$ in phosphate $(5.0 \mathrm{mM})$. Either monensin $(0.1 \mathrm{~mol} \%)$ or valinomycin $(0.1 \mathrm{~mol} \%)$ are added in combination with an anionophore and chloride efflux is driven by the large chloride concentration gradient.

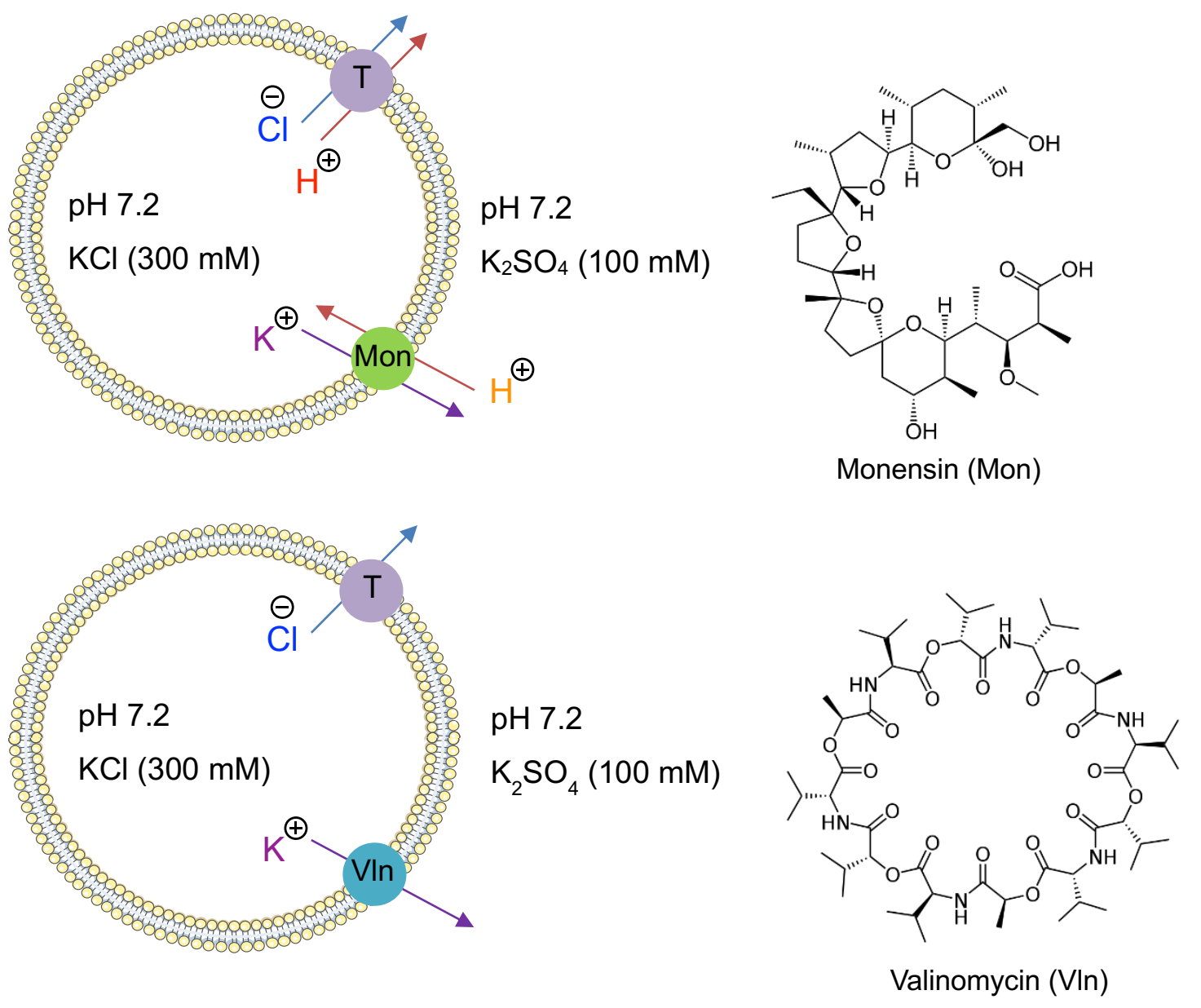

Fig. S19 Illustration of Cationophore coupled assay with monensin and valinomycin. 


\section{S2.4 $\mathrm{Cl}^{-} / \mathrm{NO}_{3}{ }^{-}$exchange assay data and Hill analysis}
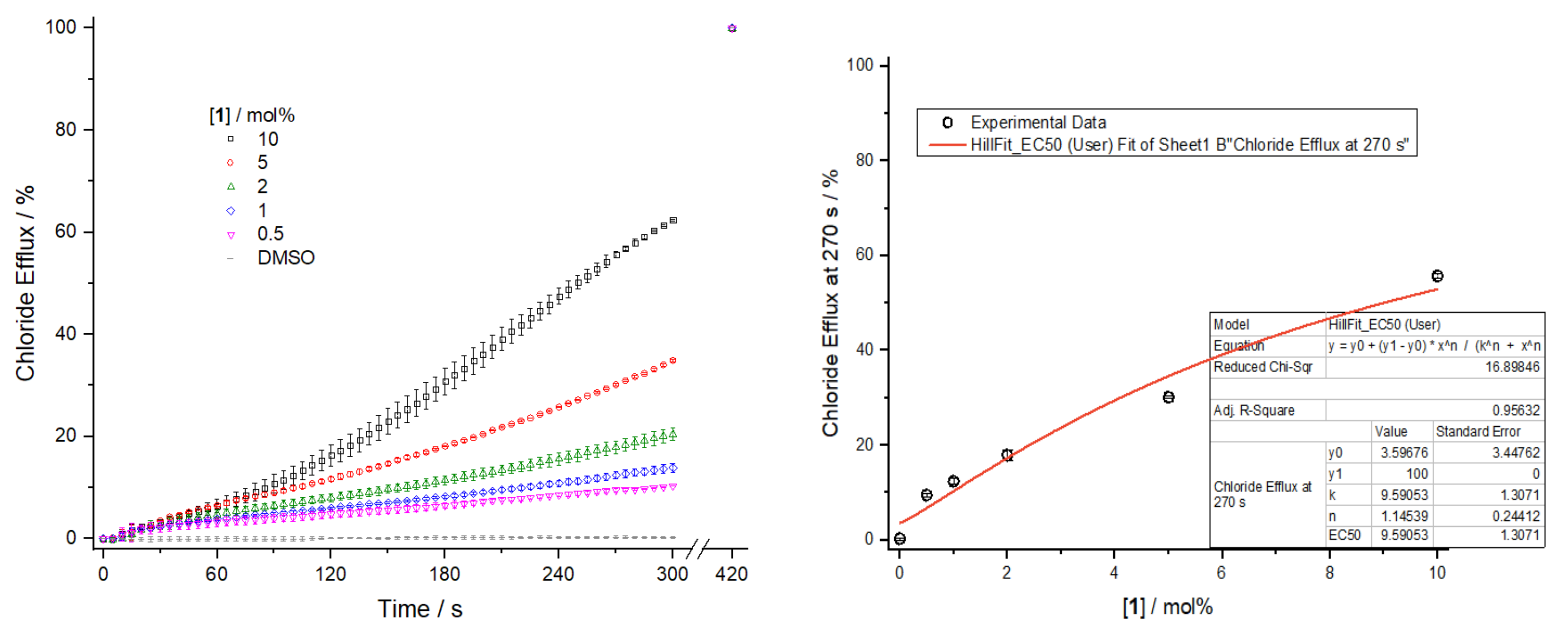

Fig. S20 Plots for Hill analysis of chloride efflux $\left(\mathrm{Cl}^{-} / \mathrm{NO}_{3}{ }^{-}\right.$exchange $)$at $270 \mathrm{~s}$, mediated by compound 1 at $\mathrm{pH}$ 7.2. Each data point represents the average of two or three repeat measurements with error bars indicating the standard deviation.
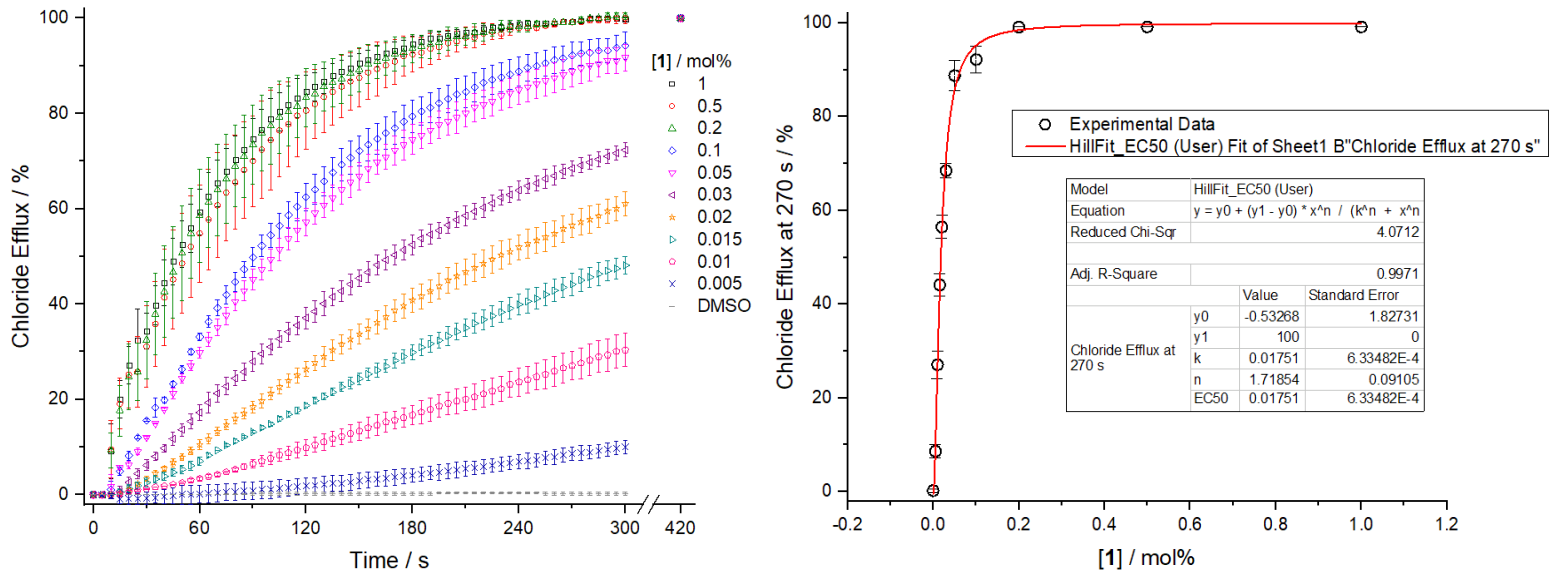

Fig. S21 Plots for Hill analysis of chloride efflux $\left(\mathrm{Cl}^{-} / \mathrm{NO}_{3}{ }^{-}\right.$exchange $)$at $270 \mathrm{~s}$, mediated by compound 1 at $\mathrm{pH}$ 4.5. Each data point represents the average of two or three repeat measurements with error bars indicating the standard deviation. 

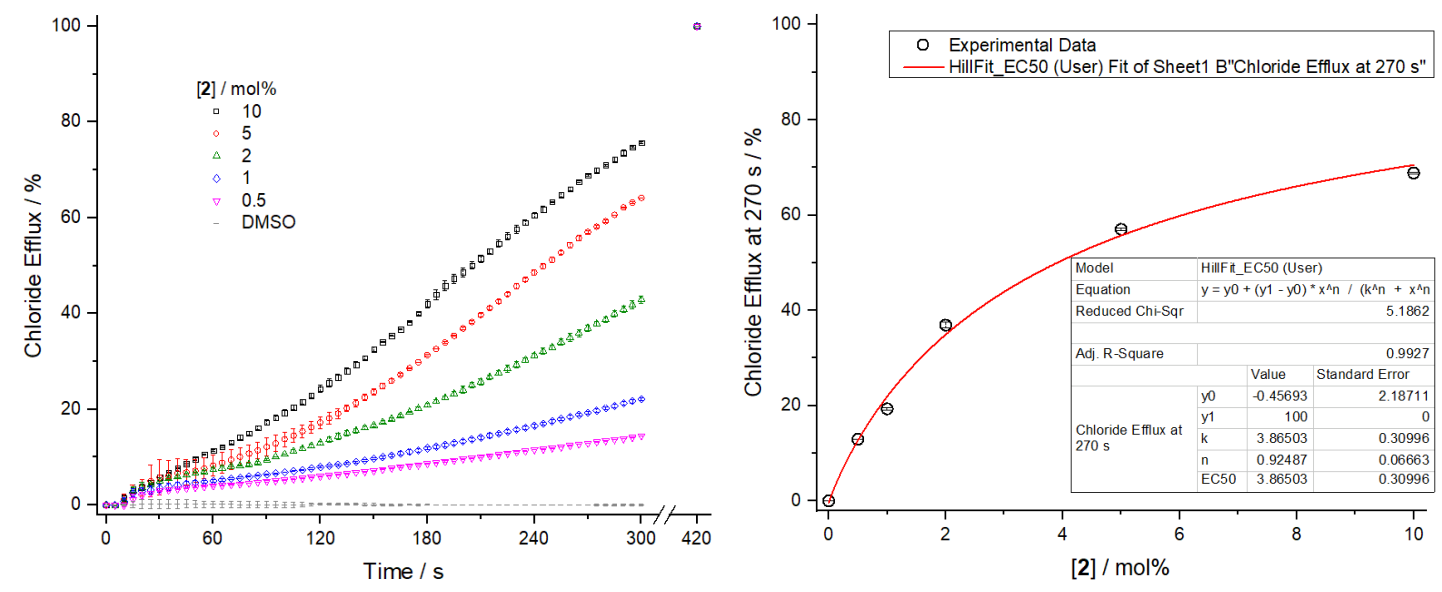

Fig. S22 Plots for Hill analysis of chloride efflux $\left(\mathrm{Cl}^{-} / \mathrm{NO}_{3}{ }^{-}\right.$exchange $)$at $270 \mathrm{~s}$, mediated by compound 2 at $\mathrm{pH}$ 7.2. Each data point represents the average of two or three repeat measurements with error bars indicating the standard deviation.
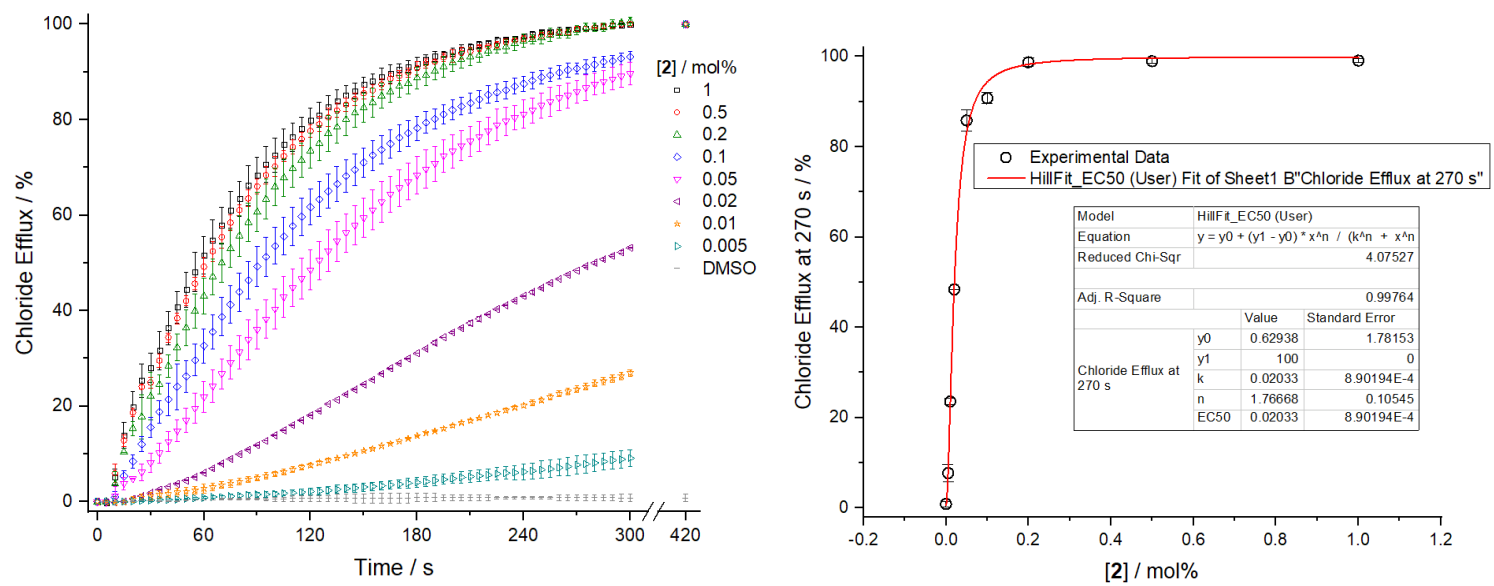

Fig. S23 Plots for Hill analysis of chloride efflux $\left(\mathrm{Cl}^{-} / \mathrm{NO}_{3}{ }^{-}\right.$exchange) at $270 \mathrm{~s}$, mediated by compound 2 at $\mathrm{pH}$ 4.5. Each data point represents the average of two or three repeat measurements with error bars indicating the standard deviation. 

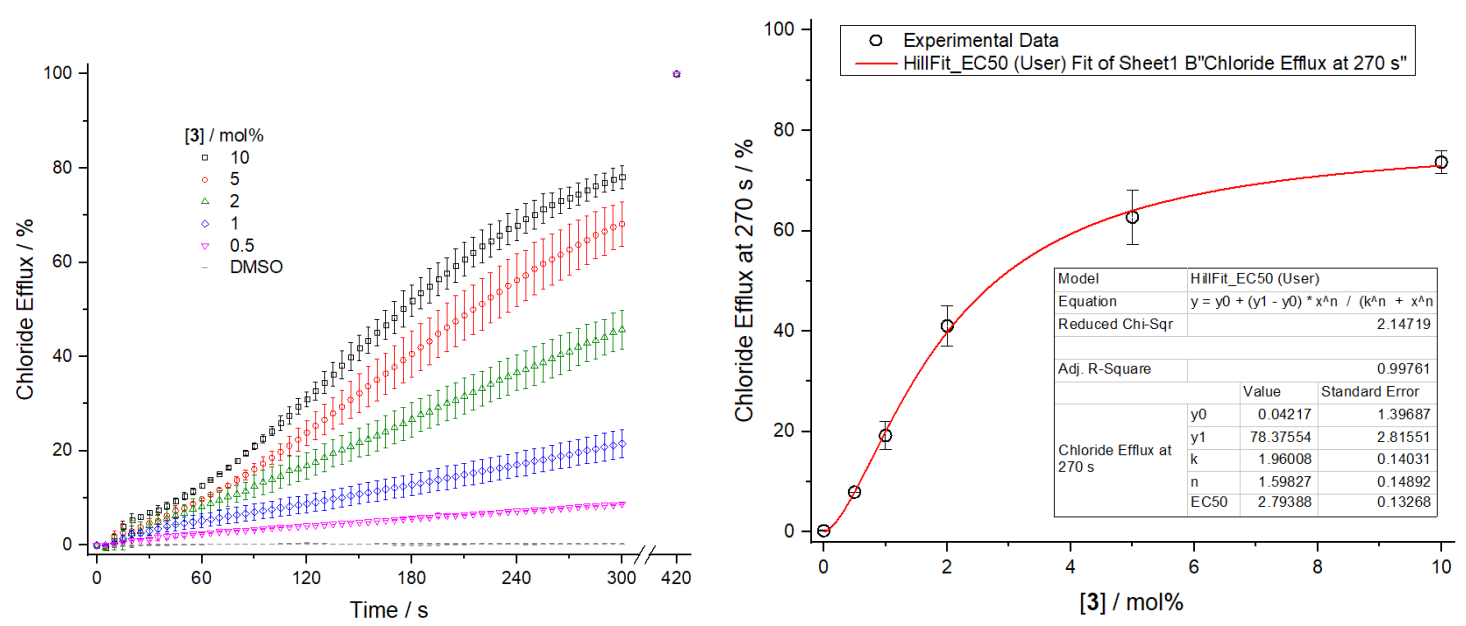

Fig. S24 Plots for Hill analysis of chloride efflux $\left(\mathrm{Cl}^{-} / \mathrm{NO}_{3}{ }^{-}\right.$exchange $)$at $270 \mathrm{~s}$, mediated by compound 3 at $\mathrm{pH}$ 7.2. Each data point represents the average of two or three repeat measurements with error bars indicating the standard deviation.
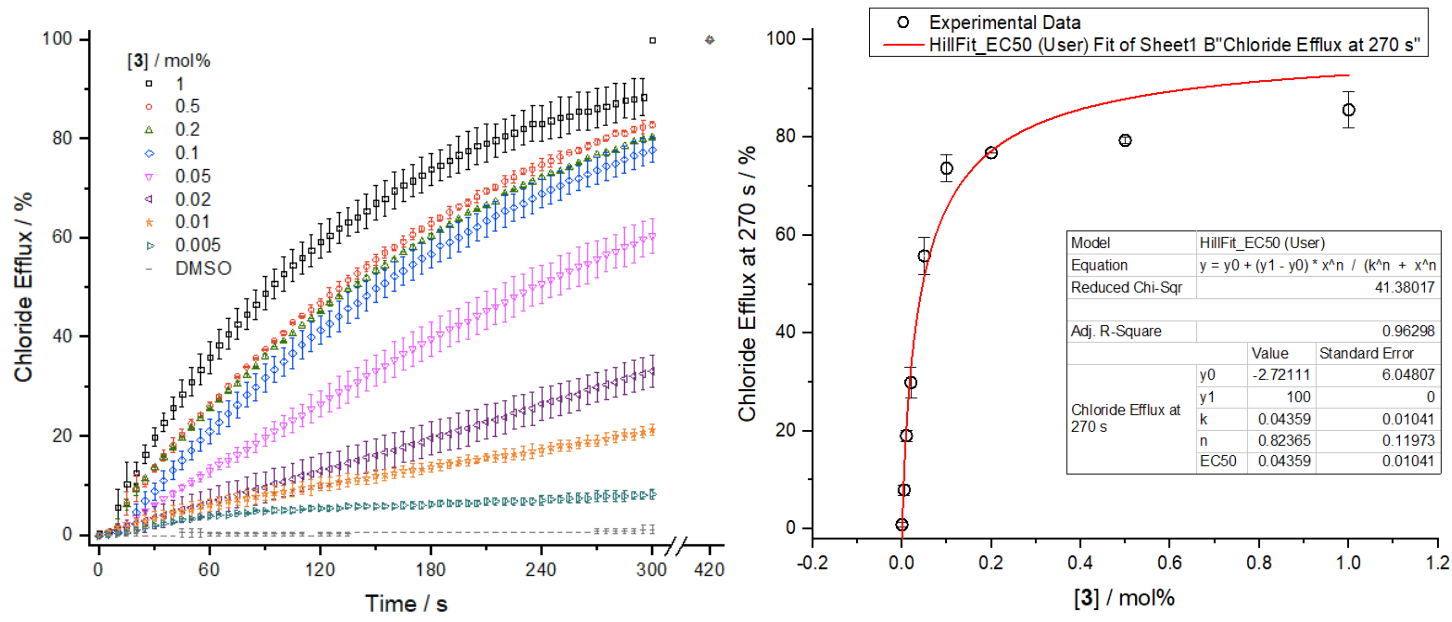

Fig. S25 Plots for Hill analysis of chloride efflux ( $\left(\mathrm{Cl}^{-} / \mathrm{NO}_{3}{ }^{-}\right.$exchange) at $270 \mathrm{~s}$, mediated by compound 3 at $\mathrm{pH}$ 4.5. Each data point represents the average of two or three repeat measurements with error bars indicating the standard deviation. 


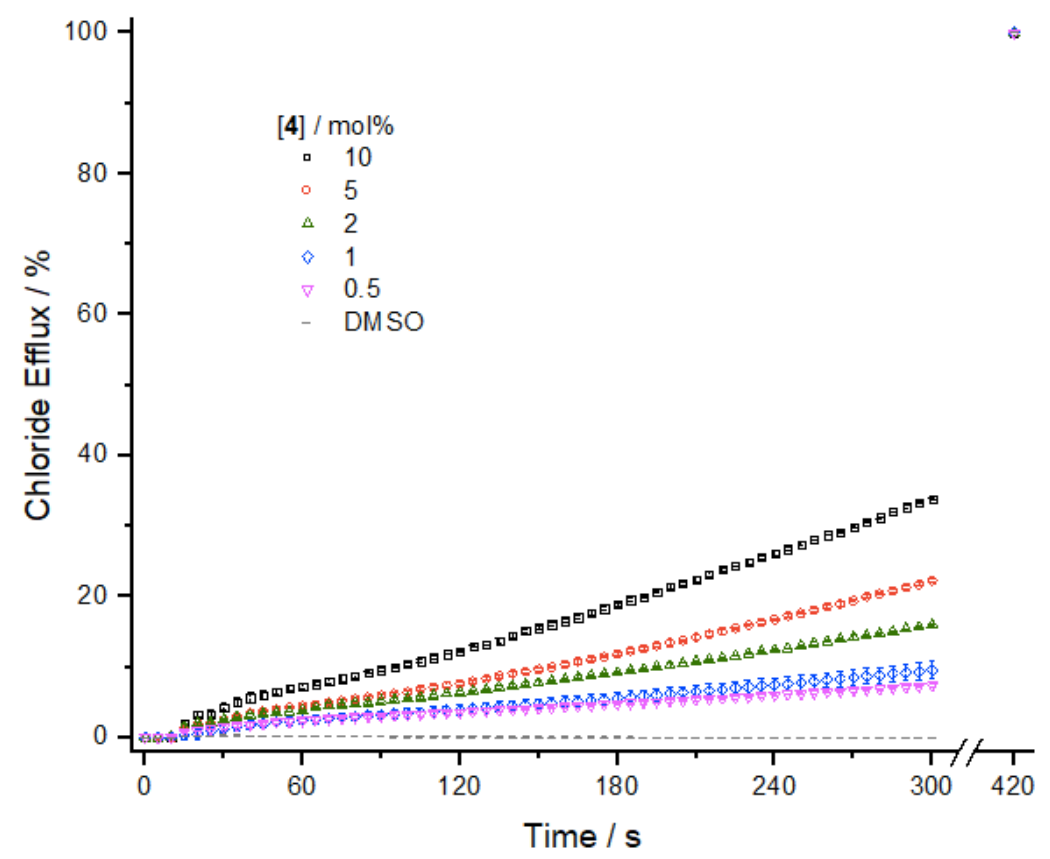

Fig. S26 Plots for Hill analysis of chloride efflux $\left(\mathrm{Cl}^{-} / \mathrm{NO}_{3}{ }^{-}\right.$exchange $)$at $270 \mathrm{~s}$, mediated by compound 4 at $\mathrm{pH}$ 4.5. Each data point represents the average of two or three repeat measurements with error bars indicating the standard deviation.
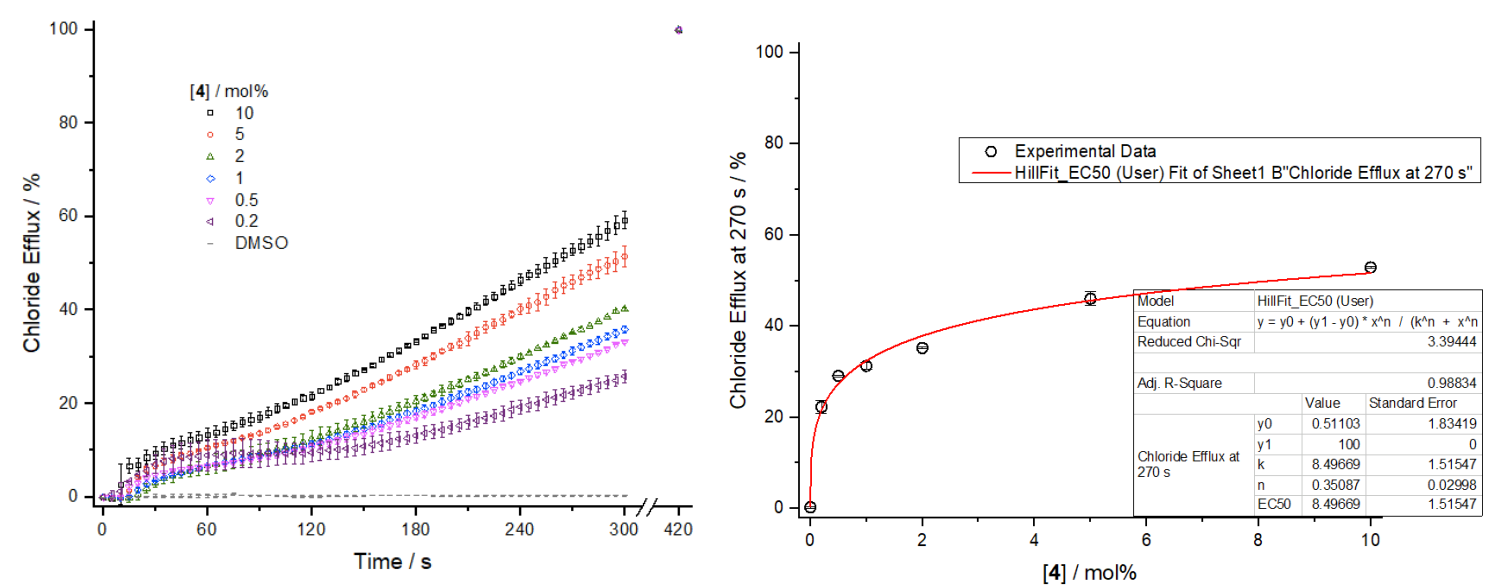

Fig. S27 Plots for attempted Hill analysis of chloride efflux $\left(\mathrm{Cl}^{-} / \mathrm{NO}_{3}{ }^{-}\right.$exchange $)$at $270 \mathrm{~s}$, mediated by compound 4 at pH 7.2. Each data point represents the average of two or three repeat measurements with error bars indicating the standard deviation. 


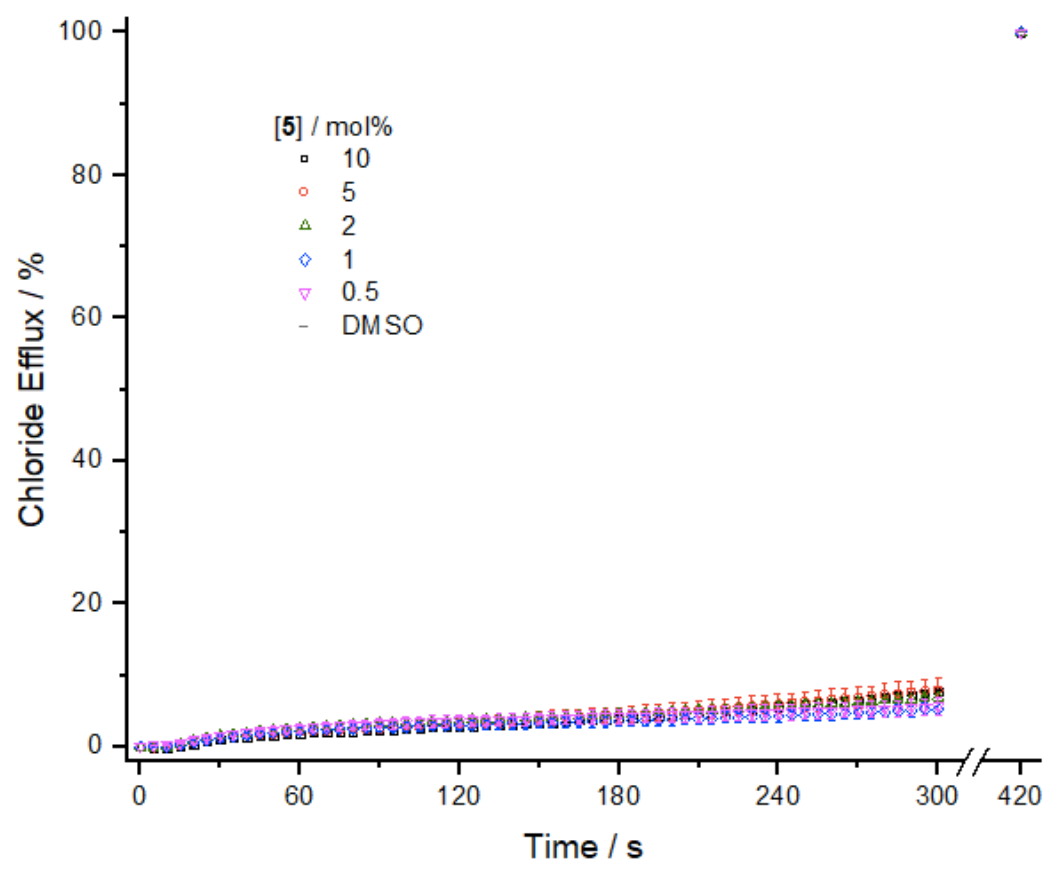

Fig. S28 Plots for attempted Hill analysis of chloride efflux $\left(\mathrm{Cl}^{-} / \mathrm{NO}_{3}{ }^{-}\right.$exchange $)$at $270 \mathrm{~s}$, mediated by compound 5 at $\mathrm{pH}$ 7.2. Each data point represents the average of two or three repeat measurements with error bars indicating the standard deviation.
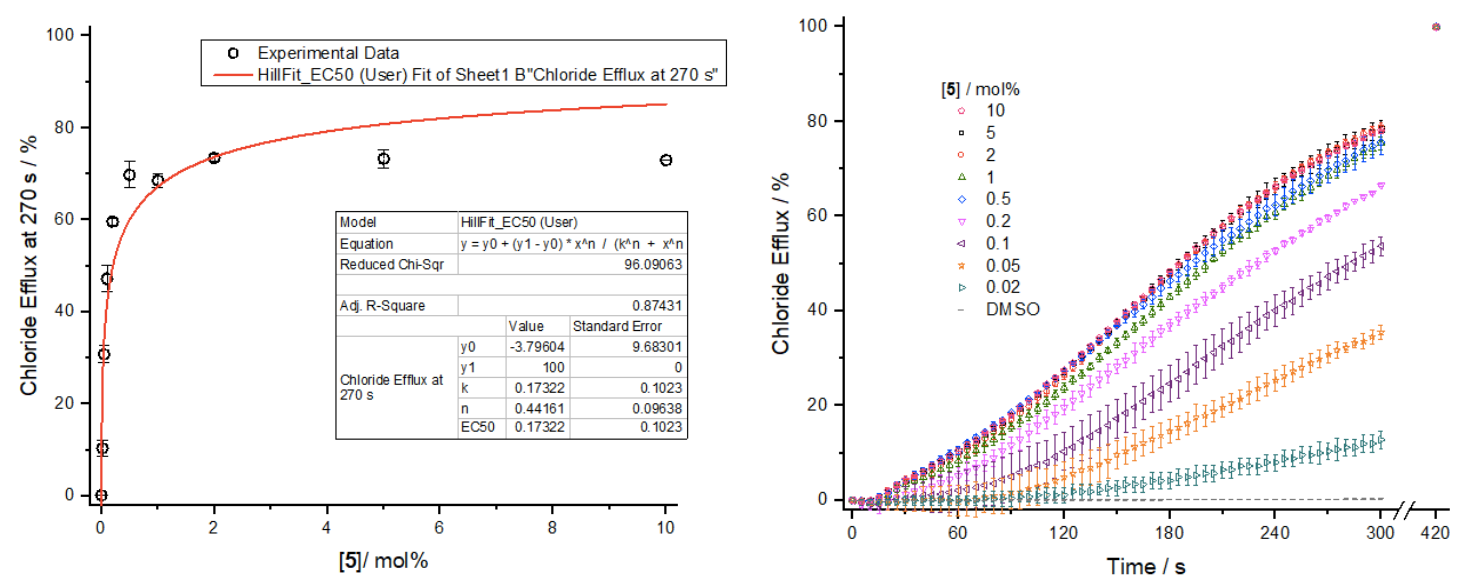

Fig. S29 Plots for Hill analysis of chloride efflux $\left(\mathrm{Cl}^{-} / \mathrm{NO}_{3}{ }^{-}\right.$exchange $)$at $270 \mathrm{~s}$, mediated by compound 5 at $\mathrm{pH}$ 4.5. Each data point represents the average of two or three repeat measurements with error bars indicating the standard deviation. 


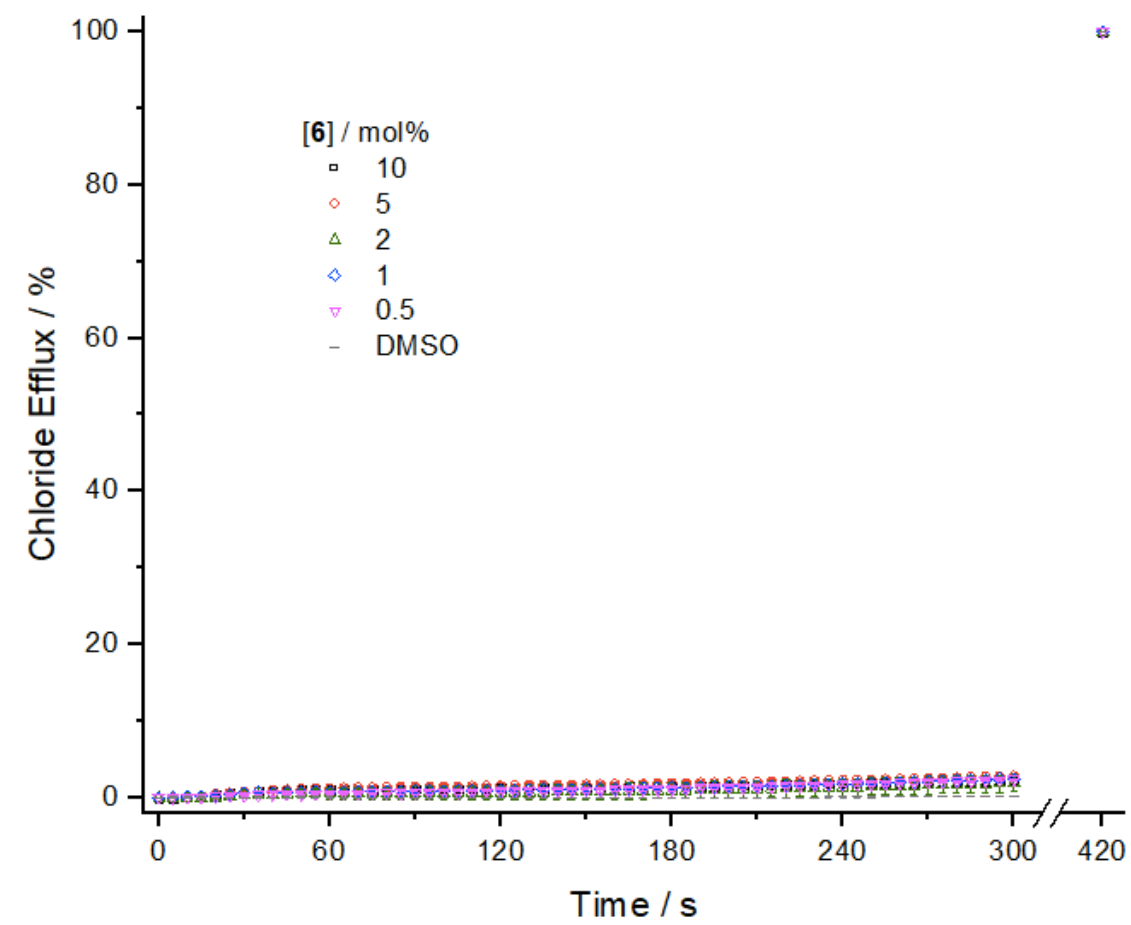

Fig. S30 Plots for attempted Hill analysis of chloride efflux $\left(\mathrm{Cl}^{-} / \mathrm{NO}_{3}{ }^{-}\right.$exchange $)$at $270 \mathrm{~s}$, mediated by compound 6 at pH 7.2. Each data point represents the average of two or three repeat measurements with error bars indicating the standard deviation.

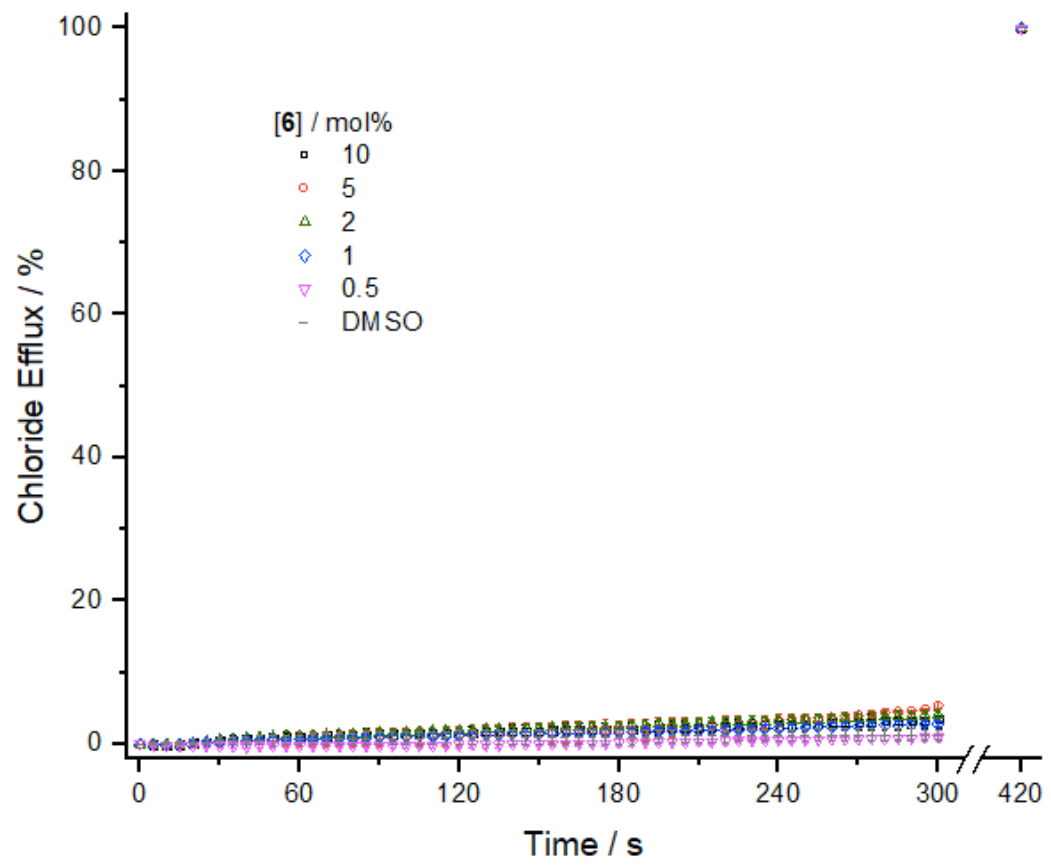

Fig. S31 Plots for attempted Hill analysis of chloride efflux $\left(\mathrm{Cl}^{-} / \mathrm{NO}_{3}{ }^{-}\right.$exchange $)$at $270 \mathrm{~s}$, mediated by compound 6 at $\mathrm{pH}$ 4.5. Each data point represents the average of two or three repeat measurements with error bars indicating the standard deviation. 


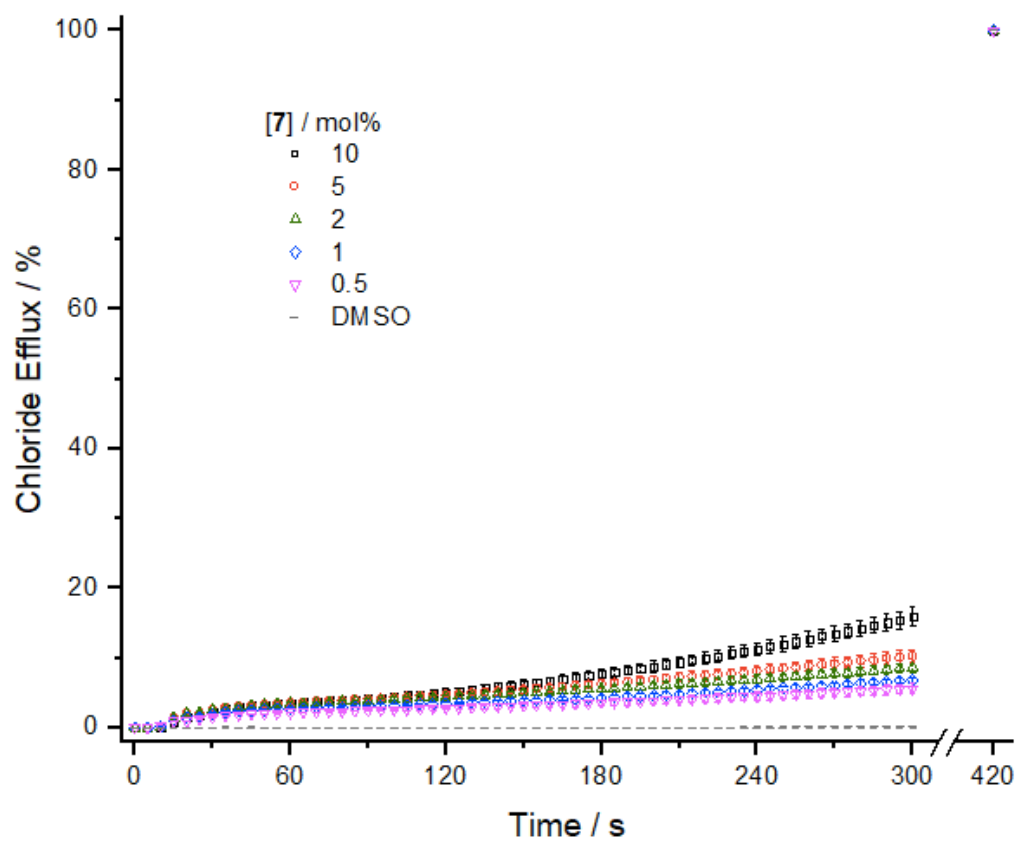

Fig. S32 Plots for attempted Hill analysis of chloride efflux $\left(\mathrm{Cl}^{-} / \mathrm{NO}_{3}{ }^{-}\right.$exchange $)$at $270 \mathrm{~s}$, mediated by compound 7 at pH 7.2. Each data point represents the average of two or three repeat measurements with error bars indicating the standard deviation.
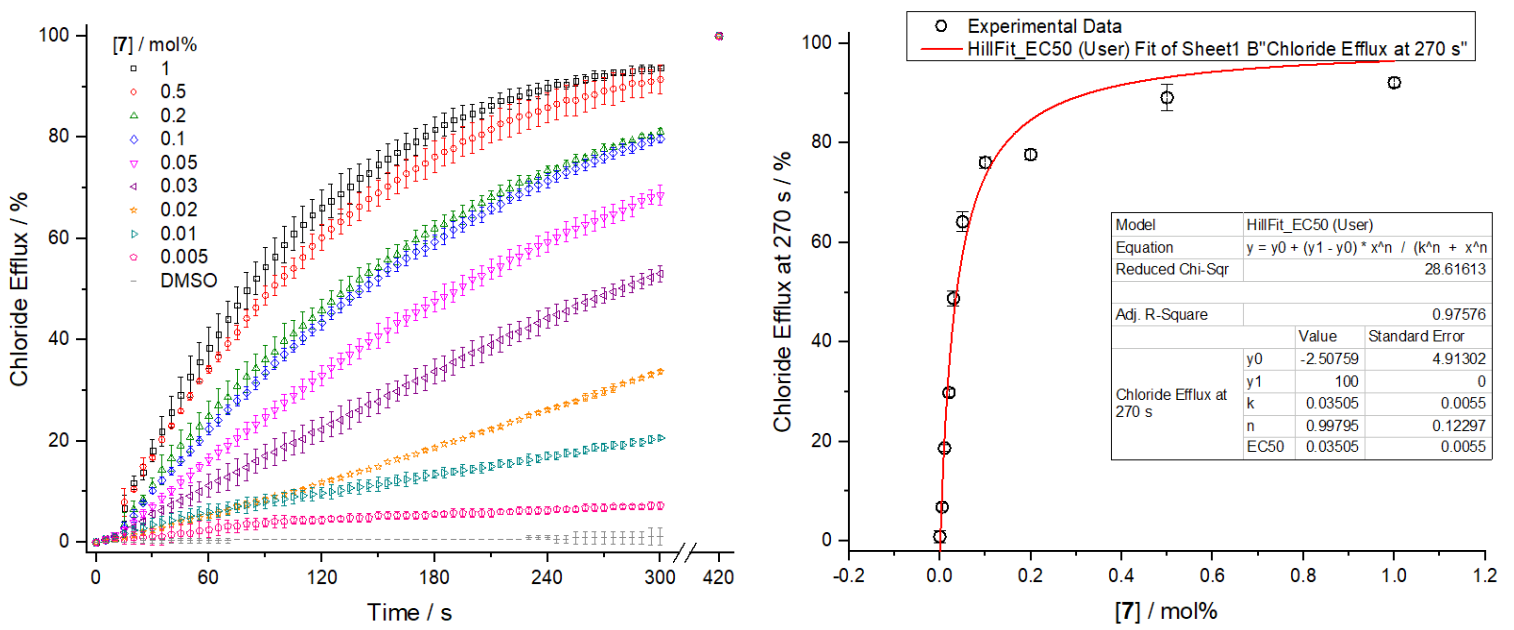

Fig. S33 Plots for Hill analysis of chloride efflux $\left(\mathrm{Cl}^{-} / \mathrm{NO}_{3}{ }^{-}\right.$exchange) at $270 \mathrm{~s}$, mediated by compound 7 at $\mathrm{pH}$ 4.5. Each data point represents the average of two or three repeat measurements with error bars indicating the standard deviation. 


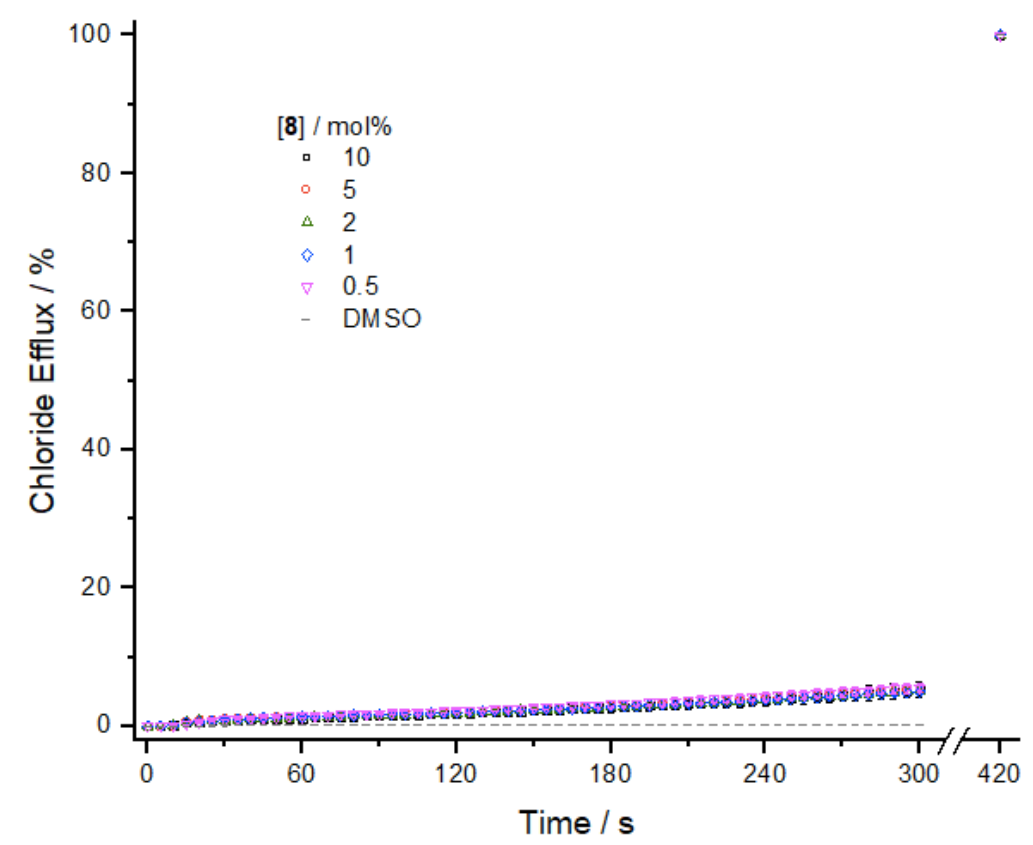

Fig. S34 Plots for attempted Hill analysis of chloride efflux $\left(\mathrm{Cl}^{-} / \mathrm{NO}_{3}{ }^{-}\right.$exchange $)$at $270 \mathrm{~s}$, mediated by compound 8 at pH 7.2. Each data point represents the average of two or three repeat measurements with error bars indicating the standard deviation.
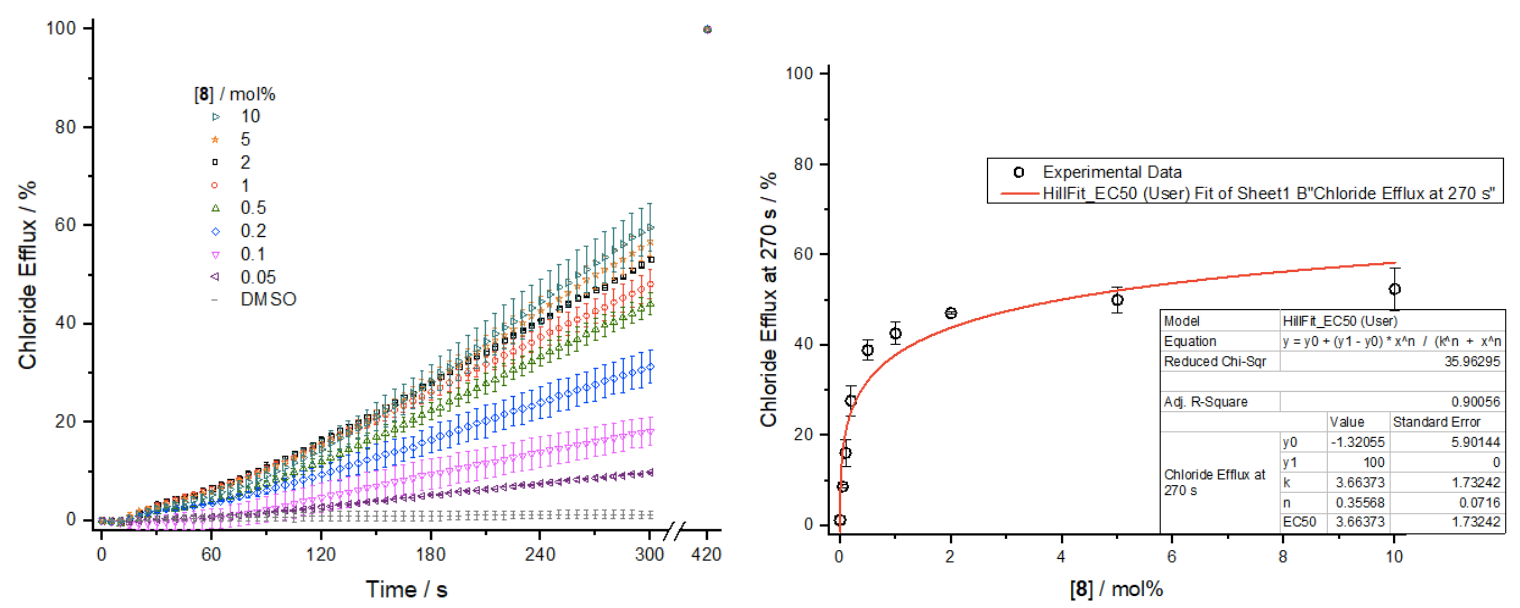

Fig. S35 Plots for Hill analysis of chloride efflux $\left(\mathrm{Cl}^{-} / \mathrm{NO}_{3}{ }^{-}\right.$exchange $)$at $270 \mathrm{~s}$, mediated by compound 8 at $\mathrm{pH}$ 4.5. Each data point represents the average of two or three repeat measurements with error bars indicating the standard deviation. 


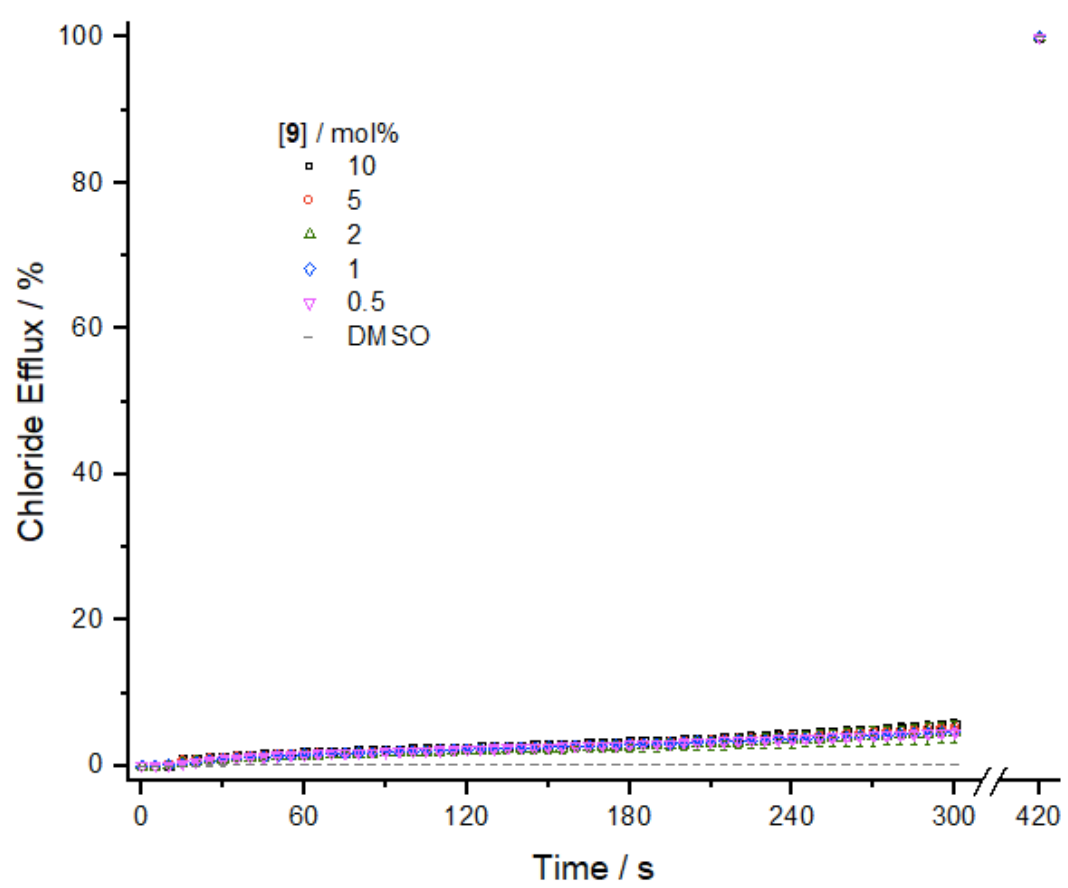

Fig. S36 Plots for attempted Hill analysis of chloride efflux $\left(\mathrm{Cl}^{-} / \mathrm{NO}_{3}{ }^{-}\right.$exchange $)$at $270 \mathrm{~s}$, mediated by compound 9 at $\mathrm{pH}$ 7.2. Each data point represents the average of two or three repeat measurements with error bars indicating the standard deviation.
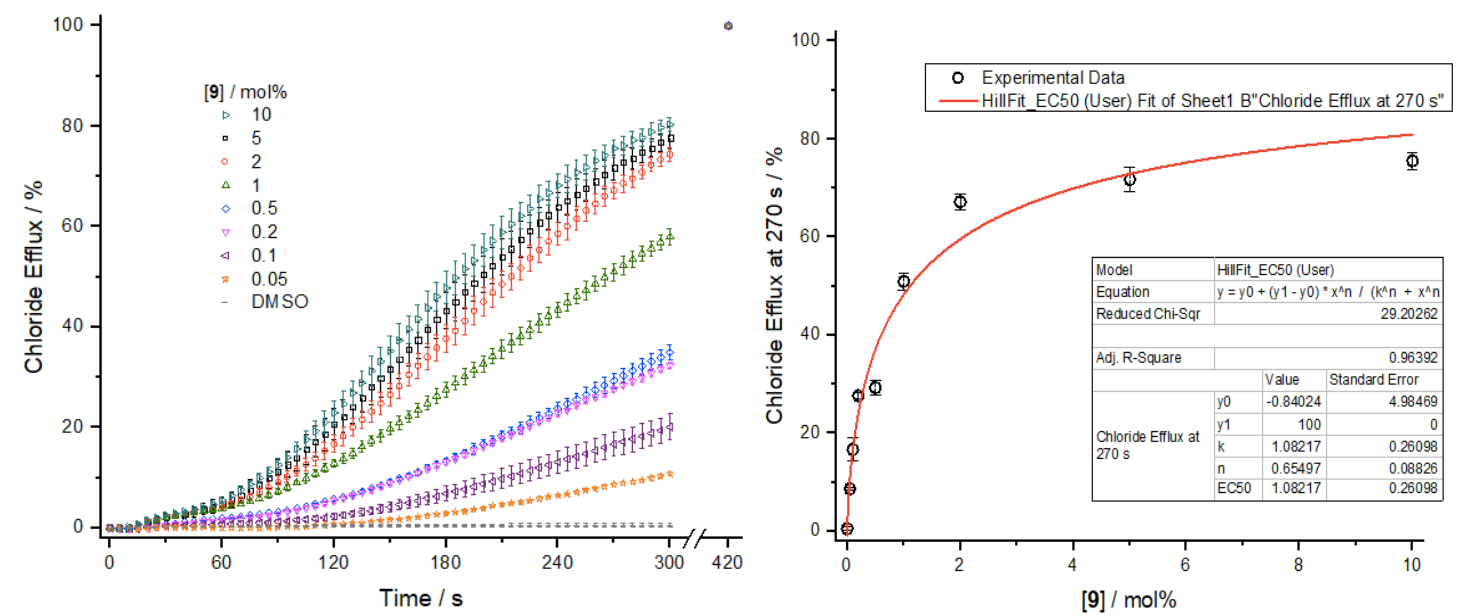

Fig. S37 Plots for Hill analysis of chloride efflux $\left(\mathrm{Cl}^{-} / \mathrm{NO}_{3}{ }^{-}\right.$exchange $)$at $270 \mathrm{~s}$, mediated by compound 9 at $\mathrm{pH}$ 4.5. Each data point represents the average of two or three repeat measurements with error bars indicating the standard deviation. 


\section{S2.5 Cationophore-coupled assay data}

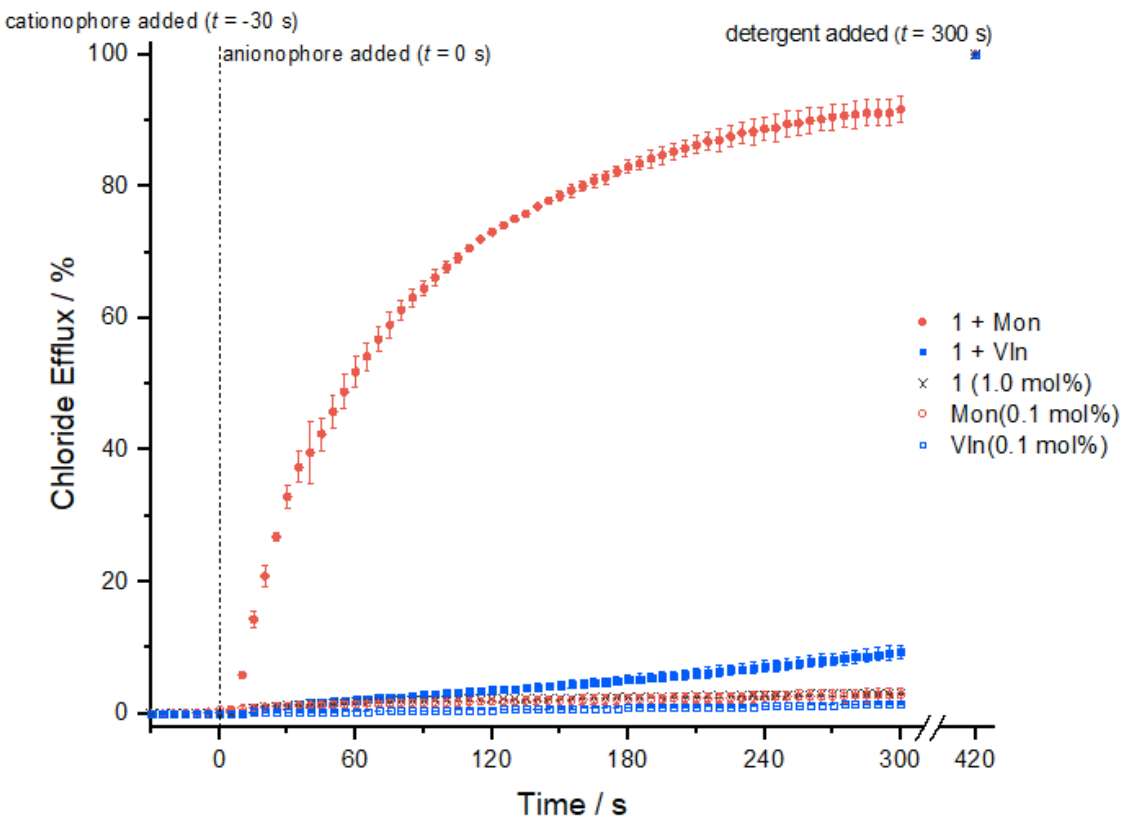

Fig. S38 Plot for chloride efflux mediated by compound $\mathbf{1}(1 \mathrm{~mol} \%)$ in the presence of monensin and valinomycin at $\mathrm{pH}$ 7.2. Each data point represents the average of three repeat measurements with error bars indicating the standard deviation.

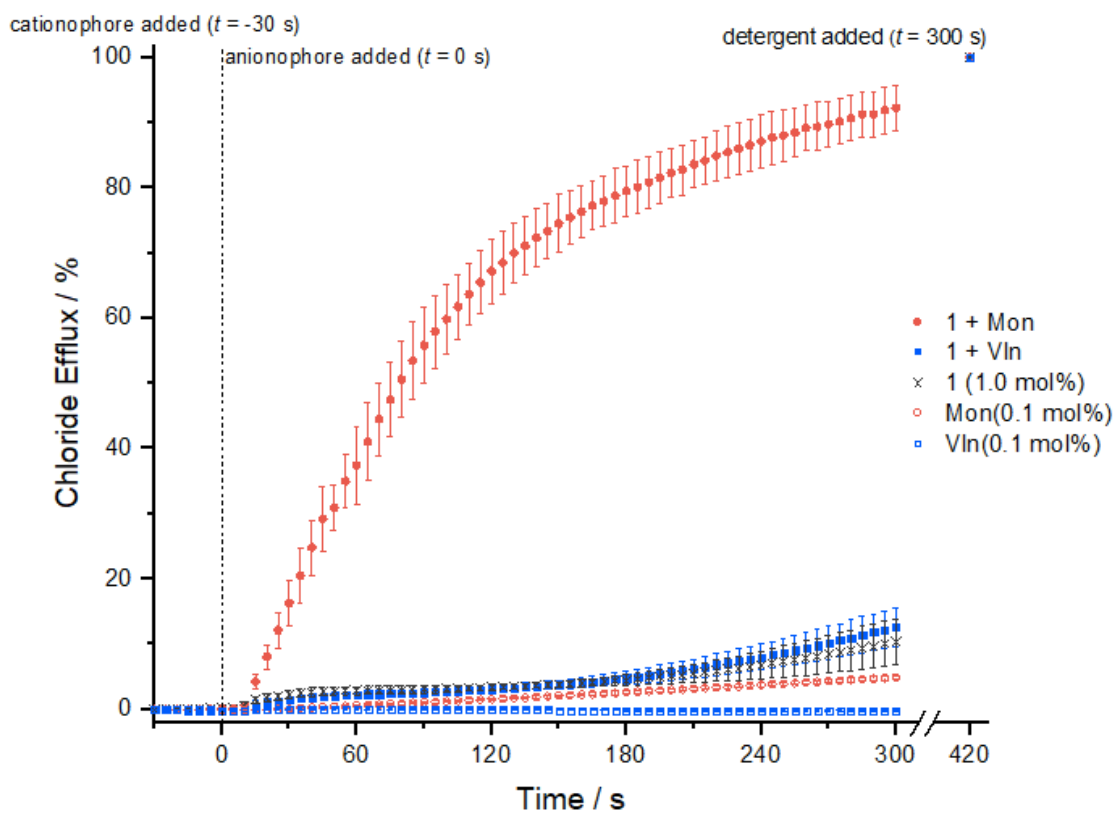

Fig. S39 Plot for chloride efflux mediated by compound $1(1 \mathrm{~mol} \%)$ in the presence of monensin and valinomycin at $\mathrm{pH}$ 4.5. Each data point represents the average of three repeat measurements with error bars indicating the standard deviation. 


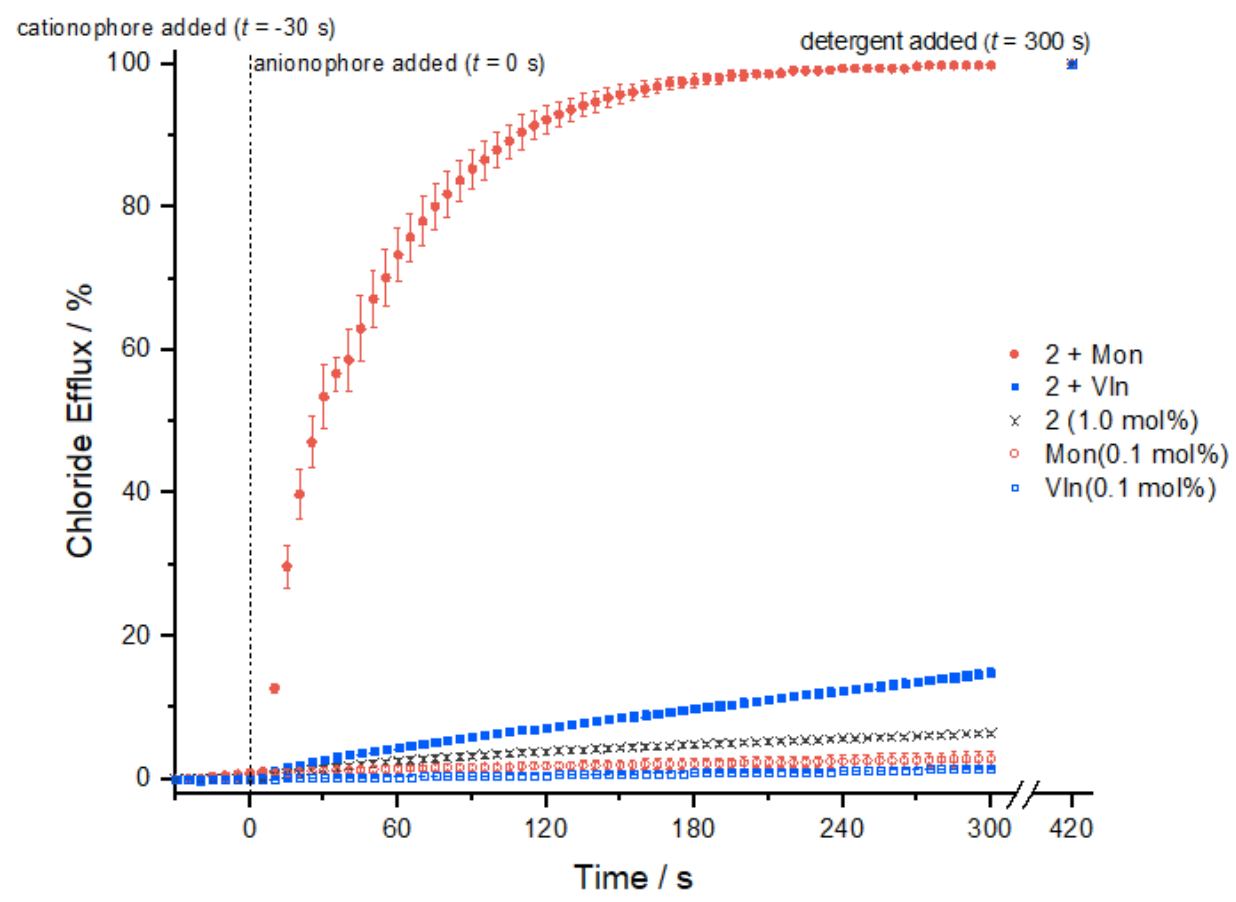

Fig. S40 Plot for chloride efflux mediated by compound $2(1 \mathrm{~mol} \%)$ in the presence of monensin and valinomycin at $\mathrm{pH}$ 7.2. Each data point represents the average of three repeat measurements with error bars indicating the standard deviation.

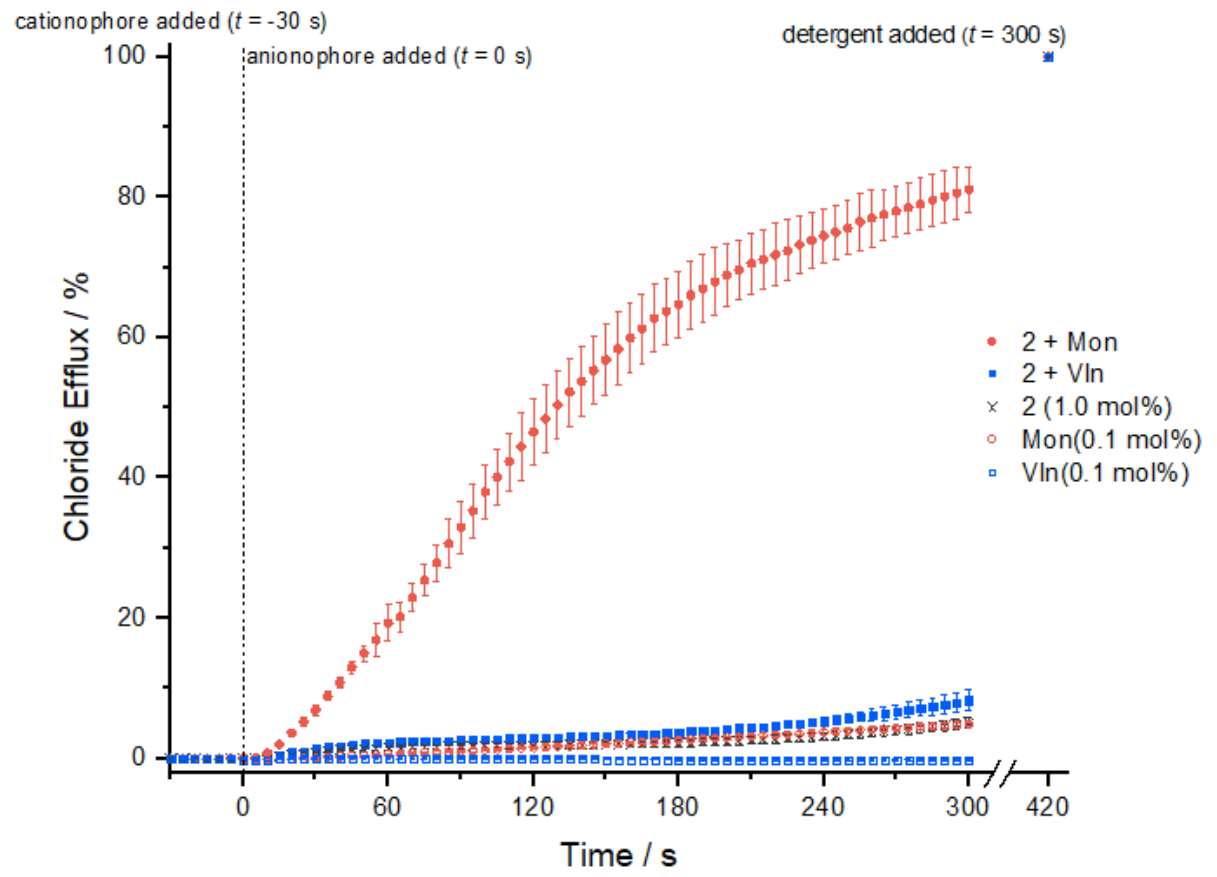

Fig. S41 Plot for chloride efflux mediated by compound $2(1 \mathrm{~mol} \%)$ in the presence of monensin and valinomycin at $\mathrm{pH}$ 4.5. Each data point represents the average of three repeat measurements with error bars indicating the standard deviation. 


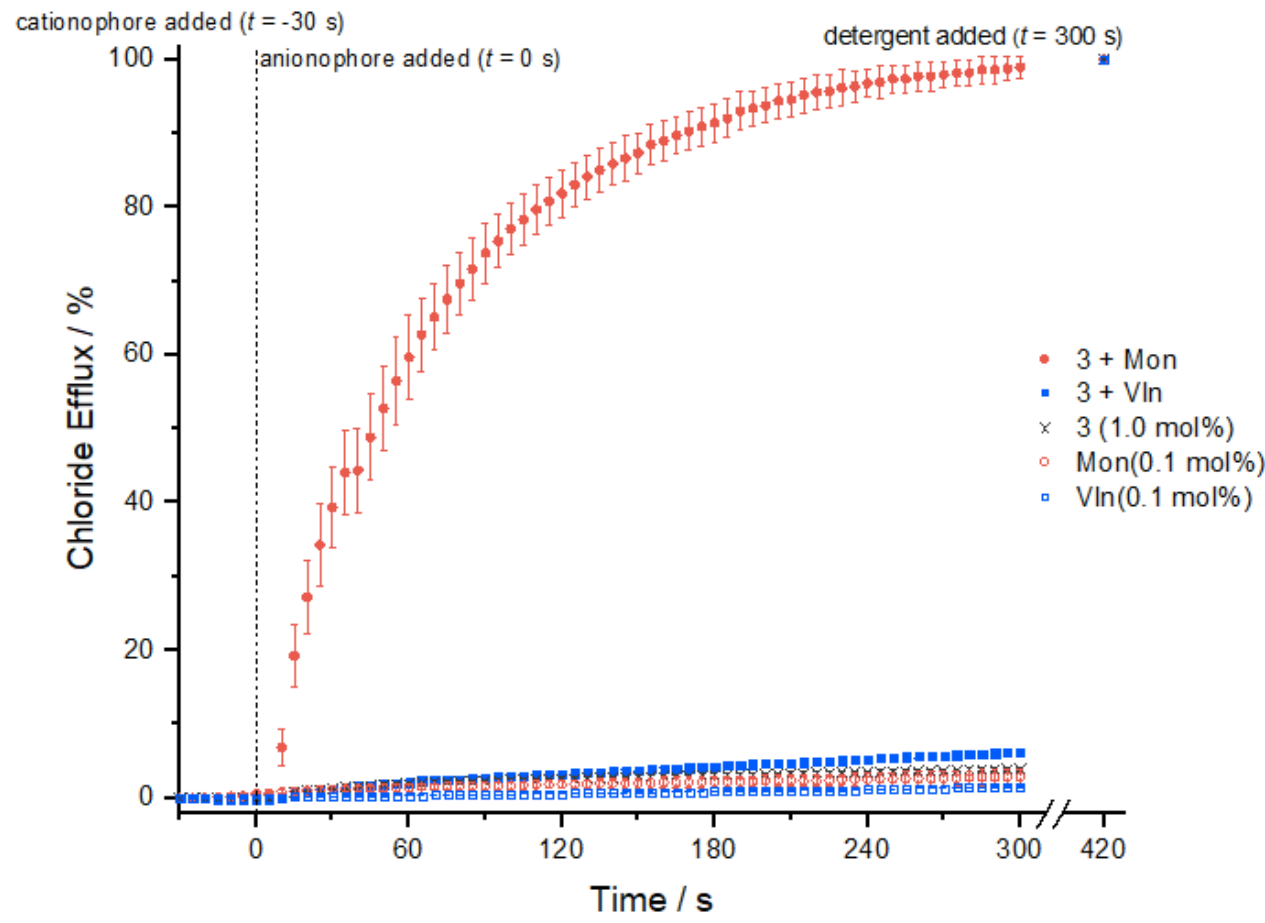

Fig. S42 Plot for chloride efflux mediated by compound $3(1 \mathrm{~mol} \%)$ in the presence of monensin and valinomycin at $\mathrm{pH}$ 7.2. Each data point represents the average of three repeat measurements with error bars indicating the standard deviation.

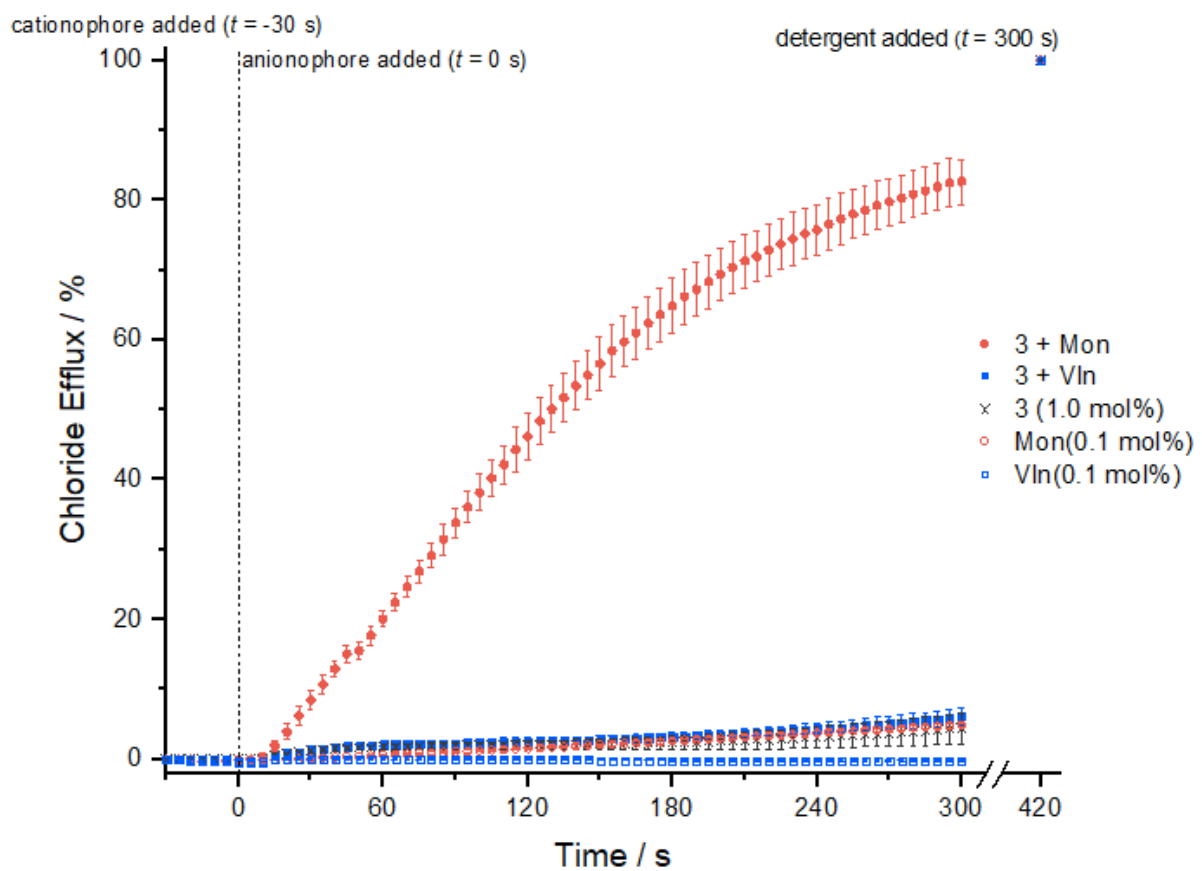

Fig. S43 Plot for chloride efflux mediated by compound $3(1 \mathrm{~mol} \%)$ in the presence of monensin and valinomycin at $\mathrm{pH}$ 4.5. Each data point represents the average of three repeat measurements with error bars indicating the standard deviation. 


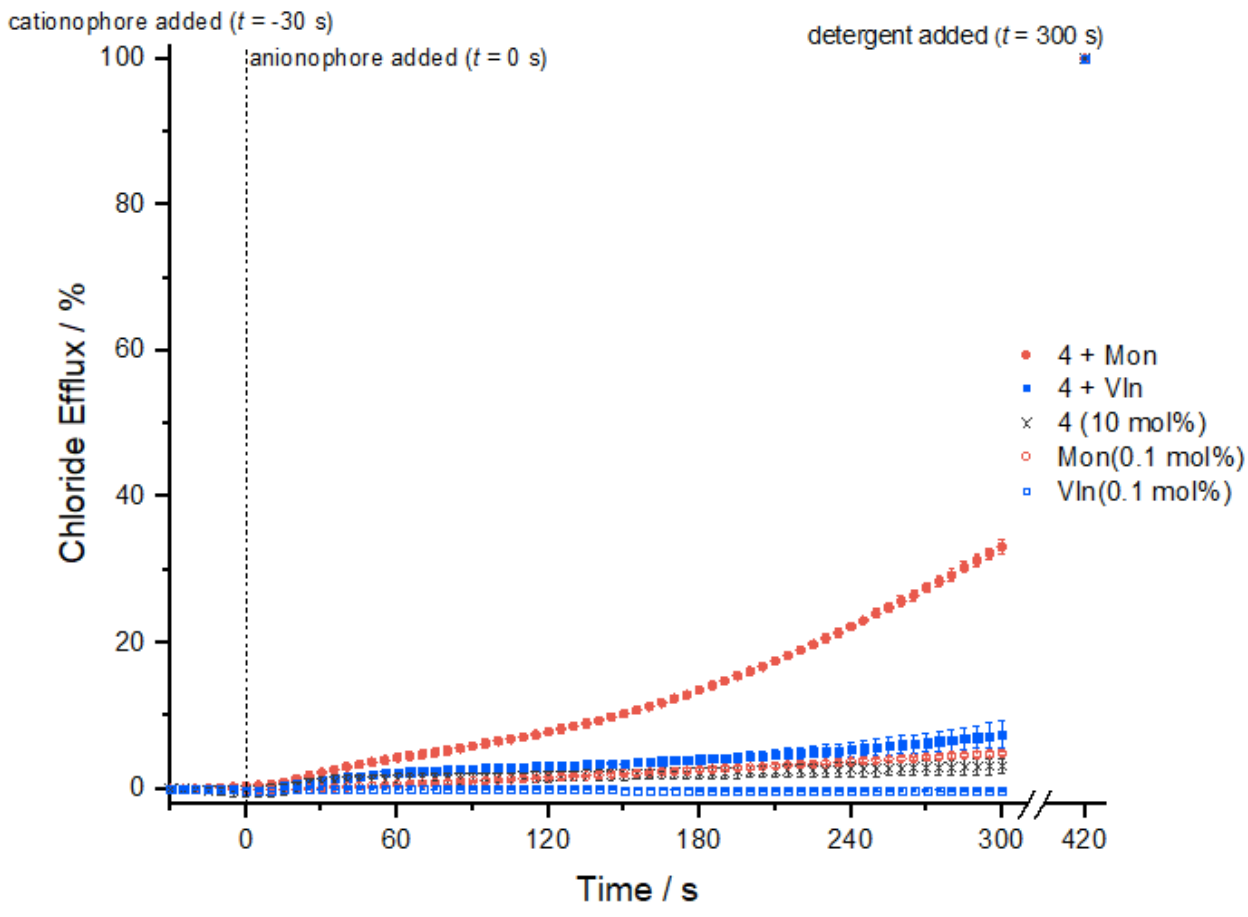

Fig. S44 Plot for chloride efflux mediated by compound $4(10 \mathrm{~mol} \%)$ in the presence of monensin and valinomycin at $\mathrm{pH}$ 7.2. Each data point represents the average of three repeat measurements with error bars indicating the standard deviation.

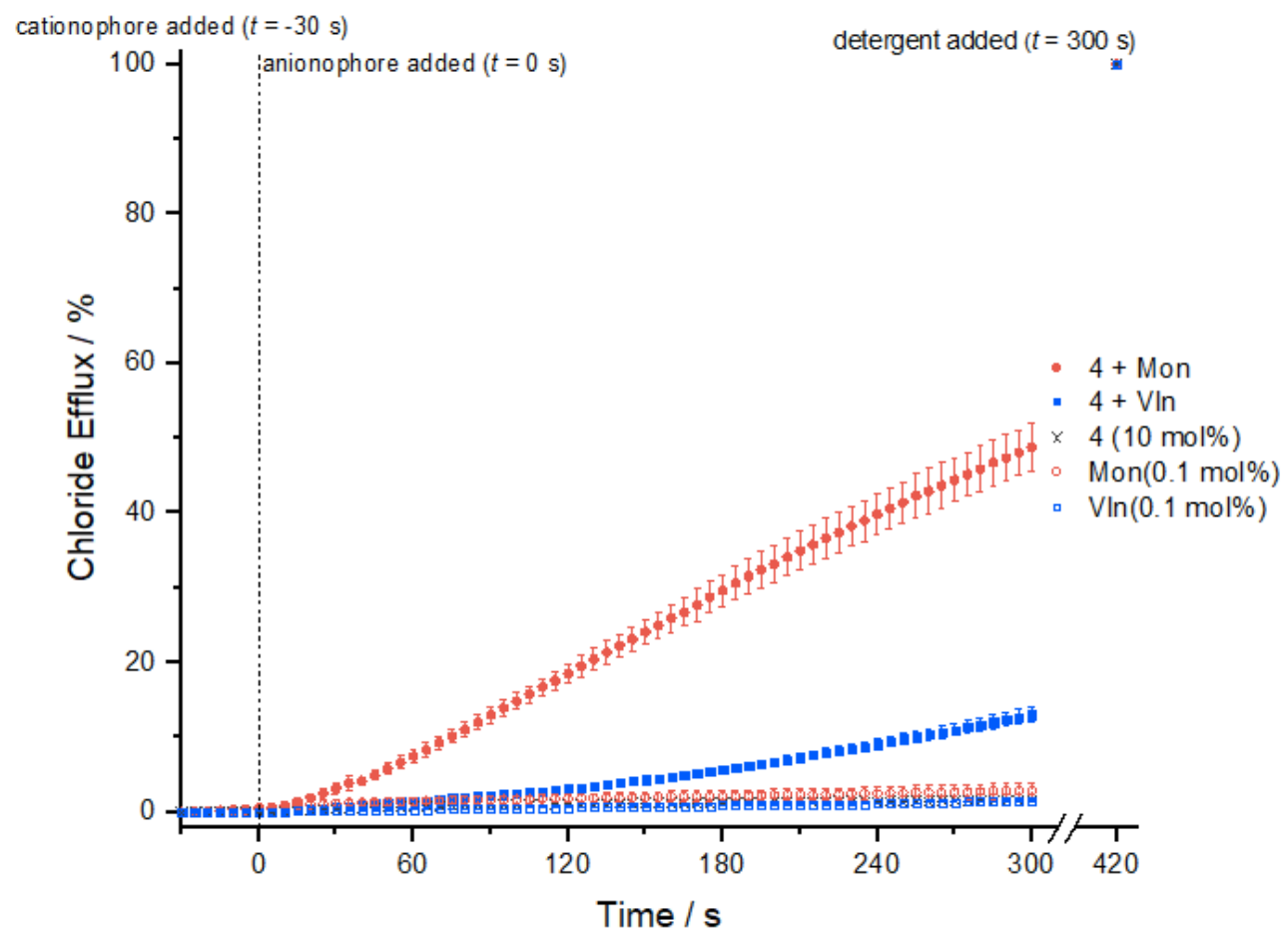

Fig. S45 Plot for chloride efflux mediated by compound 4 (10 mol\%) in the presence of monensin and valinomycin at $\mathrm{pH}$ 4.5. Each data point represents the average of three repeat measurements with error bars indicating the standard deviation. 


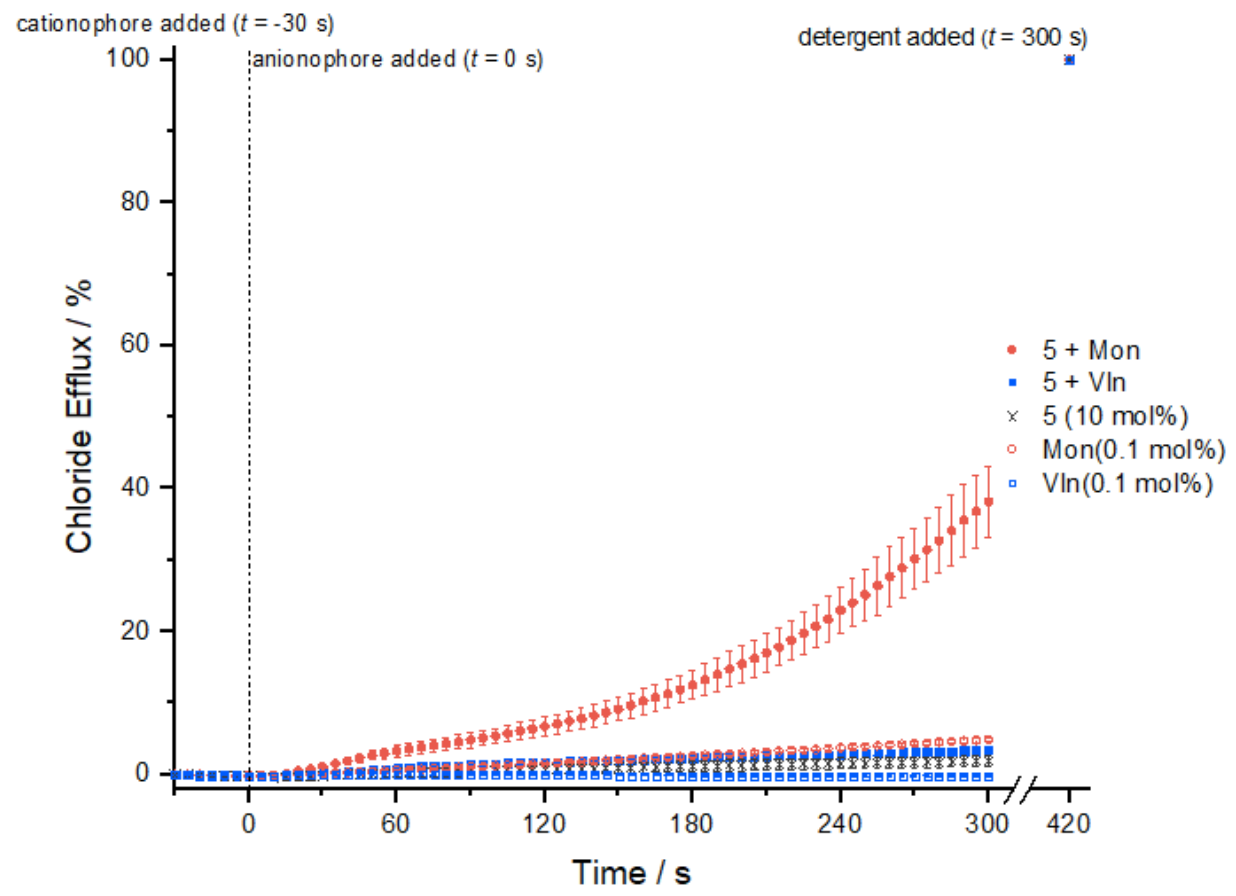

Fig. S46 Plot for chloride efflux mediated by compound 5 (10 mol\%) in the presence of monensin and valinomycin at $\mathrm{pH}$ 7.2. Each data point represents the average of three repeat measurements with error bars indicating the standard deviation.

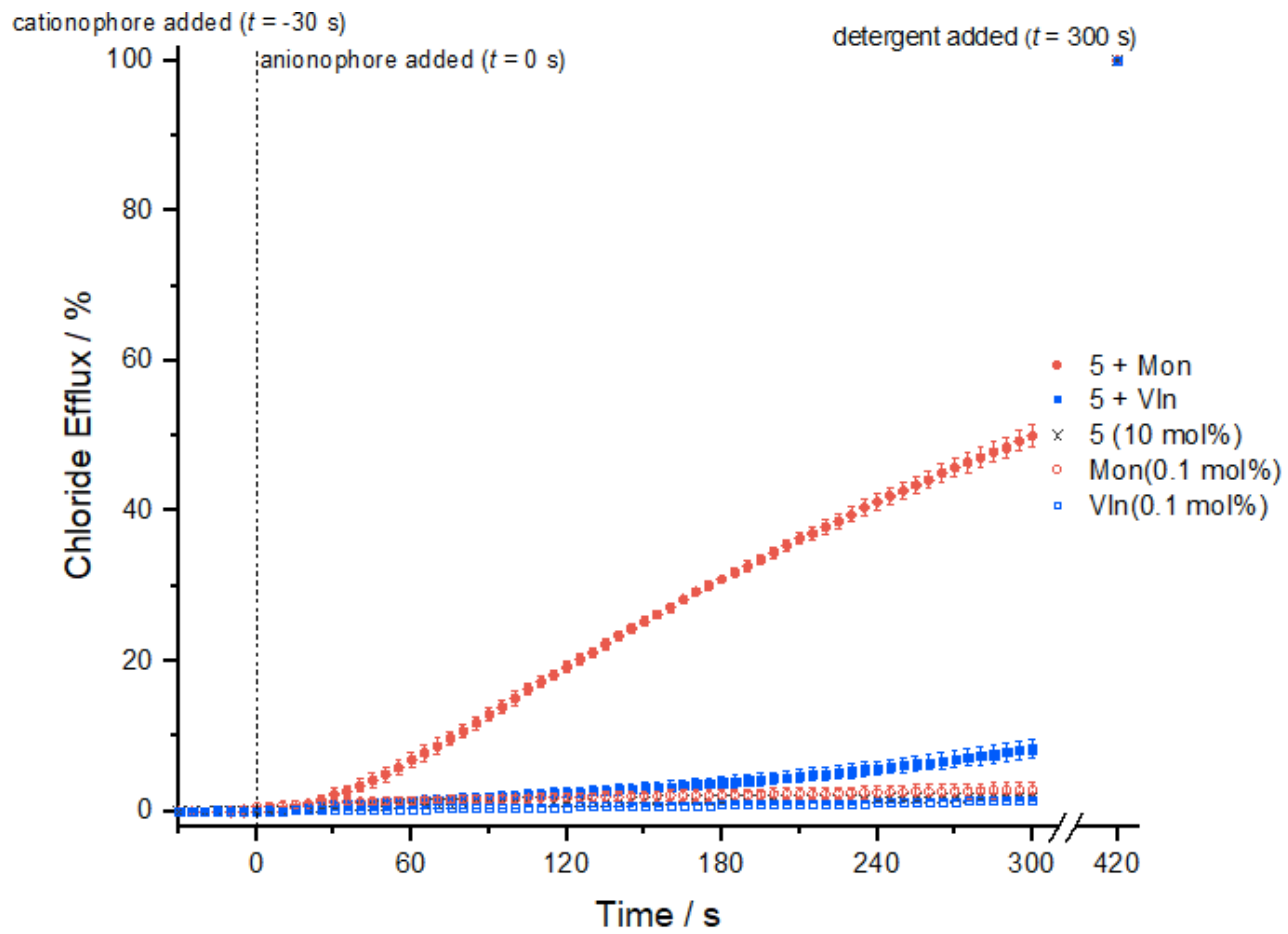

Fig. S47 Plot for chloride efflux mediated by compound 5 (10 mol\%) in the presence of monensin and valinomycin at $\mathrm{pH}$ 4.5. Each data point represents the average of three repeat measurements with error bars indicating the standard deviation. 


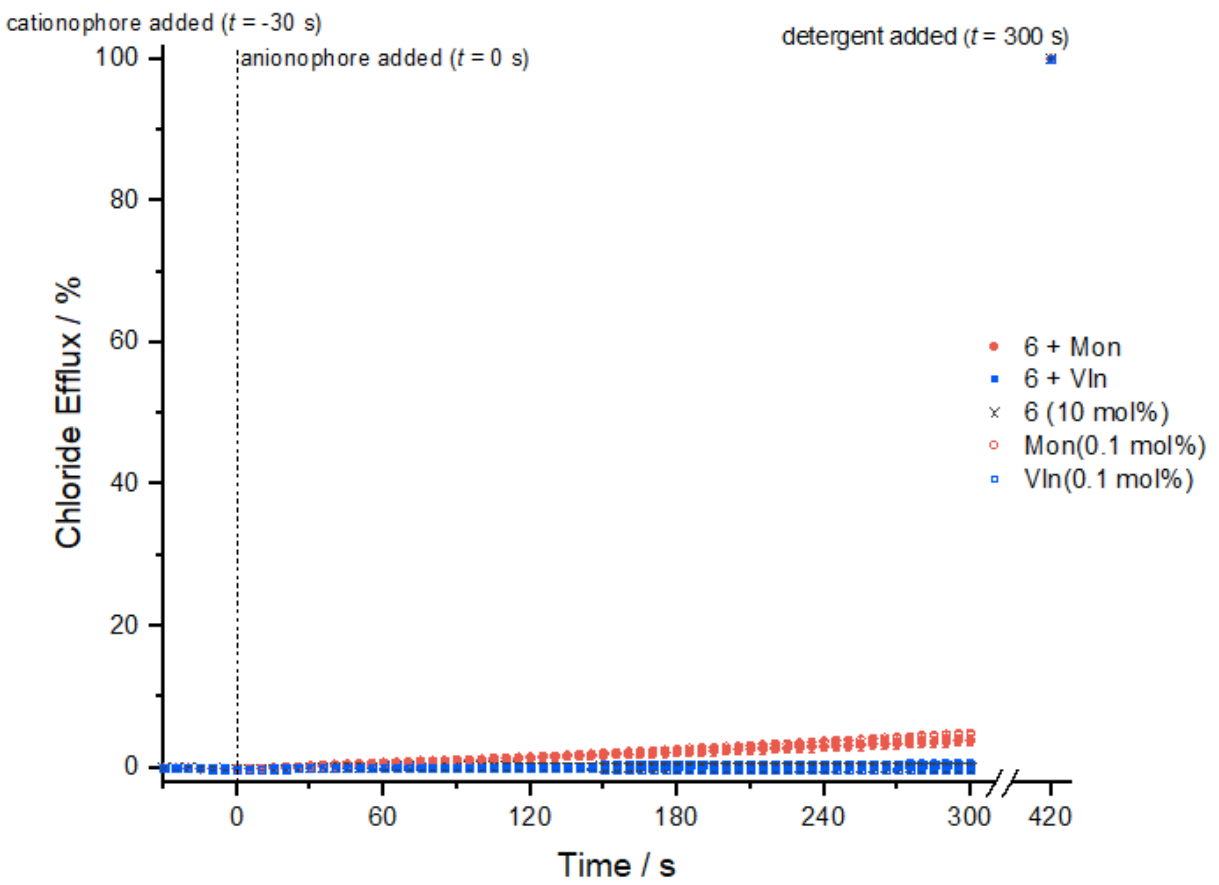

Fig. S48 Plot for chloride efflux mediated by compound 6 (10 mol\%) in the presence of monensin and valinomycin at $\mathrm{pH}$ 7.2. Each data point represents the average of three repeat measurements with error bars indicating the standard deviation.

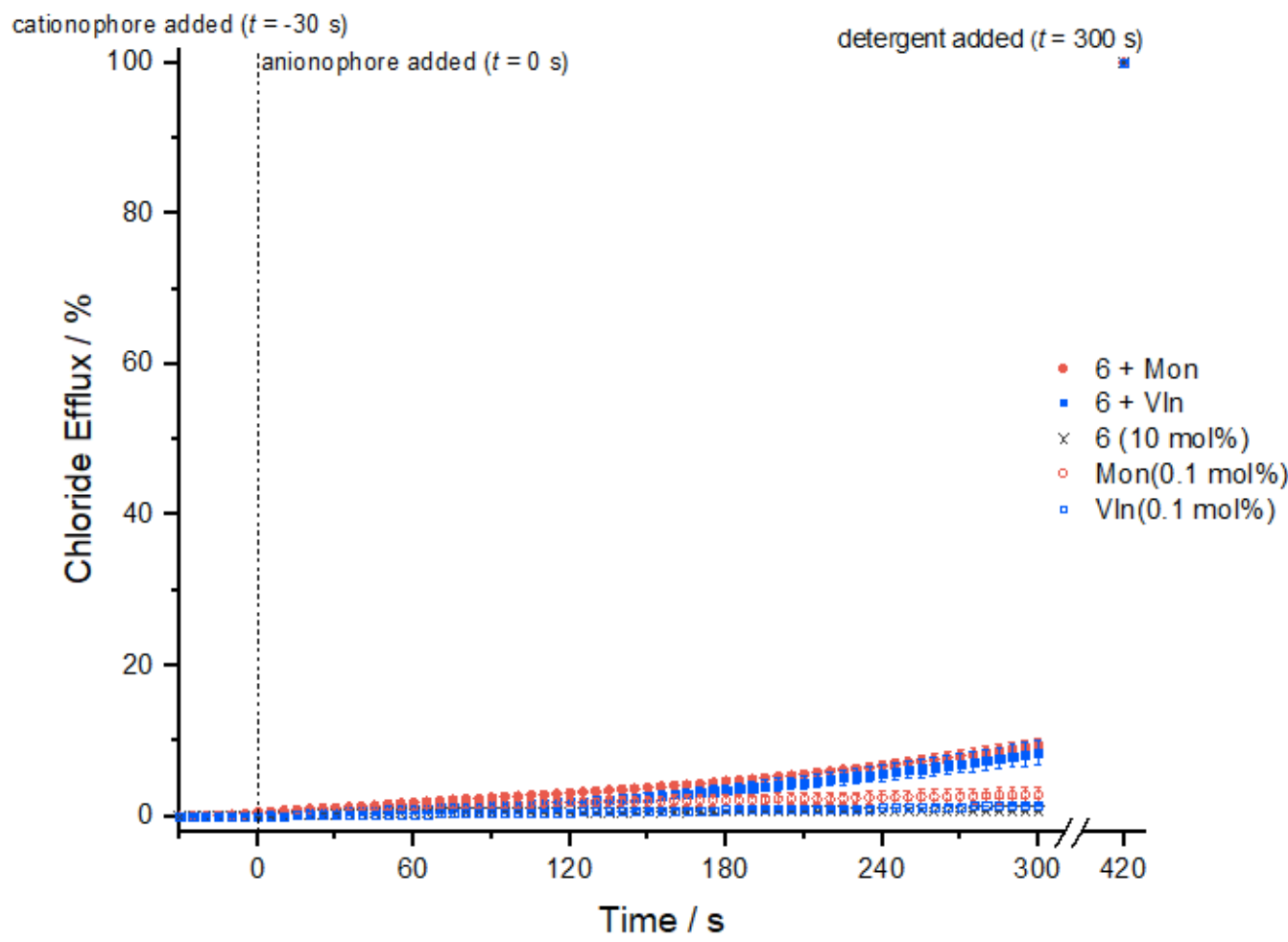

Fig. S49 Plot for chloride efflux mediated by compound 6 (10 mol\%) in the presence of monensin and valinomycin at $\mathrm{pH}$ 4.5. Each data point represents the average of three repeat measurements with error bars indicating the standard deviation. 


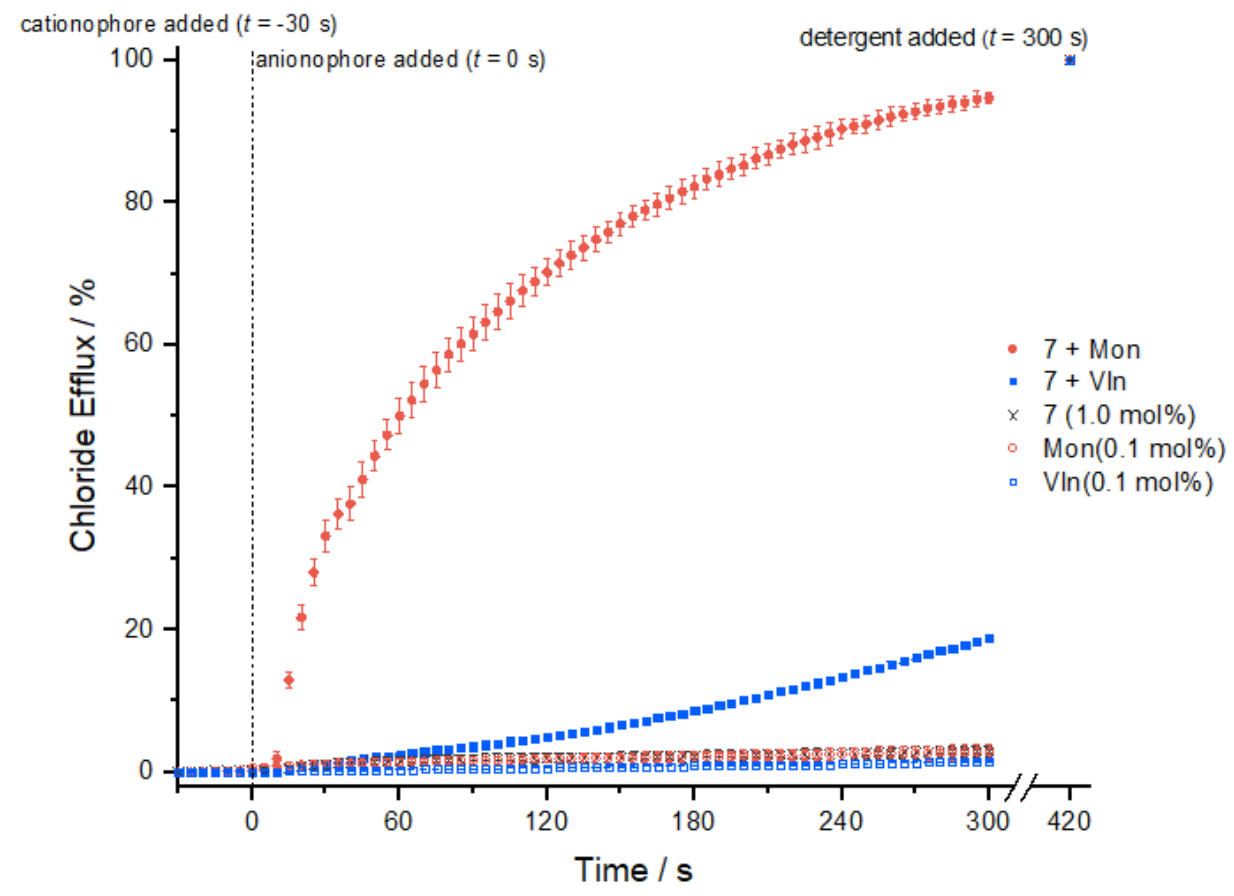

Fig. S50 Plot for chloride efflux mediated by compound $7(1 \mathrm{~mol} \%)$ in the presence of monensin and valinomycin at $\mathrm{pH}$ 7.2. Each data point represents the average of three repeat measurements with error bars indicating the standard deviation.

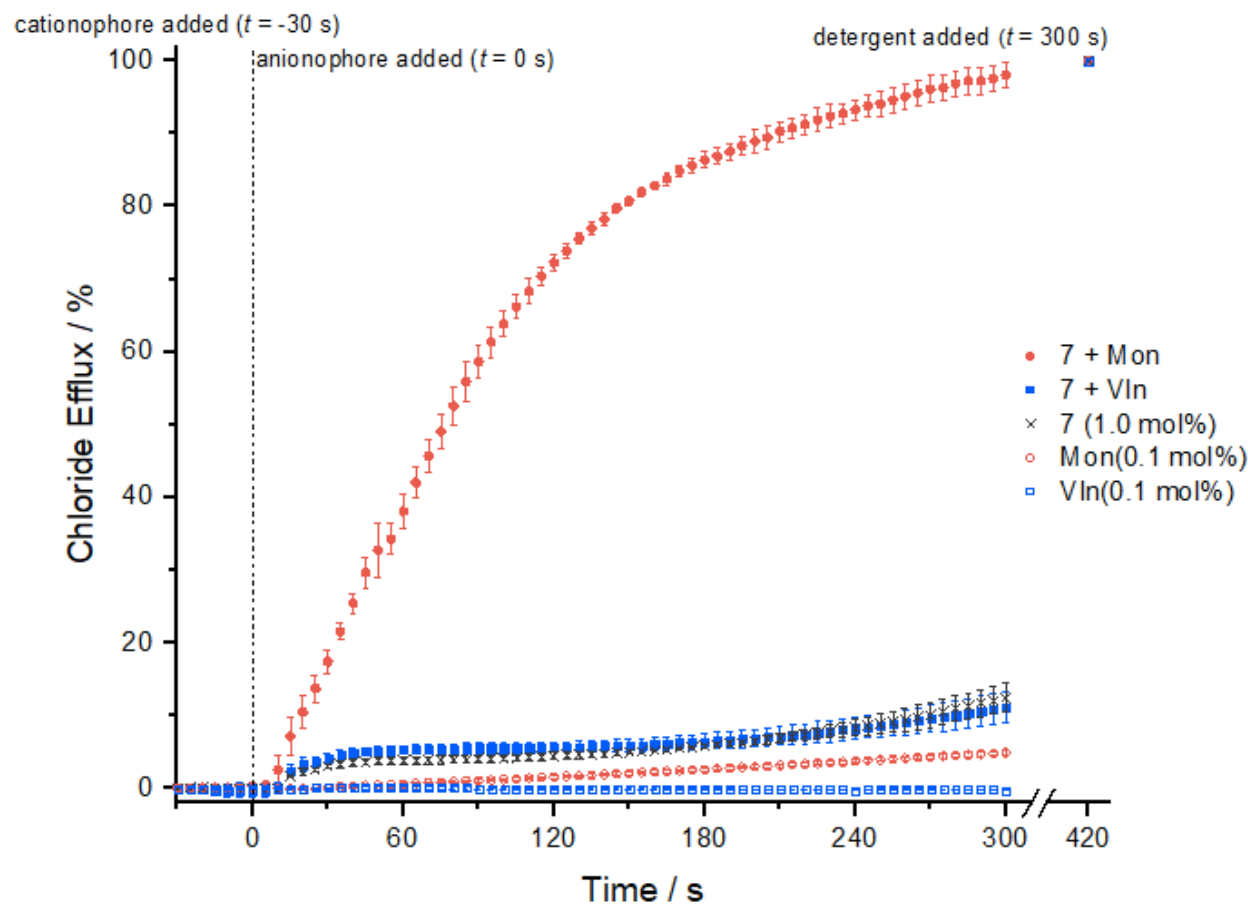

Fig. S51 Plot for chloride efflux mediated by compound $7(1 \mathrm{~mol} \%)$ in the presence of monensin and valinomycin at $\mathrm{pH}$ 4.5. Each data point represents the average of three repeat measurements with error bars indicating the standard deviation. 


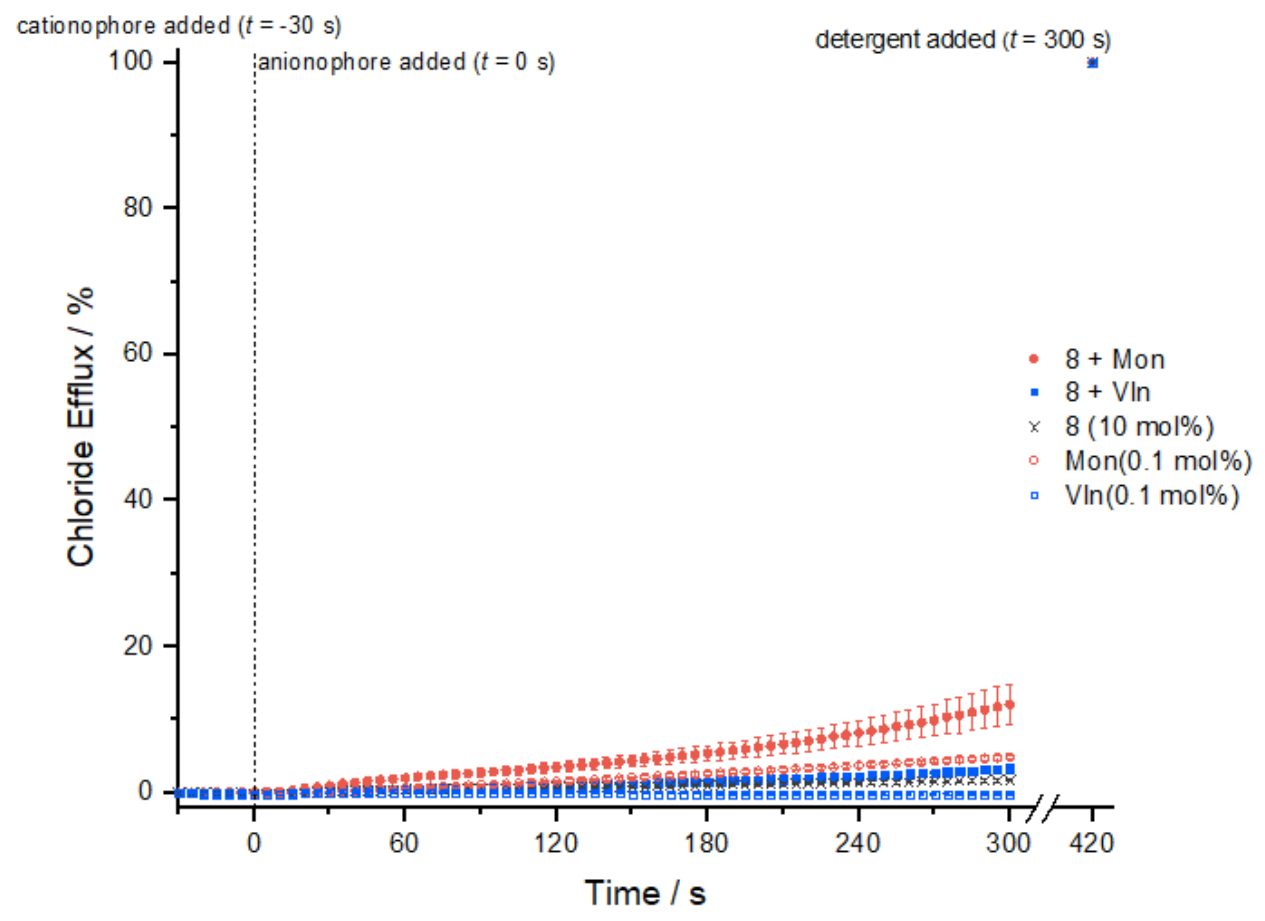

Fig. S52 Plot for chloride efflux mediated by compound 8 (10 mol\%) in the presence of monensin and valinomycin at $\mathrm{pH}$ 7.2. Each data point represents the average of three repeat measurements with error bars indicating the standard deviation.

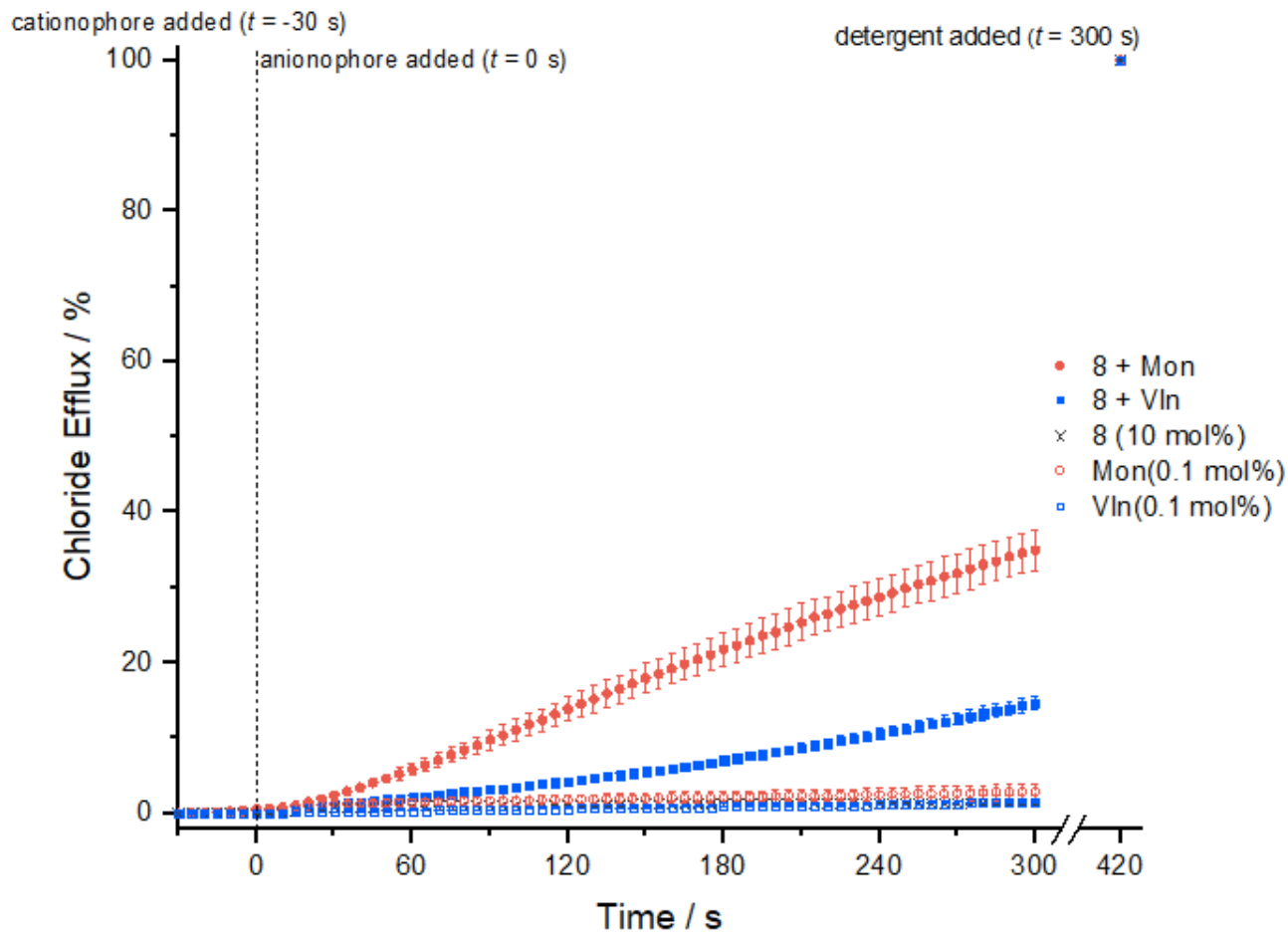

Fig. S53 Plot for chloride efflux mediated by compound 8 (10 mol\%) in the presence of monensin and valinomycin at $\mathrm{pH}$ 4.5. Each data point represents the average of three repeat measurements with error bars indicating the standard deviation. 


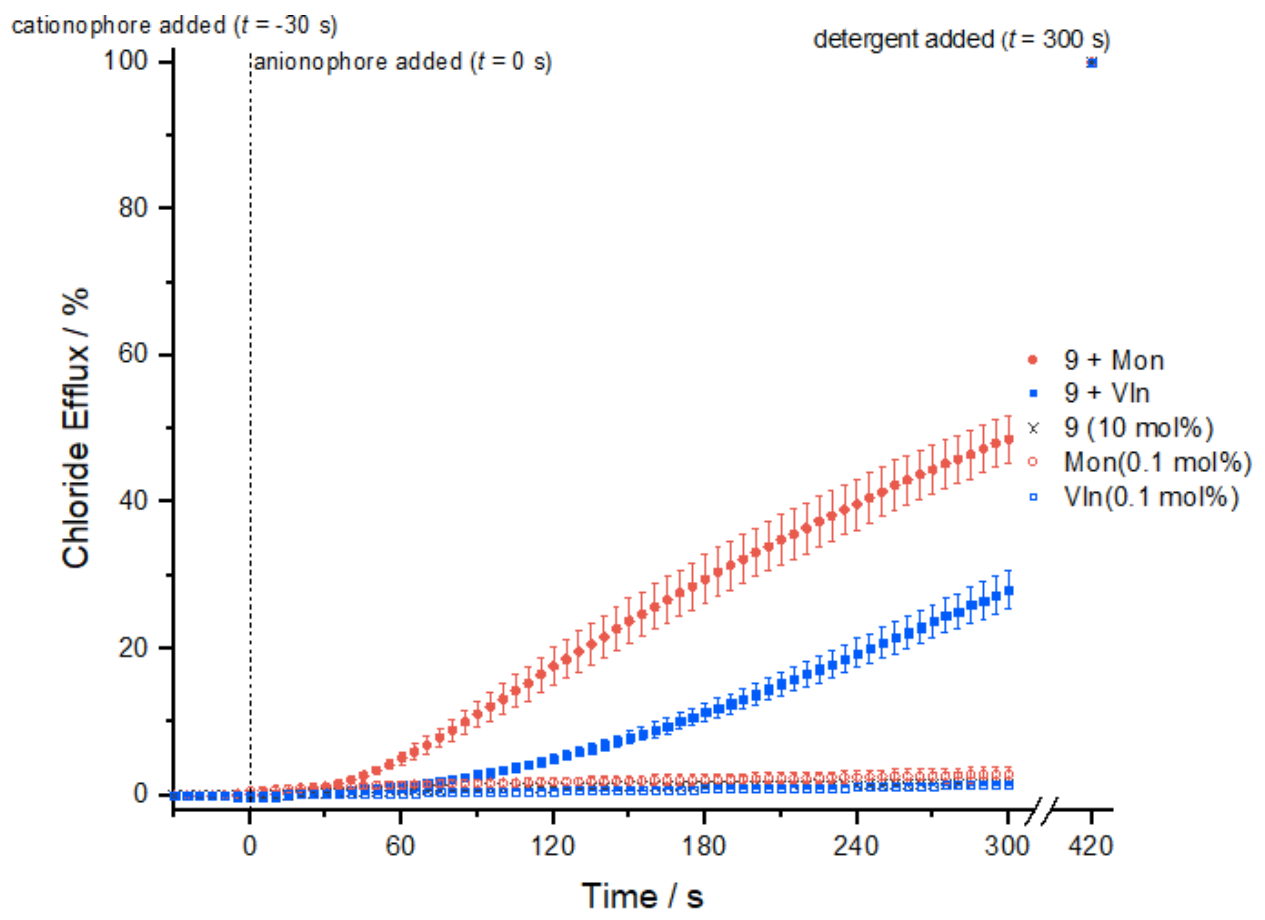

Fig. S54 Plot for chloride efflux mediated by compound 9 (10 mol\%) in the presence of monensin and valinomycin at $\mathrm{pH}$ 7.2. Each data point represents the average of three repeat measurements with error bars indicating the standard deviation.

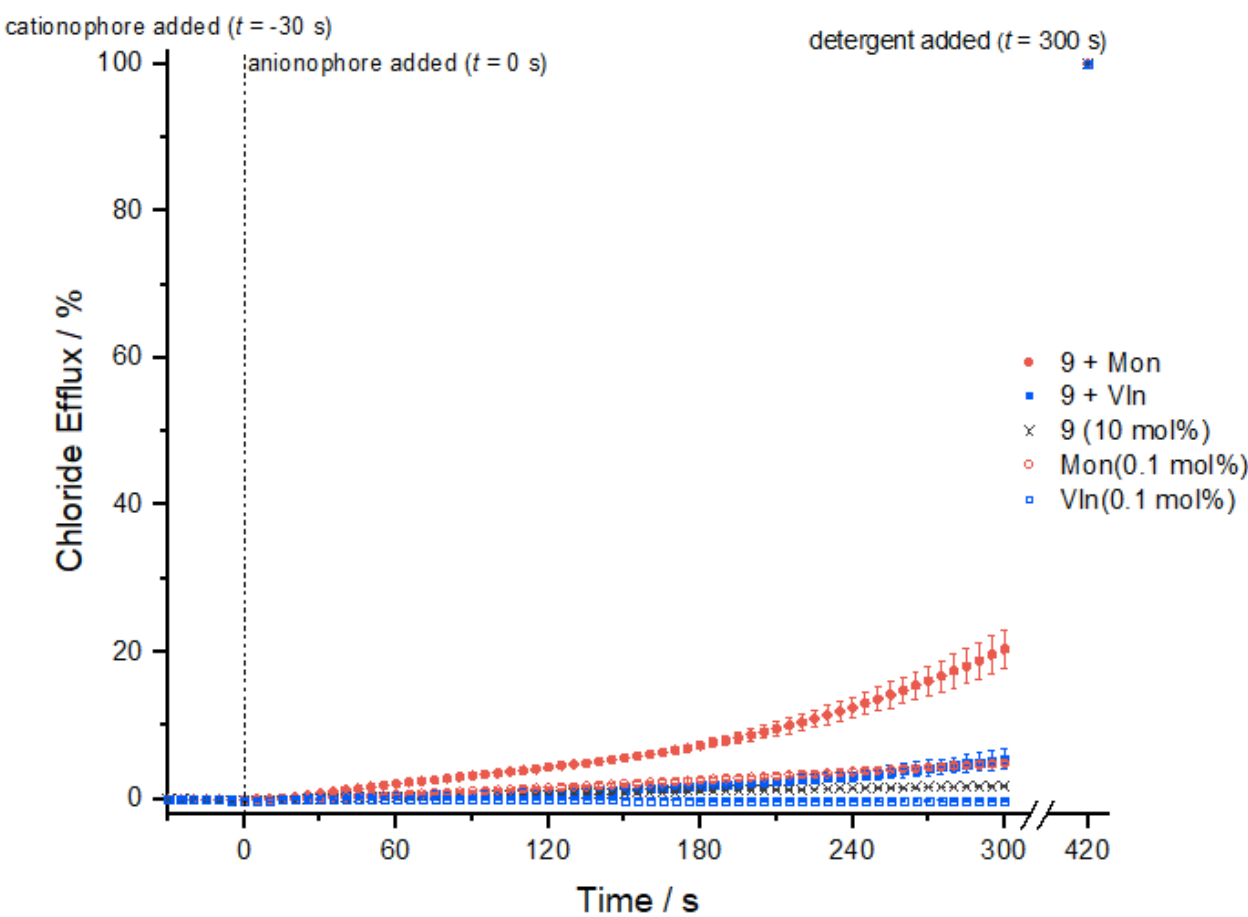

Fig. S55 Plot for chloride efflux mediated by compound 9 (10 mol\%) in the presence of monensin and valinomycin at $\mathrm{pH}$ 4.5. Each data point represents the average of three repeat measurements with error bars indicating the standard deviation. 


\section{S2.6 Comparison of $\mathrm{Cl}^{-} / \mathrm{NO}_{3}{ }^{-}$exchange and cationophore-coupled assay}

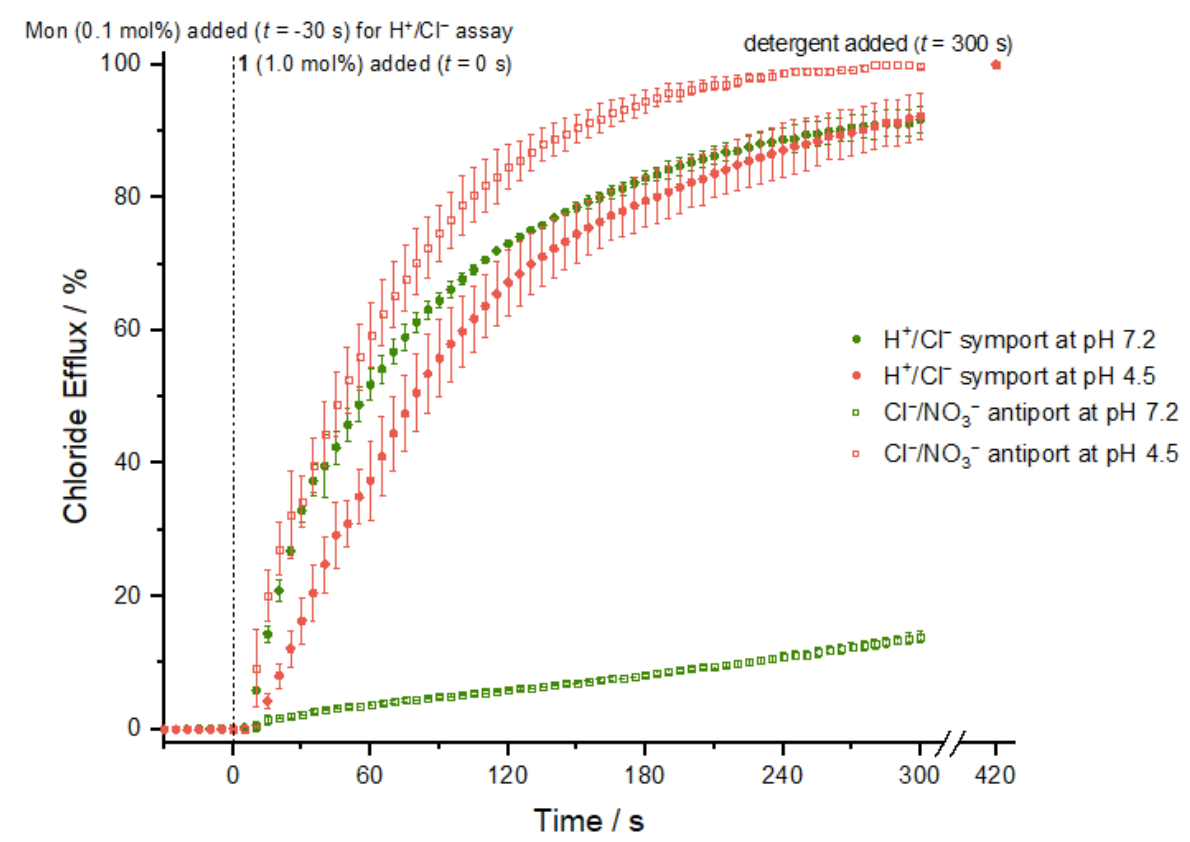

Fig. S56 Comparison plot for chloride efflux mediated by compound $1(1 \mathrm{~mol} \%)$ in the presence of monensin and valinomycin and $\mathrm{Cl} / \mathrm{NO}_{3}{ }^{-}$exchange at $\mathrm{pH} 4.5$ and 7.2. Each data point represents the average of two or three repeat measurements with error bars indicating the standard deviation.

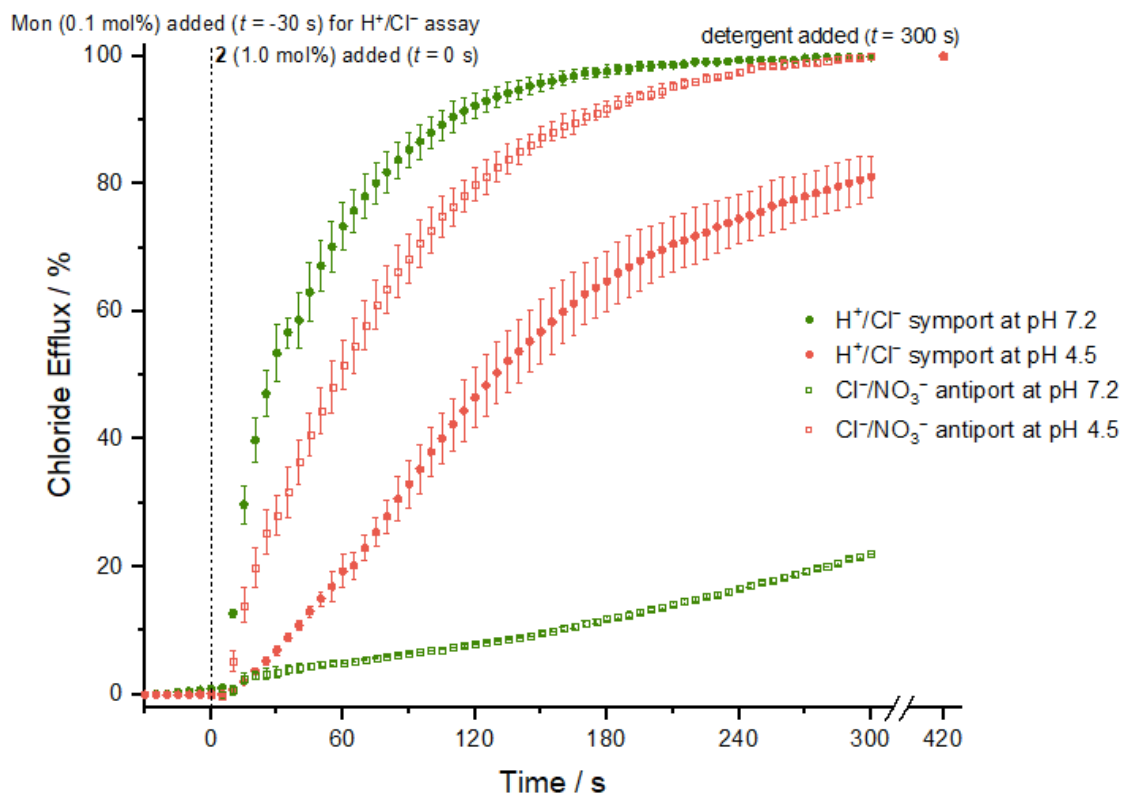

Fig. S57 Comparison plot for chloride efflux mediated by compound $2(1 \mathrm{~mol} \%)$ in the presence of monensin and valinomycin and $\mathrm{Cl}^{-} / \mathrm{NO}_{3}{ }^{-}$exchange at $\mathrm{pH} 4.5$ and 7.2. Each data point represents the average of two or three repeat measurements with error bars indicating the standard deviation. 


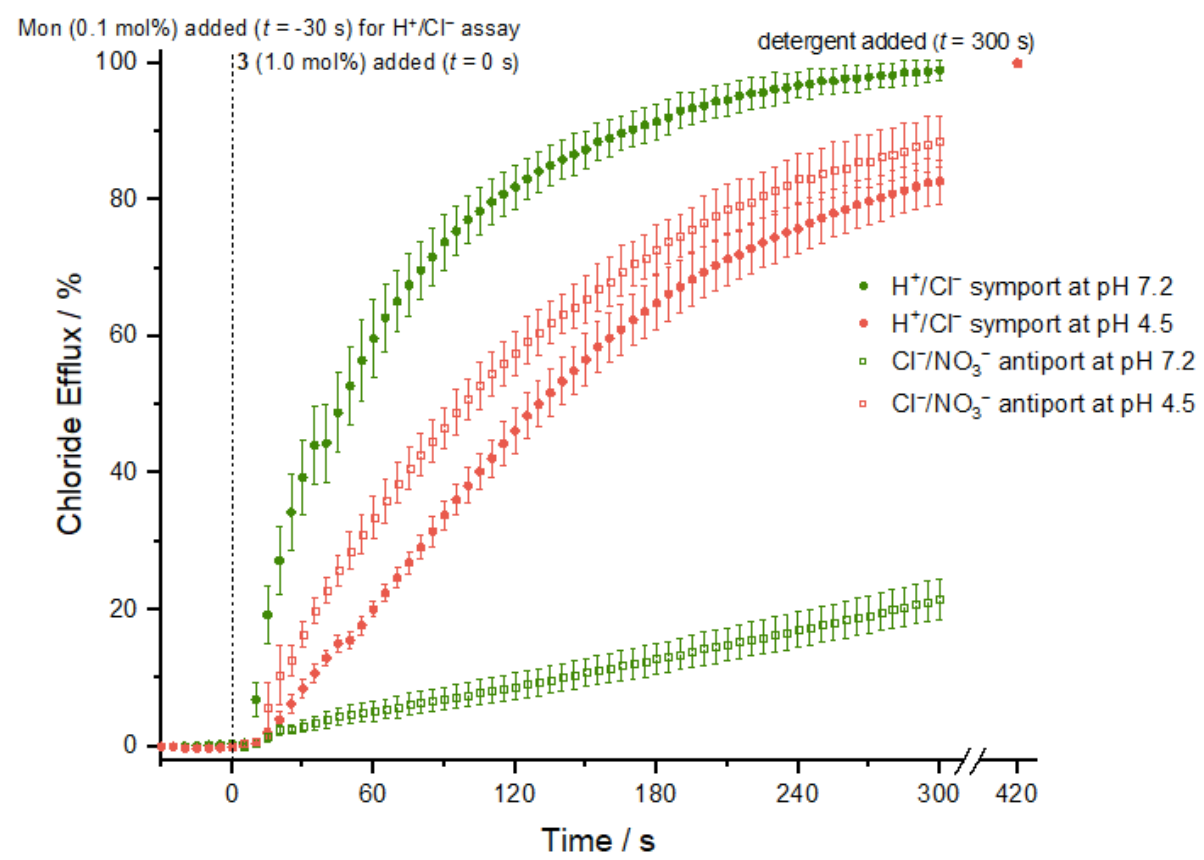

Fig. S58 Comparison plot for chloride efflux mediated by compound $3(1 \mathrm{~mol} \%)$ in the presence of monensin and valinomycin and $\mathrm{Cl}-/ \mathrm{NO}_{3}{ }^{-}$exchange at $\mathrm{pH} 4.5$ and 7.2. Each data point represents the average of two or three repeat measurements with error bars indicating the standard deviation.

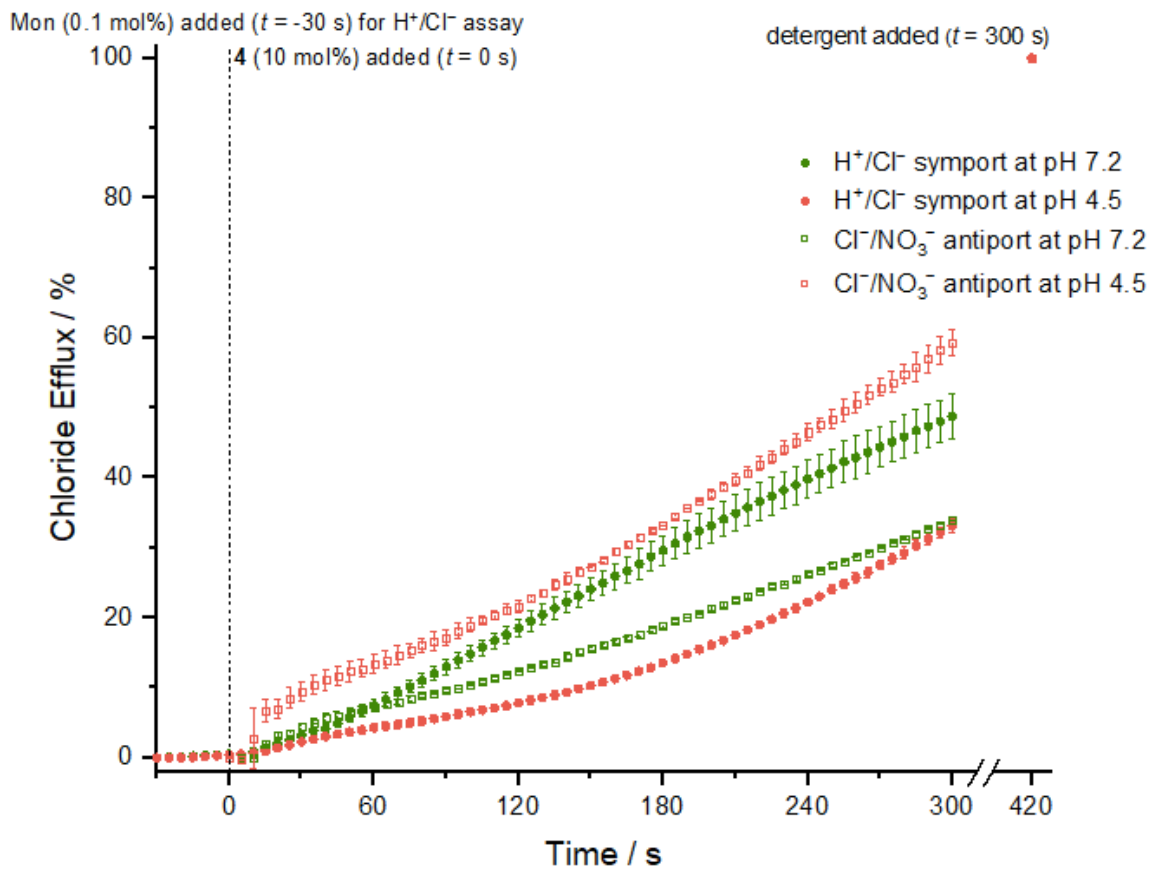

Fig. S59 Comparison plot for chloride efflux mediated by compound 4 (10 mol\%) in the presence of monensin and valinomycin and $\mathrm{Cl} / \mathrm{NO}_{3}{ }^{-}$exchange at $\mathrm{pH} 4.5$ and 7.2. Each data point represents the average of two or three repeat measurements with error bars indicating the standard deviation. 


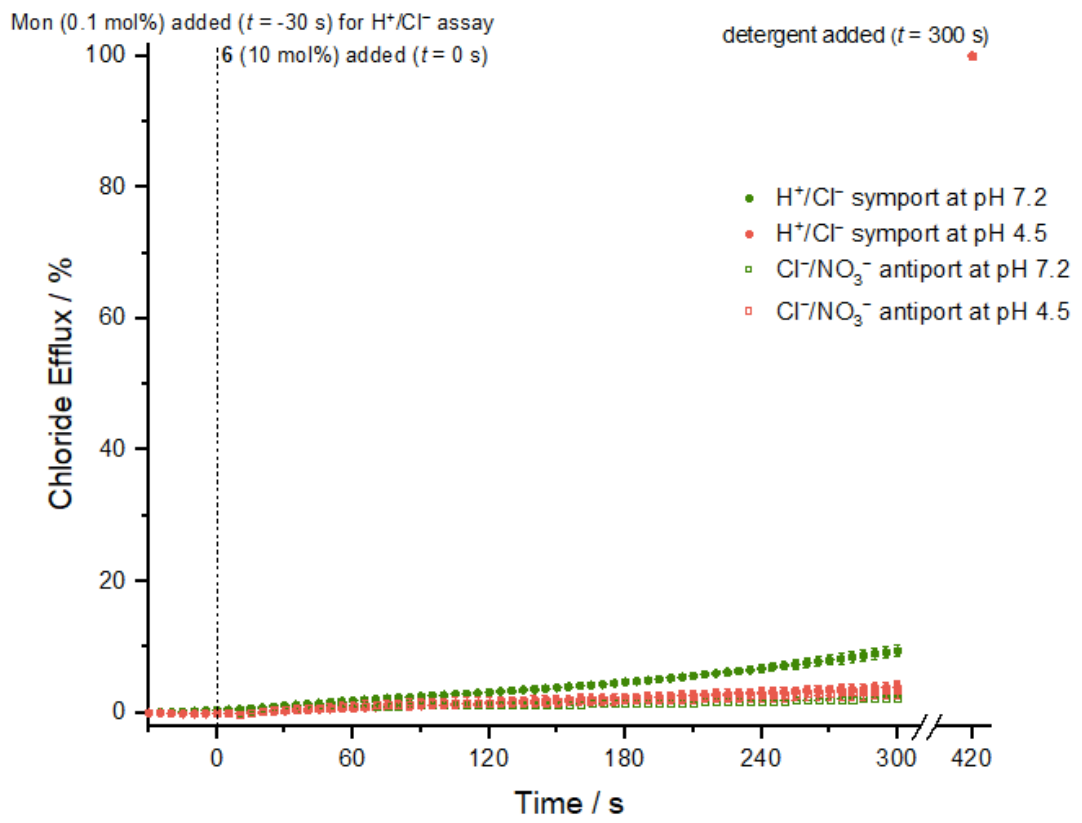

Fig. S60 Comparison plot for chloride efflux mediated by compound $5(10 \mathrm{~mol} \%)$ in the presence of monensin and valinomycin and $\mathrm{Cl}^{-} / \mathrm{NO}_{3}{ }^{-}$exchange at $\mathrm{pH} 4.5$ and 7.2. Each data point represents the average of two or three repeat measurements with error bars indicating the standard deviation.

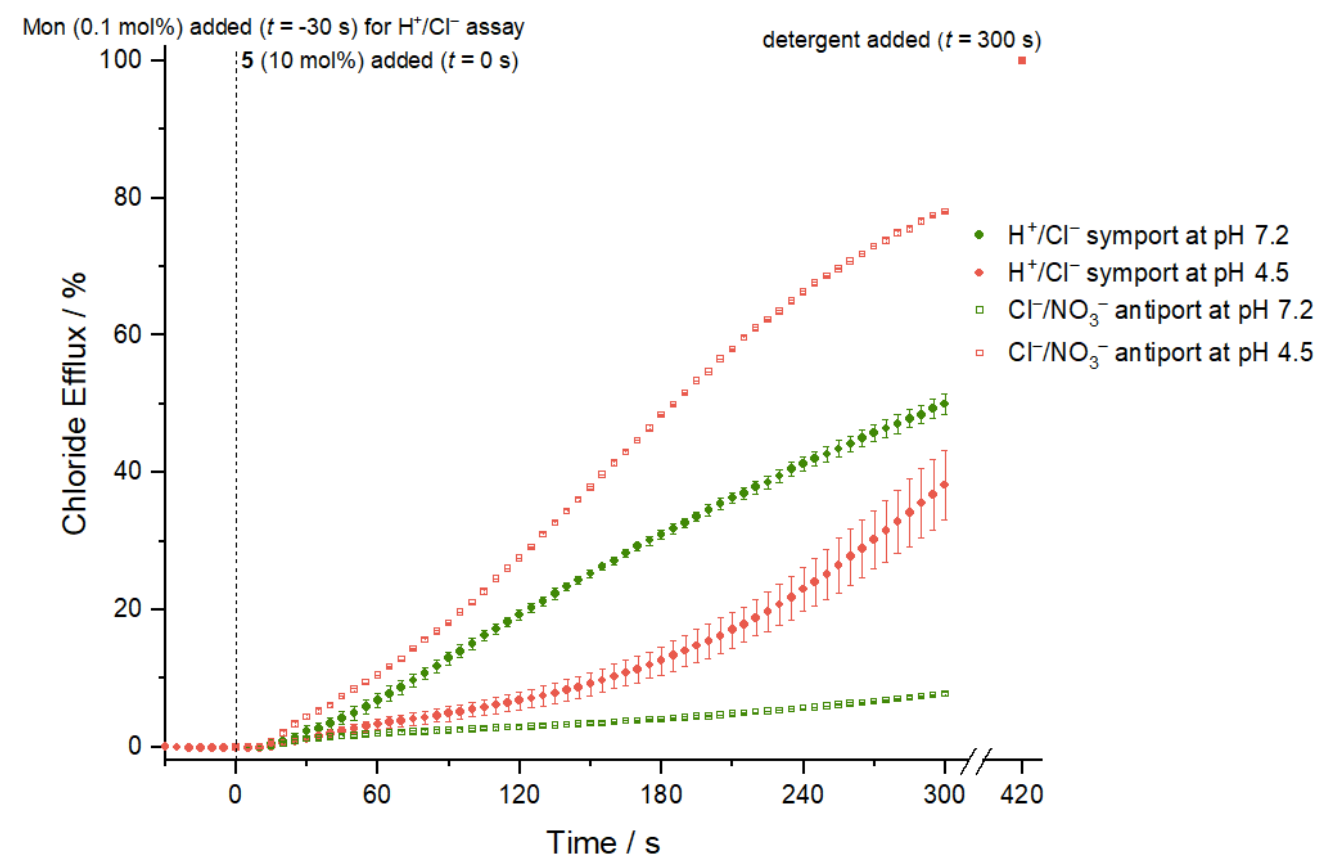

Fig. S61 Comparison plot for chloride efflux mediated by compound 6 (10 mol\%) in the presence of monensin and valinomycin and $\mathrm{Cl}-/ \mathrm{NO}_{3}{ }^{-}$exchange at $\mathrm{pH} 4.5$ and 7.2. Each data point represents the average of two or three repeat measurements with error bars indicating the standard deviation. 


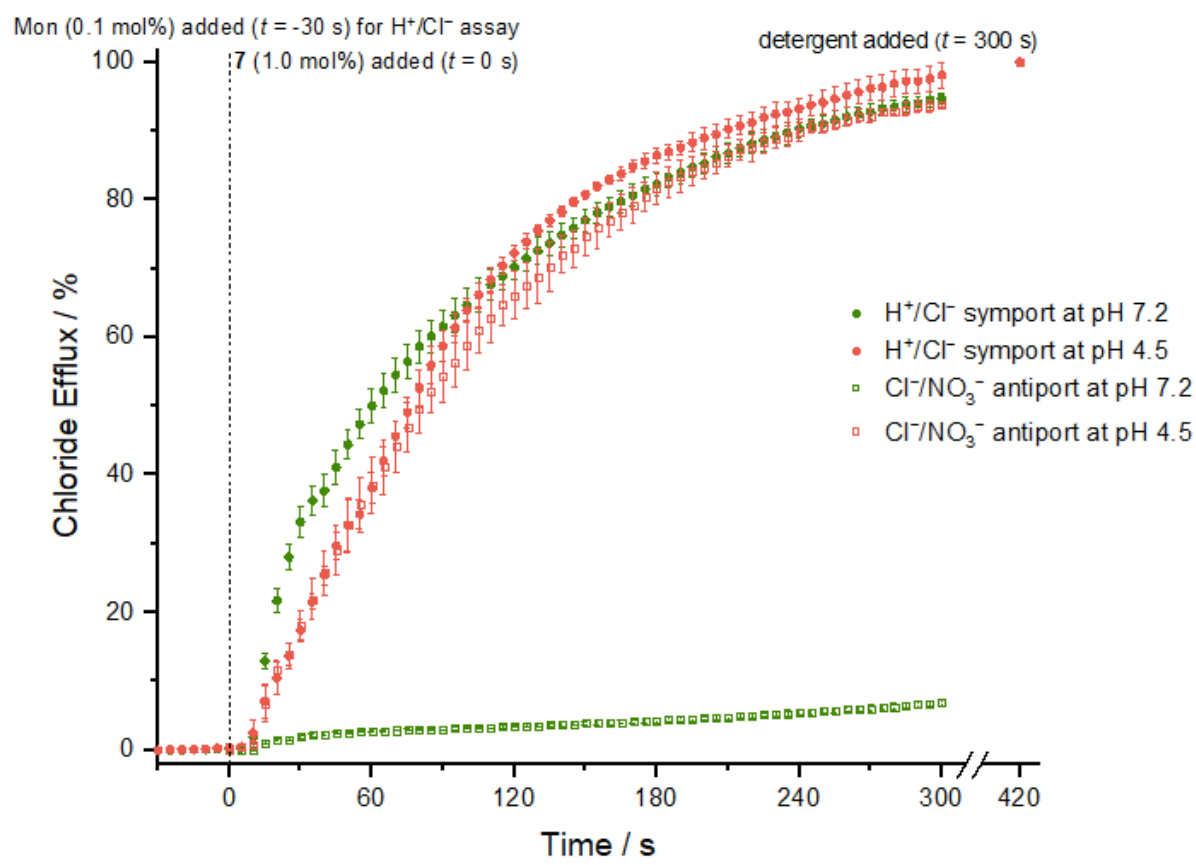

Fig. S62 Comparison plot for chloride efflux mediated by compound $7(1 \mathrm{~mol} \%)$ in the presence of monensin and valinomycin and $\mathrm{Cl}^{-} / \mathrm{NO}_{3}{ }^{-}$exchange at $\mathrm{pH} 4.5$ and 7.2. Each data point represents the average of two or three repeat measurements with error bars indicating the standard deviation.

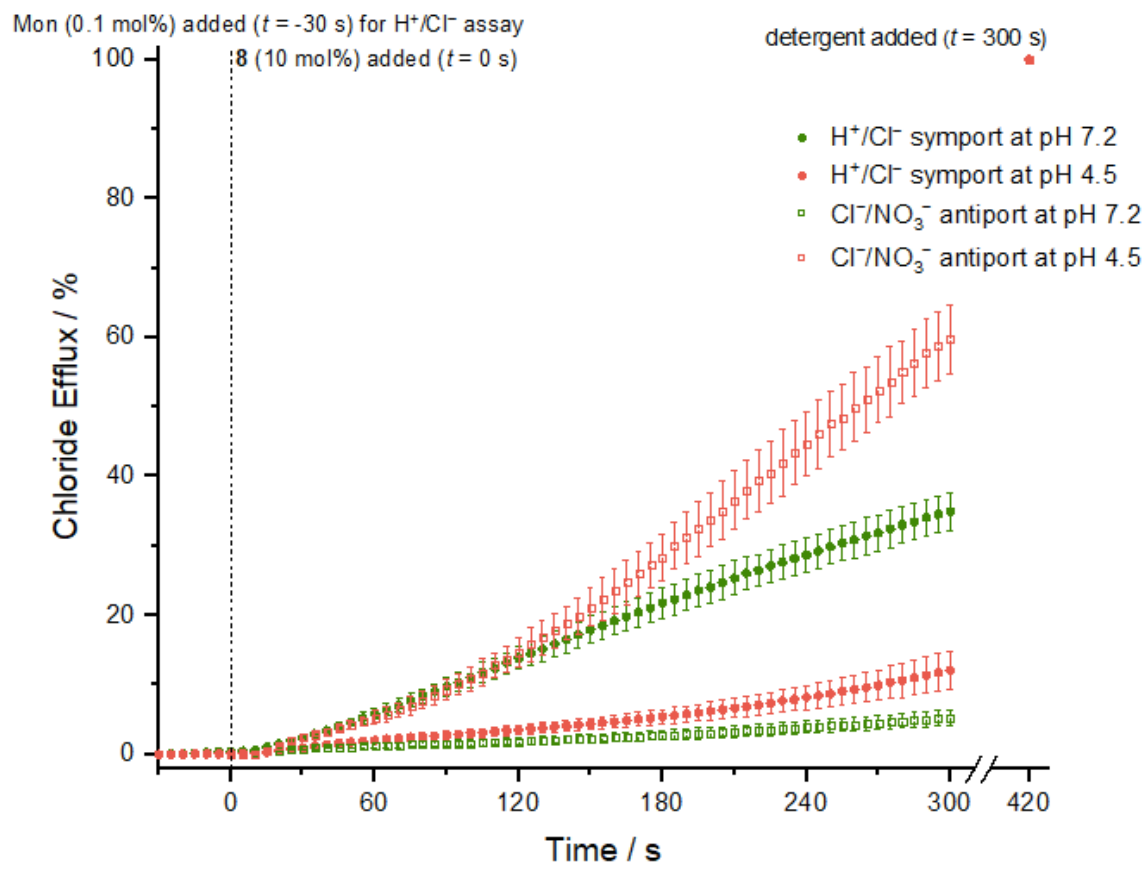

Fig. S63 Comparison plot for chloride efflux mediated by compound $8(10 \mathrm{~mol} \%)$ in the presence of monensin and valinomycin and $\mathrm{Cl}^{-} / \mathrm{NO}_{3}{ }^{-}$exchange at $\mathrm{pH} 4.5$ and 7.2. Each data point represents the average of two or three repeat measurements with error bars indicating the standard deviation. 


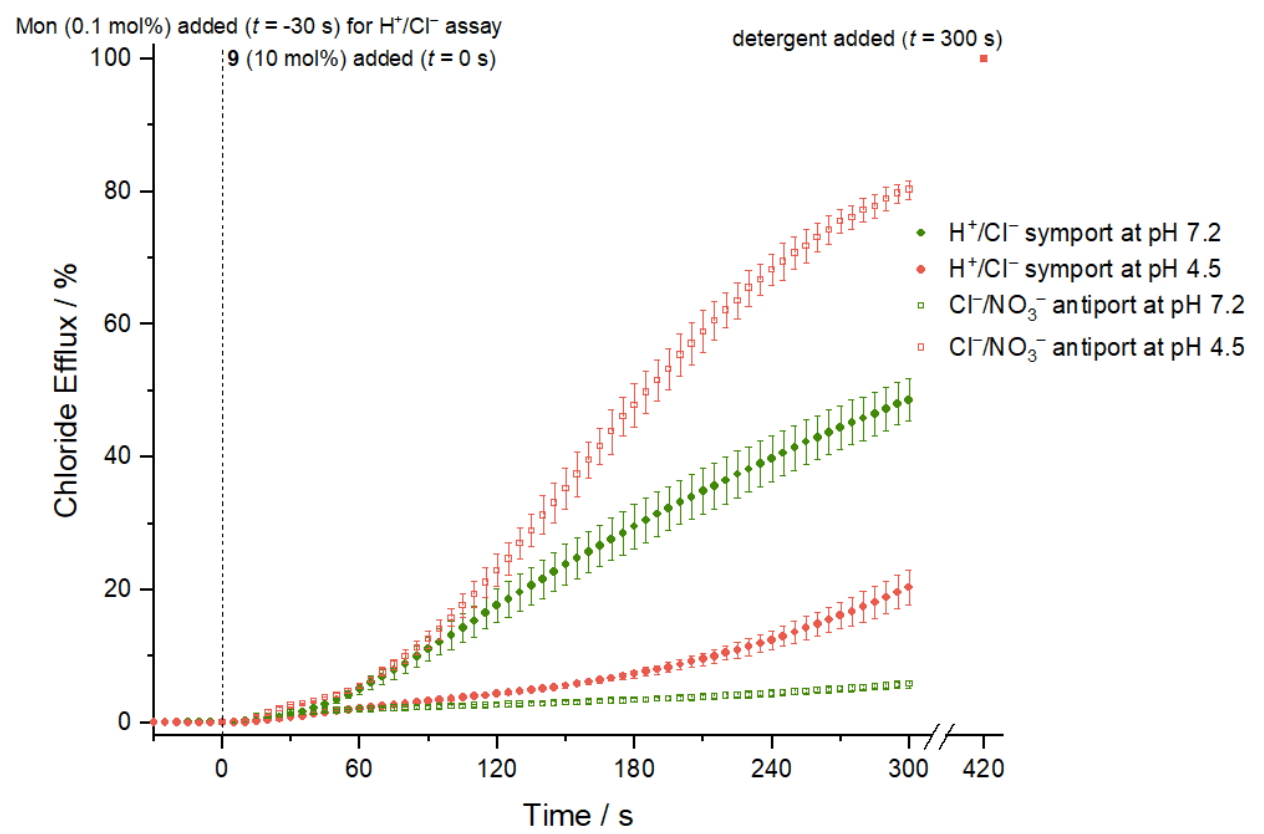

Fig. S64 Comparison plot for chloride efflux mediated by compound $9(10 \mathrm{~mol} \%)$ in the presence of monensin and valinomycin and $\mathrm{Cl}^{-} / \mathrm{NO}_{3}{ }^{-}$exchange at $\mathrm{pH} 4.5$ and 7.2. Each data point represents the average of two or three repeat measurements with error bars indicating the standard deviation.

\section{S3 HPTS assay}

\section{S3.1 Vesicle preparation}

HPTS assays ${ }^{1}$ were conducted using POPC LUVs (mean diameter $200 \mathrm{~nm}$ ) loaded with the pH-sensitive fluorescence dye HPTS (1 mM). The HPTS-loaded POPC LUVs were prepared as follows. A chloroform solution of POPC was evaporated in a round-bottom flask and the lipid film formed was dried under vacuum for at least $6 \mathrm{~h}$. Then, the lipid film was hydrated by vortexing with an internal solution containing HPTS (1 mM) and $\mathrm{NaX}\left(100 \mathrm{mM}, \mathrm{X}=\mathrm{Cl}^{-}, \mathrm{Br}^{-}\right.$, $\mathrm{NO}_{3}{ }^{-}, \mathrm{I}^{-}$, or $\mathrm{ClO}_{4}{ }^{-}$) buffered at $\mathrm{pH} 7.0$ with $10 \mathrm{mM} \mathrm{HEPES}$. The lipid suspension was subjected to nine freeze/thaw cycles and then extruded 25 times through a $200 \mathrm{~nm}$ polycarbonate membrane. The unentrapped HPTS was removed by a Sephadex G-25 column using an external solution of $\mathrm{NaX}$ buffered at $\mathrm{pH} 7.0$ with $10 \mathrm{mM} \mathrm{HEPES}$, to obtain $\mathrm{NaX} /{ }^{\text {in }} / \mathrm{NaX}{ }^{\text {out }}$ vesicle stock suspensions (with POPC concentration of $\sim 10 \mathrm{mM}$ ).

\section{S3.2 Anion gradient assay}

Following vesicle preparation according to the general procedure, the $\mathrm{NaCl}$-containing vesicles were diluted using $\mathrm{NaX}(100 \mathrm{mM})$ external solutions to obtain $\mathrm{NaCl} / \mathrm{NaX}^{\text {in }}$ vesicles suspended in $2.5 \mathrm{~mL}$ samples containing $0.1 \mathrm{mM}$ of POPC. The samples were stirred at 298 $\mathrm{K}$.

No base pulse was added so no $\mathrm{pH}$ gradient was initially present. Transporter 1 (added in $5 \mu \mathrm{L}$ of DMSO) was added at time 0 to induce $\mathrm{pH}_{\text {in }}$ changes. The $\mathrm{pH}_{\text {in }}$ was monitored by the 
ratiometric fluorescence response of HPTS $I_{460} / I_{403}\left(\lambda_{\mathrm{ex}}=460 \mathrm{~nm}, \lambda_{\mathrm{em}}=510 \mathrm{~nm}\right.$ divided by $\lambda_{\mathrm{ex}}=403 \mathrm{~nm}, \lambda_{\mathrm{em}}=510 \mathrm{~nm}$ ). The $I_{460} / I_{403}$ values were converted to $\mathrm{pH}_{\text {in }}$ using previously reported calibration.

\section{S3.3 pH gradient dissipation assay}

Following vesicle preparation according to the general procedure, the $\mathrm{NaX}$-containing vesicles were diluted using $\mathrm{NaX}(100 \mathrm{mM})$ external solutions to obtain $\mathrm{NaX}{ }^{\mathrm{in}} / \mathrm{NaX}{ }^{\text {out }}$ vesicles suspended in $2.5 \mathrm{~mL}$ samples containing 0.1 or $1.0 \mathrm{mM}$ of POPC. The samples were stirred at $298 \mathrm{~K}$.

A base pulse of $\mathrm{NaOH}(25 \mu \mathrm{L}$ of $0.5 \mathrm{M} \mathrm{NaOH}$ solution, final concentration $5 \mathrm{mM}$ ) was added to the vesicle samples to generate a $\mathrm{pH}$ gradient with $\mathrm{pH} 7.0$ inside and $\mathrm{pH} 8.0$ outside vesicles. Subsequently, an anion transporter (added in $5 \mu \mathrm{L}$ of DMSO) was added at time 0 and the rate of the $\mathrm{pH}$ gradient dissipation was monitored by the ratiometric fluorescence response of HPTS $I_{460} / I_{403}\left(\lambda_{\mathrm{ex}}=460 \mathrm{~nm}, \lambda_{\mathrm{em}}=510 \mathrm{~nm}\right.$ divided by $\lambda_{\mathrm{ex}}=403 \mathrm{~nm}, \lambda_{\mathrm{em}}=510$ $\mathrm{nm})$. The $I_{460} / I_{403}$ data were converted to fractional fluorescence $\left(I_{f}\right)$ values using the following equation:

$$
I_{f}=\frac{R_{\mathrm{t}}-R_{0}}{R_{\mathrm{f}}-R_{0}}
$$

where $R_{\mathrm{t}}$ is the fluorescence ratio at time $\mathrm{t}, R_{0}$ is the fluorescence ratio at time 0 , and $R_{\mathrm{f}}$ is the fluorescence ratio after the addition of detergent.

We have previously shown that the $I_{460} / I_{403}$ value, instead of the $\mathrm{pH}_{\text {in }}$, is proportional to the amount of $\mathrm{H}^{+}$efflux. ${ }^{2}$ Therefore, here for the purpose of indicating the progress of membrane transport, the $I_{460} / I_{403}$ values were not converted to $\mathrm{pH}_{\text {in }}$ values. 


\section{S4 X-ray crystallography}

Table S1. Crystal and data refinement parameters for the X-ray studies.

\begin{tabular}{|c|c|}
\hline & 1 \\
\hline CCDC Deposition number & 2103182 \\
\hline Formula & C18 H21 N3 S \\
\hline Formula weight & 311.44 \\
\hline Temperature/K & $100(2)$ \\
\hline Crystal system & monoclinic \\
\hline Space group & $\mathrm{P} 2{ }_{1} / c$ \\
\hline $\mathrm{a}(\AA)$ & $10.43746(18)$ \\
\hline $\mathrm{b}(\AA)$ & $13.7931(2)$ \\
\hline$c(\AA)$ & $23.7555(5)$ \\
\hline$B\left({ }^{\circ}\right)$ & $99.3315(17)$ \\
\hline Volume $\left(\AA^{3}\right)$ & $3374.69(11)$ \\
\hline Z & 8 \\
\hline$\rho_{\text {calc }} / \mathrm{g} \mathrm{cm}^{-3}$ & 1.226 \\
\hline$\mu\left(\mathrm{mm}^{-1}\right)$ & 1.688 \\
\hline$F(000)$ & 1328 \\
\hline Reflections collected & 13684 \\
\hline Independent reflections & {$\left[R_{\text {int }}=0.0235, R_{\text {sigma }}=0.0309\right]$} \\
\hline Data/restraints/parameters & $13684 / 0 / 411$ \\
\hline GooF & 1.063 \\
\hline Final $R$ indexes $[I>=2 \sigma(I)]$ & $R_{1}=0.0468, w R_{2}=0.1192$ \\
\hline Final R indexes [all data] & $R_{1}=0.0548, w R_{2}=0.1247$ \\
\hline Largest diff. peak/hole / e $\AA^{-3}$ & $0.505 /-0.262$ \\
\hline
\end{tabular}

Table S2. Hydrogen-bonding parameters from the X-ray study of $\mathbf{1 .}$

\begin{tabular}{|c|c|c|c|}
\hline Interaction & $H \cdots A[A]^{B}$ & $D \cdots A[A]^{B}$ & $\mathrm{D}-\mathrm{H} \cdots \mathrm{A}\left[{ }^{\circ}\right]^{\mathrm{B}}$ \\
\hline$N(2) \cdots S(2)^{1}$ & $2.52(3)$ & $3.3644(17)$ & $163(2)$ \\
\hline$N(8) \cdots S(2)^{1}$ & 2.97 & $3.7656(19)$ & 142.5 \\
\hline$C(5) \cdots S(2)$ & 2.84 & $3.677(2)$ & 148.2 \\
\hline$C(13) \cdots N(6)$ & 2.74 & $3.570(3)$ & 146.3 \\
\hline$N(5) \cdots S(1)^{2}$ & $2.64(3)$ & $3.4939(17)$ & $170(2)$ \\
\hline$C(26) \cdots s(1)^{2}$ & 2.99 & $3.8440(19)$ & 149.7 \\
\hline
\end{tabular}

${ }^{1} 1-X, 1 / 2+Y, 3 / 2-Z,{ }^{2} 1-X,-1 / 2+Y, 3 / 2-Z$ 


\section{S5 References}

1. S. Matile and N. Sakai, in Analytical Methods in Supramolecular Chemistry, ed. C. A. Schalley, Wiley-VCH, Weinheim, 2012, pp. 711-742.

2. H. J. Clarke, X. Wu, M. E. Light and P. A. Gale, J Porphyr Phthalocya, 2020, 24, 473-479. 